\title{
Tuning Material Properties of Oxides and Nitrides by Substrate Biasing during Plasma-Enhanced Atomic Layer Deposition on Planar and 3D Substrate Topographies
}

Tahsin Faraz, ${ }^{* \dagger \odot}$ Harm C. M. Knoops, ${ }^{\dagger, \#}$ Marcel A. Verheijen, ${ }^{\dagger, \dagger}$ Cristian A. A. van Helvoirt, ${ }^{\dagger}$ Saurabh Karwal, ${ }^{\dagger}$ Akhil Sharma, ${ }^{\dagger}$ Vivek Beladiya, ${ }^{\perp}$ Adriana Szeghalmi, ${ }^{\perp, \infty}{ }^{\text {Dennis M. Hausmann, }}{ }^{\S}$ Jon Henri, ${ }^{\S}$ Mariadriana Creatore, ${ }^{\dagger}$ and Wilhelmus M. M. Kessels ${ }^{*}, \dagger$

${ }^{\dagger}$ Eindhoven University of Technology, P.O. Box 513, $5600 \mathrm{MB}$ Eindhoven, The Netherlands

\# Oxford Instruments Plasma Technology, North End, Bristol, BS49 4AP, United Kingdom

${ }^{\ddagger}$ Philips Innovation Services, High Tech Campus 4, 5656 AE Eindhoven, The Netherlands

${ }^{\perp}$ Friedrich Schiller University Jena, Albert-Einstein-Str. 13, 07745 Jena, Germany

${ }^{\infty}$ Fraunhofer Institute for Applied Optics and Precision Engineering IOF, Albert-Einstein-Str. 7, 07745 Jena, Germany

${ }^{\S}$ Lam Research Corporation, 11155 SW Leveton Drive, Tualatin, Oregon 97062, United States

Supporting Information

ABSTRACT: Oxide and nitride thin-films of $\mathrm{Ti}, \mathrm{Hf}$, and $\mathrm{Si}$ serve numerous applications owing to the diverse range of their material properties. It is therefore imperative to have proper control over these properties during materials processing. Ion-surface interactions during plasma processing techniques can influence the properties of a growing film. In this work, we investigated the effects of controlling ion characteristics (energy, dose) on the properties of the aforementioned materials during plasma-enhanced atomic layer deposition (PEALD) on planar and 3D substrate topographies. We used a $200 \mathrm{~mm}$ remote PEALD system equipped with substrate biasing to control the energy and dose of ions by varying the magnitude and duration of the applied bias, respectively, during plasma exposure. Implementing substrate biasing in these forms enhanced PEALD process capability by providing two additional parameters for tuning a wide range of material properties. Below

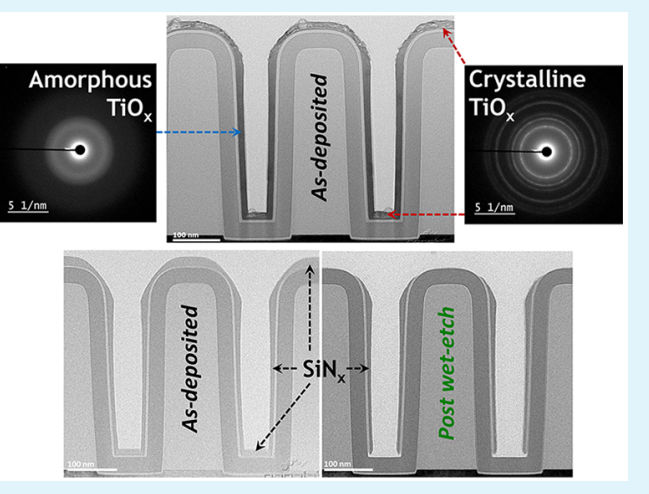
the regimes of ion-induced degradation, enhancing ion energies with substrate biasing during PEALD increased the refractive index and mass density of $\mathrm{TiO}_{x}$ and $\mathrm{HfO}_{x}$ and enabled control over their crystalline properties. PEALD of these oxides with substrate biasing at $150{ }^{\circ} \mathrm{C}$ led to the formation of crystalline material at the low temperature, which would otherwise yield amorphous films for deposition without biasing. Enhanced ion energies drastically reduced the resistivity of conductive TiN $\mathrm{N}_{x}$ and $\mathrm{HfN}_{x}$ films. Furthermore, biasing during PEALD enabled the residual stress of these materials to be altered from tensile to compressive. The properties of $\mathrm{SiO}_{x}$ were slightly improved whereas those of $\mathrm{SiN}_{x}$ were degraded as a function of substrate biasing. PEALD on 3D trench nanostructures with biasing induced differing film properties at different regions of the 3D substrate. On the basis of the results presented herein, prospects afforded by the implementation of this technique during PEALD, such as enabling new routes for topographically selective deposition on 3D substrates, are discussed.

KEYWORDS: atomic layer deposition, plasma ALD, thin film, ion energy control, substrate biasing, ion bombardment, tuning material properties, oxides, nitrides, $\mathrm{SiO}_{2}, \mathrm{SiN}_{x} \mathrm{TiO}_{2}, \mathrm{TiN}, \mathrm{HfO}_{2}, \mathrm{HfN}_{x}$

\section{INTRODUCTION}

The ubiquity of thin-films in emerging nanotechnology applications, ${ }^{1}$ together with device scaling using 3-dimensional (3D) architectures, ${ }^{2,3}$ place stringent requirements on nanoscale processing techniques used in thin-film deposition. Atomic layer deposition (ALD) is a well-known method for obtaining ultrathin films with precise growth control. ${ }^{4}$ It is a cyclic deposition process based on sequential and self-limiting reactant dose steps for synthesizing thin-films in a layer-by-layer manner. The self-limiting surface reactions during the separate reactant exposures lead to excellent film uniformity on large area substrates and unparalleled conformality on high-aspect-ratio $3 \mathrm{D}$ nanostructures. In conventional thermal ALD, the energy needed for surface reactions to proceed is provided by substrate heating. An alternate source for the required energy can be obtained by using an energy enhanced ALD method known as

Received: January 4, 2018

Accepted: March 19, 2018

Published: March 19, 2018 
plasma-enhanced atomic layer deposition (PEALD). ${ }^{5}$ In PEALD, the substrate is exposed to species generated by a plasma during one of the reactant exposure steps of an ALD cycle. ${ }^{5,6}$ These species constitute a mixture of highly reactive atomic and molecular neutrals (plasma radicals), photons, ions and electrons. The highly reactive plasma species generated during PEALD can provide an alternate source of the energy required for film growth. The high reactivity of the plasma species therefore, allows access to a parameter space such as low temperature deposition environments. Tuning material properties during film growth at a particular temperature is typically performed by varying either the substrate material or the reactants needed for film deposition. For PEALD at any given temperature, the various parameters of plasma operating conditions (e.g., reactant gas, flow rate, pressure, power, direct/remote source configuration, etc.) allow greater freedom in processing conditions for tuning the growth and material properties of thin-films. ${ }^{6}$

Apart from the contribution of highly reactive plasma radicals toward film growth during PEALD, the ions generated by the plasma can also play a significant role during film deposition., Ion-surface interactions during plasma exposure are a characteristic feature of plasma-enhanced deposition techniques. ${ }^{7-10}$ Additional energy can be provided to the deposition surface by the kinetic energy of ions impinging on the substrate. While plasma radicals can enable film growth through their high reactivity, the additional energy delivered to the deposition surface by ion bombardment can influence a wide range of material properties of the growing film. Examples reported in the literature include tailoring of the optical refractive index, electrical conductivity, mechanical stress, mass density, crystalline structure, morphology, surface roughness etc. ${ }^{9,11,12}$ The limit to which ion-surface interactions can modify such properties depends on the energy, mass, reactivity, impingement rate (or flux) and dose (or net flux integrated over time) of ionic species impinging on the film surface. ${ }^{7-9,13,14}$ On the basis of the values of these parameters, various physical, chemical or combined physicochemical processes can occur at the surface and subsurface regions of the film as the ions transfer energy and momentum during deposition. The use of an inert gas (e.g., argon) leads to predominantly physical processes which include, but are not limited to, surface or bulk atom displacements, subsurface implantation of incident ions or displaced surface atoms, desorption of adsorbed surface impurities from reactor background, etc. $^{8,9,14}$ The use of reactive gases (e.g., oxygen or hydrogen) involves an additional chemical or physicochemical component where the reactive ions can undergo chemical reactions forming, either stable products leading to film growth, or volatile products leading to film removal. ${ }^{8,10}$ However, the processes and trends of property modulation also depend on many inherent characteristics of the growing film such as the bond energy, bond type (i.e., ionic, covalent or metallic), crystallization temperature, free energy difference between crystalline and amorphous phases or a combination of several of these parameters. ${ }^{14-17}$ Given the multitude of factors that can play a role during ion-surface interactions, it is not a trivial or straightforward task to anticipate the trends in film characteristics as a result of varying the ion characteristics during deposition. Furthermore, the effects of ion-surface interactions have been extensively investigated in the literature for conventional fluxcontrolled processes, ${ }^{18}$ such as physical vapor deposition (PVD) and plasma-enhanced chemical vapor deposition (PECVD), that lead to continuous film growth. In the surface-controlled process $^{18}$ of PEALD where self-limiting film growth occurs by sequential doses of a precursor and plasma activated coreactant, ion-surface interactions only occur during the plasma exposure step of a PEALD cycle. Consequently, only the characteristics of those ionic species generated during plasma activation of the coreactant can affect film properties in PEALD. These effects may or may not be different from those occurring in continuous growth process like PECVD in which both the precursor and coreactant contribute species to the mixture of ions formed during deposition. The first experimental investigation on the role of ions during PEALD was reported by Profijt et al. ${ }^{19,20}$ in previous work conducted within our group. They looked into the effects of enhancing oxygen ion energies during PEALD on the growth and material properties of aluminum oxide, titanium oxide and cobalt oxide. ${ }^{19,20}$ The films were deposited in a homebuilt remote plasma ALD tool equipped with substrate biasing. In a remote plasma source configuration, the ion energy can be controlled during plasma exposure by varying (or biasing) the substrate potential, either by adjusting the impedance between the substrate and ground, or by applying a voltage signal on the substrate. ${ }^{19}$ Enhancing ion energies with substrate biasing during the plasma exposure step of PEALD was observed to have significant effects during film growth that were material or process-specific. Increasing bias voltages during oxygen plasma exposure increased the growth rate and oxygen content of aluminum oxide films while lowering their mass density. ${ }^{19}$ The residual stress of the deposited films was also observed to be altered from tensile to compressive with the use of substrate biasing. The growth rate, density and oxygen content of titanium oxide films deposited with substrate biasing during oxygen plasma exposure showed a similar behavior as aluminum oxide. $^{19,20}$ However, an additional effect was observed in case of titanium oxide where its crystalline phase could be gradually tailored from anatase to rutile with increasing bias voltages. ${ }^{19,20}$ For cobalt oxide, the growth rate decreased and the film density increased at higher bias voltages while the films became slightly oxygen deficient. ${ }^{19}$ The aforementioned results were demonstrated for film deposition only on planar substrates having a small area $(1 \times 1$ in. pieces of Si wafer $)$ and by applying substrate biasing for the entire duration of the plasma exposure step.

In this work, we continued the research on the role of ions during PEALD by analyzing the effects of enhanced ion energies on the material properties of films grown on both planar and 3D substrate topographies. The ion energy was enhanced during plasma exposure using a commercial remote plasma ALD system (Oxford Instruments FlexAL) equipped with radio frequency (RF) substrate biasing. The effect of enhancing oxygen ion energies during PEALD of titanium oxide was reinvestigated in this system on large area substrates $(200 \mathrm{~mm})$ using a different titanium precursor with additional material characterization, compared to the previous work conducted by Profijt et al. ${ }^{19,20}$ This provided further insight on the effects of ion energy control during PEALD of titanium oxide. Additionally, the effects of varying the dose of higher energy ions on the growth and material properties of titanium oxide was also investigated. The effects of ion-surface interactions on material properties during PEALD were investigated for two more oxides, namely hafnium oxide and silicon oxide. Furthermore, the scope of our research on the role of ions during PEALD was expanded by looking into the effects of ion-surface interactions for another group of materials, namely, the nitrides of titanium, hafnium and silicon deposited using different plasmas (i.e., hydrogen, argon/hydrogen, and nitrogen). The oxides and nitrides of these three elements form 
dielectric or conductive materials that are used in a variety of applications (see Supporting Information). The diverse range of applications that are heavily reliant on the properties of these materials highlights the necessity for precise control over those properties during film deposition. Enhancing ion energies with substrate biasing during PEALD on planar substrates was observed to have pronounced effects on the growth and material properties of the aforementioned thin-films. A comprehensive analysis of these properties was undertaken by characterizing the growth rate, mass density, refractive index (for dielectric materials), resistivity (for conductive materials), residual stress, and surface roughness of the films deposited on planar substrates. The role of ion energy control on film microstructure and crystallinity was also investigated. The effect of enhanced ion energies on the thickness uniformity of materials deposited on large area planar substrates $(200 \mathrm{~mm} \mathrm{Si}$ wafer $)$ was also investigated compared to previous work carried out on smaller substrates. ${ }^{19,20}$ Owing to the material and/or process specific effects of substrate biasing observed in previous work, an empirical investigation comprised of an extensive characterization of film properties spanning six different materials was undertaken in this work. It was observed that substrate biasing can enhance the versatility of PEALD processes by providing two additional parameters (magnitude, duration/duty cycle of bias) for tuning a wide range of material properties. Furthermore, biasing during PEALD on $3 \mathrm{D}$ trench nanostructures effectively delineated the role of directional ion bombardment by inducing differing film properties at different (planar and vertical) regions of the 3D substrate. These results demonstrate the potential of substrate biasing during PEALD in enabling routes toward topographically selective ${ }^{3}$ processing on $3 \mathrm{D}$ substrates.

\section{APPLYING SUBSTRATE BIAS DURING PEALD CYCLES}

In a remote plasma ALD reactor configuration, the plasma source generating radicals and ions is located at a distance away from the substrate stage thus allowing the plasma and substrate conditions to be varied quite independently of each other. The ion flux impinging on the substrate can be increased by increasing the source power. When the substrate is exposed to the plasma, a positive space charge layer called the sheath is formed between the plasma and the substrate due to the difference in mobilities of the heavy ions and light electrons in the plasma. The voltage across the sheath $\left(\Delta V_{\text {sheath }}\right)$ is the difference between the plasma potential $\left(V_{\mathrm{p}}\right)$ and the substrate potential $\left(V_{\text {sub }}\right)$. The sheath voltage repels electrons from the substrate into the plasma and accelerates ions toward the substrate resulting in so-called ion bombardment. At sufficiently low pressures, the ion mean free path is larger than the plasma sheath thickness, so the ions are accelerated over the full sheath width without undergoing collisions. This collisionless plasma sheath condition leads to the highly directional or anisotropic nature of ion bombardment. Typical sheath thicknesses for processing plasmas are on the order of $10^{-4}-10^{-2} \mathrm{~m}$, and therefore, the sheath does not follow the profile of $3 \mathrm{D}$ structures (e.g., trenches and vias) with microor nanoscale dimensions. As a result, directional ions accelerated through a collisionless sheath will mainly collide with substrate surfaces parallel to the sheath, for example, the planar top and bottom surfaces of a 3D trench nanostructure and not its vertical sidewalls. The energy $\left(E_{i}\right)$ of directional ions impinging on planar substrate surfaces is proportional to the sheath voltage, as shown in equation 1

$$
E_{i}=q\left(\Delta V_{\text {sheath }}\right)=q\left(V_{\mathrm{p}}-V_{\text {sub }}\right)
$$

where $q$ is the charge of an ion (assuming an electropositive plasma). When the substrate is placed on a grounded reactor table, it is at zero potential $\left(V_{\text {sub }}=0 \mathrm{~V}\right)$, so the sheath voltage equates to the plasma potential. Equation 1 indicates that the ion energy can be enhanced by increasing the sheath voltage. If the system is equipped with substrate biasing, that is, by tuning the impedance between substrate table and ground or by connecting the substrate table to an additional power source, then the substrate potential can be set or biased to have a nonzero value $\left(V_{\text {sub }} \neq 0 \mathrm{~V}\right) .{ }^{19}$ When a sinusoidal radio frequency (RF) voltage signal is applied to the substrate through a blocking capacitor, it acquires a negative average or DC offset value such that the net flux of ions and electrons to the substrate stage over one RF cycle is zero. The negative DC offset or time-averaged substrate bias voltage $\left(V_{\text {sub }}=-\left\langle V_{\text {bias }}\right\rangle\right)$ can be increased by increasing the amplitude of the bias signal applied to the substrate table. This causes $\Delta V_{\text {sheath }}$ to increase which in turn enhances $E_{i}$, thus allowing the ion energy to be controlled during plasma exposure.

To perform PEALD with substrate biasing, an existing process can be modified by applying a bias on the substrate table during the plasma exposure step. The step sequences of the PEALD processes without and with substrate biasing are shown in Figure 1. The substrate bias can be applied for the whole duration (bias duty cycle $=100 \%$, Figure $1 \mathrm{~b})$ or a part of the duration $(0 \%<$ bias duty cycle $<100 \%$, Figure 1c) of the plasma exposure step. For example, during a plasma exposure step of $10 \mathrm{~s}$, the bias can be active for all $10 \mathrm{~s}$ (Figure $1 \mathrm{~b}$ ) or half of this duration $(5 \mathrm{~s})$ by

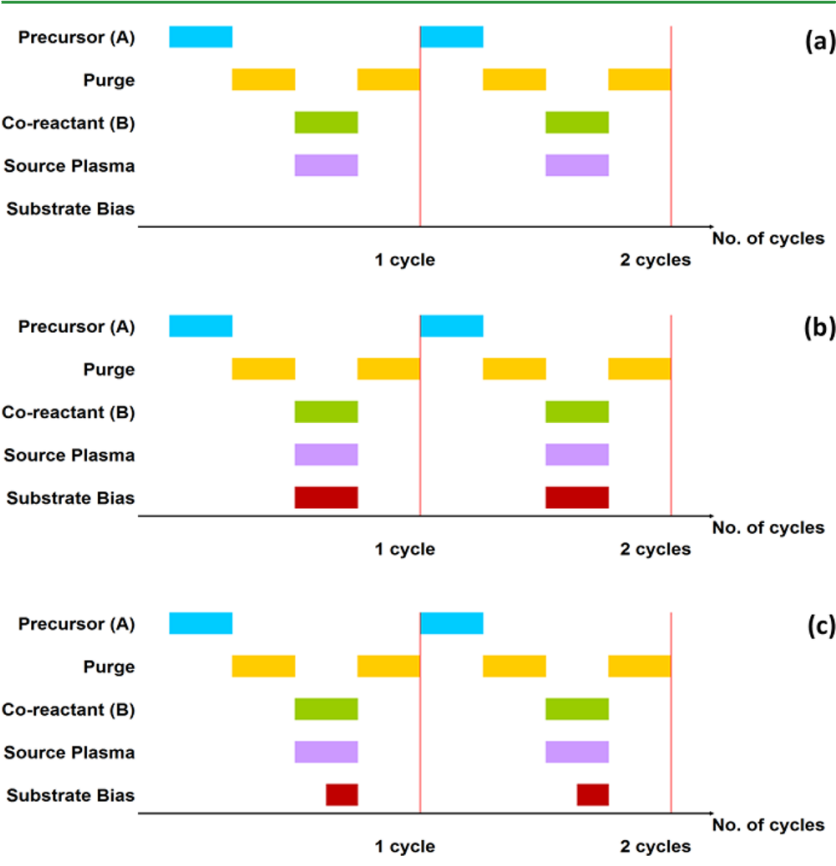

Figure 1. Step sequence for two-step $[A B]_{n}$ plasma ALD cycles (a) without any substrate biasing during plasma exposure where the substrate table is grounded (source plasma "ON", substrate bias "OFF", bias duty cycle $=0 \%$ ), (b) with substrate biasing during plasma exposure where the bias is applied for the full duration of the plasma exposure step (source plasma "ON", substrate bias "ON", bias duty cycle = 100\%), and (c) with interleaved substrate biasing where the bias is applied for a fraction of the plasma exposure step (source plasma "ON", substrate bias "ON", $0 \%<$ bias duty cycle $<100 \%)$. A refers to the precursor dose step; $B$ is the coreactant or plasma gas exposure step, and $n$ is the number of ALD cycles. 
Table 1. PEALD Process Conditions for the Materials Deposited with and without Substrate Biasing during Plasma Exposure

\begin{tabular}{|c|c|c|c|c|c|c|}
\hline material & $\mathrm{TiO}_{x}$ & $\operatorname{TiN}_{x}$ & $\mathrm{HfO}_{x}$ & $\mathrm{HfN}_{x}$ & $\mathrm{SiO}_{x}$ & $\mathrm{SiN}_{x}$ \\
\hline precursor & \multicolumn{2}{|c|}{ TDMAT $^{a}$} & \multicolumn{2}{|c|}{ TDMACpH $^{b}$} & BDEAS $^{c}$ & DSBAS $^{d}$ \\
\hline bubbler temperature $\left({ }^{\circ} \mathrm{C}\right)$ & \multicolumn{2}{|c|}{60} & \multicolumn{2}{|c|}{60} & 50 & 40 \\
\hline precursor delivery & \multicolumn{2}{|c|}{ bubbled with $100 \mathrm{sccm} \mathrm{Ar}$} & \multicolumn{2}{|c|}{ bubbled with $100 \mathrm{sccm} \mathrm{Ar}$} & \multicolumn{2}{|c|}{ vapor drawn } \\
\hline stage temperature $\left({ }^{\circ} \mathrm{C}\right)$ & 150 and 300 & 200 & 150 & 450 & 200 & 500 \\
\hline precursor dose time (ms) & 200 & 200 & 400 & 400 & 175 & 500 \\
\hline precursor reaction step $(\mathrm{s})$ & & & & & 1 & 3 \\
\hline precursor purge time $(\mathrm{s})$ & 3 & 3 & 2 & 2 & 3 & 2 \\
\hline plasma gas & $\mathrm{O}_{2}$ & $\mathrm{Ar}+\mathrm{H}_{2}$ & $\mathrm{O}_{2}$ & $\mathrm{H}_{2}$ & $\mathrm{O}_{2}$ & $\mathrm{~N}_{2}$ \\
\hline plasma gas flow $(\mathrm{sccm})$ & 100 & $10+40$ & 100 & 100 & 100 & 100 \\
\hline plasma pressure (mTorr) & 9 & 6 & 15 & 30 & 15 & 11 \\
\hline RF-ICP power $(\mathrm{W})$ & 200 & 100 & 400 & 100 & 200 & 600 \\
\hline plasma exposure time $(\mathrm{s})$ & 10 & 10 & 8 & 10 & 5 & 20 \\
\hline plasma purge time $(s)$ & 3 & 4 & 3 & 4 & 2 & 3 \\
\hline$\left\langle V_{\text {bias }}\right\rangle$ or average bias voltage $(\mathrm{V})$ & 0 to -254 & 0 to -255 & 0 to -280 & 0 to -210 & 0 to -295 & 0 to -103 \\
\hline bias during plasma & all $10 \mathrm{~s}$, last $5 \mathrm{~s}$ & last $5 \mathrm{~s}$ & last $4 \mathrm{~s}$ & all $10 \mathrm{~s}$, last $5 \mathrm{~s}$ & all $5 \mathrm{~s}$ & last $10 \mathrm{~s}$ \\
\hline
\end{tabular}

applying it in an interleaved manner either at the beginning, middle or end (Figure 1c) of the plasma exposure step. Varying the duration of the applied bias translates to changing the dose or fluence $^{13,14,21}$ (i.e., particle flux integrated over time) of higher energy ions impinging on the substrate. Substrate biasing during PEALD can also be implemented in many other configurations (see Figures S1 and S2).

\section{EXPERIMENTAL DETAILS}

PEALD Process Conditions. Film deposition using PEALD was performed in an Oxford Instruments FlexAL reactor equipped with substrate biasing (Figure 2). The reactor consists of a radio frequency (RF) power supply (13.56 MHz, up to $600 \mathrm{~W}$ ) connected to a watercooled copper coil wrapped around a cylindrical alumina tube to generate an inductively coupled-plasma (ICP). This remote RF-ICP source generates the radicals and ions during the plasma exposure step of PEALD. For the specific FlexAL configuration, an additional external RF power supply (13.56 MHz, up to $100 \mathrm{~W}$ ) can be connected to the reactor table that allows for substrate biasing (up to $\left\langle V_{\text {bias }}\right\rangle \approx-350 \mathrm{~V}$ at $\sim 10$ mTorr) during plasma exposure. Both RF power sources were connected to the system via automated matching networks consisting of inductive and capacitive components. The FlexAL system provides a readout for $\left\langle V_{\text {bias }}\right\rangle$ when applying an RF bias signal during plasma exposure. Additionally, an oscilloscope was connected to the reactor table via a high-voltage probe from which sinusoidal RF bias voltage waveforms developing on the table could be measured. These oscilloscope measurements were used to independently verify $\left\langle V_{\text {bias }}\right\rangle$ readouts from the FlexAL system (within $\pm 5 \mathrm{~V}$ ). A base pressure in the reactor chamber of $\sim 10^{-6}$ Torr was obtained using a turbo pump. A butterfly valve in front of the turbo pump controlled the effective pumping speed and functioned as an automated pressure controller. The chamber wall temperature was set to $150{ }^{\circ} \mathrm{C}$ while the substrate stage temperature was set between 150 and $500^{\circ} \mathrm{C}$. All substrates underwent a 30 min heating step prior to commencing deposition in order to ensure substrate temperature stabilization. The precursor delivery lines were heated to $70{ }^{\circ} \mathrm{C}$ to prevent precursor condensation. The oxides and nitrides of $\mathrm{Ti}, \mathrm{Hf}$, and $\mathrm{Si}$ were deposited without and with substrate biasing. The precursors, plasma gases and other PEALD process conditions for depositing the six materials are shown in Table 1. Existing PEALD processes for these six materials ${ }^{22-28}$ were used for the runs without any biasing where the substrate table was grounded during the plasma exposure step. For the runs performed with substrate biasing, the PEALD processes were modified by applying an RF bias signal to the substrate table during the plasma exposure step. PEALD step sequences without (Figure 1a) and with substrate biasing (Figure $1 \mathrm{~b}$ and $\mathrm{c}$ ) were implemented. Details regarding PEALD process conditions are further outlined in the Supporting Information.

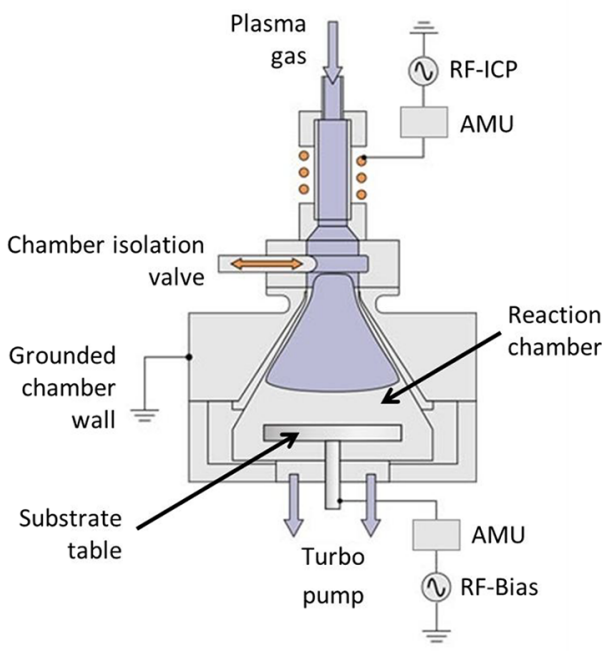

Figure 2. Schematic of an Oxford Instruments FlexAL system equipped with substrate biasing. A radio frequency inductively coupled-plasma (RF-ICP) source acts as the remote plasma generator allowing control over the flux of radicals and ions impinging on the substrate. A second RF power supply (RF-Bias) connected to the substrate table enables substrate biasing which allows control over the ion energy. Both RF power sources are connected to the system via automated matching units (AMU) consisting of inductive and capacitive components.

Thin-Film Characterization on Planar and 3D Substrates. Unless otherwise stated, the planar substrates used for depositing films with and without substrate biasing were single side polished (SSP) c-Si (100) substrates having a thin native oxide layer $(\sim 1.5 \mathrm{~nm})$ for dielectric materials and SSP c-Si (100) substrates having a thick thermal oxide layer $(\sim 450 \mathrm{~nm})$ for conductive materials. Film thicknesses between $\sim 20$ and $\sim 80 \mathrm{~nm}$ were deposited for material characterization on planar substrates (except for $\mathrm{SiO}_{x}$ films which were $\sim 200 \mathrm{~nm}$ ). The optical properties and film thickness of the deposited layers on c-Si substrates were measured by means of spectroscopic ellipsometry (SE) using a J.A. Woollam M2000D rotating compensator ellipsometer $(1.2-6.5 \mathrm{eV})$. SE measurements were also used to determine the thickness uniformity of films deposited on $200 \mathrm{~mm}$ planar c-Si wafers with and without substrate biasing by mapping film thickness at several locations across the wafers. For $\mathrm{SiO}_{x}$ and $\mathrm{SiN}_{x}$ films deposited with and without substrate biasing, the optical model used consisted of a silicon substrate, $\sim 1.5 \mathrm{~nm}$ native oxide and the deposited layer parametrized with a Cauchy dispersion relation. ${ }^{27,28}$ A similar three layer optical model was used for analyzing the ellipsometry data of $\mathrm{TiO}_{x}$ and $\mathrm{HfO}_{x}$ films grown with and without 
biasing where the deposited layer was parametrized using two TaucLorentz oscillators. ${ }^{19,29}$ For $\mathrm{TiN}_{x}$ and $\mathrm{HfN}_{x}$, different models were used for the films deposited with and without biasing. The optical model used for the films grown without biasing consisted of a silicon substrate, $\sim 450$ $\mathrm{nm}$ thermal oxide and the deposited layer parametrized using one Drude, one Lorentz, and one Tauc-Lorentz oscillator. ${ }^{26} \mathrm{The} \mathrm{TiN}_{x}$ and $\mathrm{HfN}_{x}$ films deposited with biasing were parametrized using one Drude and two Lorentz oscillators. ${ }^{29}$

The root-mean-squared (RMS) surface roughness and mass density of the films deposited on planar substrates were analyzed using X-ray reflectometry (XRR) performed using a Bruker AXS D8 Advance system in the grazing incidence geometry with a $\mathrm{Cu} \mathrm{K} \alpha \mathrm{X}$-ray source (radiation wavelength of $0.154 \mathrm{~nm}$ ). ${ }^{30}$ The thicknesses of the deposited films were also obtained with XRR which were in good agreement with the corresponding values obtained using SE. The residual stress levels of the deposited films were determined by means of wafer-curvature measurements at room temperature. A KLA-Tencor FLX 2320 system was used to determine the curvature of 3 in. double side polished (DSP) $\mathrm{c}-\mathrm{Si}$ (100) wafers before and after deposition of the films. Based on the difference in curvature, the residual stress of the films deposited with and without substrate biasing was calculated using the Stoney equation..$^{19,30}$ A sign convention was used where positive values represented tensile and negative values represented compressive residual stress. Rutherford backscattering spectrometry (RBS) and elastic recoil detection (ERD) measurements were used to determine the composition (stoichiometry) of films deposited on planar SSP c-Si substrates with $\sim 1.5 \mathrm{~nm}$ native oxide. The RBS and ERD measurements with subsequent data simulations were performed by the company Detect 99 using a 1.8-2 $\mathrm{MeV}$ helium-ion beam. The areal densities of the elements were determined from raw data simulations. The crystallinity of films deposited on planar c-Si substrates was analyzed using grazing incidence $\mathrm{X}$-ray diffraction (XRD). The measurements were performed in a PANalytical X'pert PRO MRD with a $\mathrm{Cu} \mathrm{K} \alpha$ X-ray source (radiation wavelength of $0.154 \mathrm{~nm}$ ) operated at an incidence angle of $0.5^{\circ}$. A JEOL ARM 200 transmission electron microscope (TEM) operated at $200 \mathrm{kV}$ was used to analyze the microstructure of films deposited on planar TEM windows. These windows consisted of $\sim 15 \mathrm{~nm} \mathrm{Si}_{3} \mathrm{~N}_{4}$ membranes coated with $5 \mathrm{~nm}$ of $\mathrm{SiO}_{2}$ grown using ALD. This ensured a $\mathrm{SiO}_{2}$ starting surface while maintaining transparency to the electron beam. Both bright-field TEM (BF-TEM) and high-angle-annular-dark-field scanning TEM (HAADF-STEM) modes were employed to characterize the samples in plan-view. Electrical sheet resistance measurements of conductive films deposited on c-Si substrates with $\sim 450 \mathrm{~nm}$ thermal oxide were performed at room temperature using a Signatone four-point probe (FPP) in combination with a Keithley 2400 Source Measurement Unit (SMU) that acted as both current source and voltage meter. The electrical resistivity was obtained from the slope of the generated $I-V$ curve and the film thickness deduced from the SE measurements.

For investigating material properties on 3D substrate topographies, films were deposited with and without substrate biasing during PEALD on coupons containing high aspect ratio trench nanostructures (width $\sim 100 \mathrm{~nm}$, height $\sim 450 \mathrm{~nm}, \mathrm{AR}=4.5: 1)$ and analyzed with crosssectional TEM. These 3D nanostructures were created $^{28}$ by first depositing a thick $\mathrm{SiO}_{2}$ film on a $\mathrm{Si}$ wafer using PECVD, that was subsequently etched into trench structures. The $\mathrm{SiO}_{2}$ trench structures were then coated with a $\mathrm{SiN}_{x}$ layer using high-temperature CVD, on which a $\mathrm{SiO}_{2}$ layer was deposited using ALD. Coupons containing these trench nanostructures were prepared and provided by Lam Research. A JEOL 2010F ultrahigh-resolution scanning TEM at $200 \mathrm{kV}$ (Nanolab Technologies) was employed to obtain cross-sectional images of the films deposited on the 3D trench nanostructures. The films were coated with a layer of spin-on epoxy to protect them from damage during sample preparation for TEM cross-sectional imaging. The samples were then placed on a $\mathrm{Cu}$ TEM grid, after which an energetic ion beam was used to mill and polish the samples at $30 \mathrm{kV}, 100 \mathrm{pA}$ and $5 \mathrm{kV}, 40 \mathrm{pA}$, respectively. The deposited film thickness was measured at three regions of several trench nanostructures in the sample, namely at the planar top and bottom regions together with the vertical bottom-side region (see Figure S3) by counting pixels in the TEM image. Conformality was determined by taking the ratio of film thicknesses at the bottom-side and bottom of the trench to that at the top of the trench. The conformality values reported are the average of the results obtained across several trench nanostructures with the same aspect ratio. For obtaining wet-etch rates (WER) of silicon nitride films at planar and vertical surfaces of the 3D substrates, coupons containing the trench nanostructures with films deposited with and without substrate biasing were dipped in a dilute hydrofluoric acid solution (HF: $\mathrm{H}_{2} \mathrm{O}=1: 100$ ) for $30 \mathrm{~s}$. Two samples for TEM cross-sectional imaging were prepared from the same coupon, one before and one after the chemical wet-etch treatments. TEM measurements were conducted at the three aforementioned regions across several trench nanostructures of the same as-deposited and post wet-etch samples. The WERs at the aforementioned trench regions were determined by comparing the as-deposited and post wet-etch film thicknesses at those regions. The WER values reported are the average of the results obtained across several trench nanostructures with the same aspect ratio. Uncertainties reported for the values were based on both the accuracy of the measurement and the variation between measurements conducted across several trench nanostructures of the same sample. Potential depletion of the etchant inside the trench was not taken into account in these experiments.

\section{RESULTS}

PEALD of Oxides on Planar Substrates. Titanium Oxide $\left(T i O_{x}\right)$. The growth and material properties of $\mathrm{TiO}_{x}$ films deposited on planar substrates at $300{ }^{\circ} \mathrm{C}$ were investigated for $\left\langle V_{\text {bias }}\right\rangle$ between 0 and $-254 \mathrm{~V}$ applied during the $\mathrm{O}_{2}$ plasma exposure step. Figure 3 shows these properties in terms of the growth per cycle (GPC), refractive index, mass density, residual stress and surface roughness expressed as a function of $\left\langle V_{\text {bias }}\right\rangle$

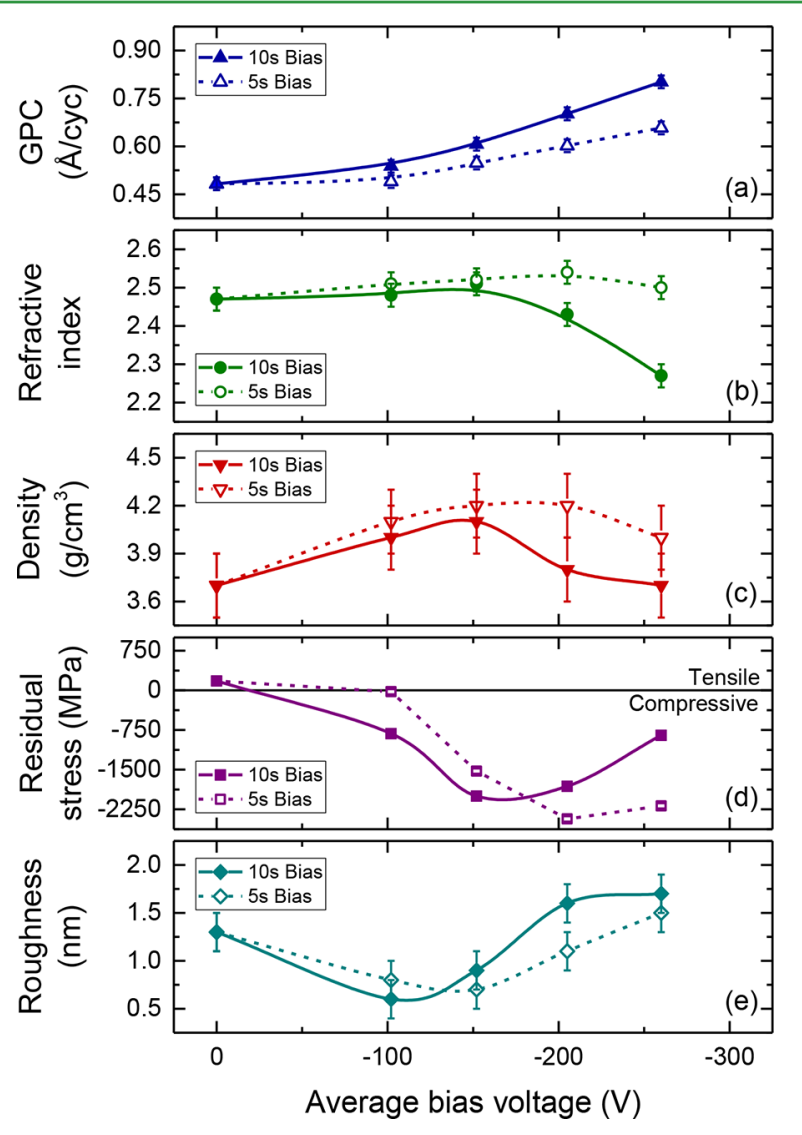

Figure 3. (a) Growth per cycle (GPC), (b) refractive index, (c) mass density, (d) residual stress, and (e) RMS surface roughness of titanium oxide films deposited at $300{ }^{\circ} \mathrm{C}$ expressed as a function of the average bias voltage, $\left\langle V_{\text {bias }}\right\rangle$, applied for the entire duration and last half $(5 \mathrm{~s})$ of the $10 \mathrm{~s}_{2}$ plasma exposure step. 
Table 2. GPC (Film Thickness Per Cycle and Number of Atoms Deposited per $\mathbf{n m}^{2}$ per Cycle) and Elemental Composition of Titanium Oxide Films Deposited at $300{ }^{\circ} \mathrm{C}$ with and without Bias Voltages Applied during the $\mathrm{O}_{2}$ Plasma Exposure Step $^{a}$

\begin{tabular}{|c|c|c|c|c|c|c|c|}
\hline \multirow[b]{2}{*}{$\begin{array}{c}\left\langle V_{\text {bias }}\right\rangle \\
(\mathrm{V})\end{array}$} & \multirow[b]{2}{*}{$\begin{array}{c}\text { bias duration during } 10 \mathrm{~s} \mathrm{O}_{2} \\
\text { plasma step }(\mathrm{s})\end{array}$} & \multirow[b]{2}{*}{$\begin{array}{c}\text { GPC } \\
(\AA / \text { cycle })\end{array}$} & \multicolumn{4}{|c|}{ RBS } & \multirow{2}{*}{$\begin{array}{c}\text { ERD } \\
{[\mathrm{H}]} \\
\text { at. \% }\end{array}$} \\
\hline & & & $\begin{array}{c}\text { GPC }[\mathrm{Ti}] \\
\left(\# \mathrm{Ti} \text { at. per } \mathrm{nm}^{2} \text { per cycle) }\right.\end{array}$ & $\begin{array}{c}\mathrm{GPC}[\mathrm{O}] \\
\left(\# \mathrm{O} \text { at. per } \mathrm{nm}^{2} \text { per cycle }\right)\end{array}$ & $\mathrm{O} / \mathrm{Ti}$ & $\begin{array}{c}{[\mathrm{C}]} \\
\text { at. } \%\end{array}$ & \\
\hline 0 & no bias & $0.48 \pm 0.02$ & $1.35 \pm 0.03$ & $2.72 \pm 0.05$ & $2.0 \pm 0.1$ & $<$ d.l..$^{b}$ & $3 \pm 7$ \\
\hline-152 & all 10 & 0.61 & 1.62 & 3.47 & 2.2 & $<$ d.l. & 3 \\
\hline & last 5 & 0.55 & 1.50 & 3.07 & 2.0 & $<$ d.l. & 3 \\
\hline-205 & all 10 & 0.70 & 1.71 & 3.85 & 2.3 & $<$ d.l. & 3 \\
\hline & last 5 & 0.60 & 1.61 & 3.67 & 2.3 & $<$ d.l. & 3 \\
\hline
\end{tabular}

${ }^{a}$ For the films deposited with biasing during plasma exposure, data are shown for average bias voltages, $\left\langle V_{\text {bias }}\right\rangle$, applied during the whole (10 s) and the last half $(5 \mathrm{~s})$ of the $10 \mathrm{~s} \mathrm{O}_{2}$ plasma step. Typical uncertainties are given in the first row. ${ }^{b}$ Values below detection limit (d.l.) of 8 at. \% for [C].

applied during plasma exposure. The solid symbols are for films deposited with $\left\langle V_{\text {bias }}\right\rangle$ applied for the entire duration of the $10 \mathrm{~s}$ plasma exposure step (bias duty cycle $=100 \%$, Figure $1 \mathrm{~b}$ ), while the hollow symbols denote films deposited with $\left\langle V_{\text {bias }}\right\rangle$ applied in an interleaved manner, that is, during the last half $(5 \mathrm{~s})$ of the $10 \mathrm{~s}$ plasma exposure step (bias duty cycle $=50 \%$, Figure $1 \mathrm{c}$ ). Table 2 outlines additional growth and material properties from RBS analysis for the films deposited with and without substrate biasing. The growth properties are outlined in terms of the number of titanium and oxygen atoms deposited per $\mathrm{nm}^{2}$ per cycle (GPC [Ti] and GPC [O], respectively) while the material properties are outlined in terms of the $\mathrm{O} / \mathrm{Ti}$ ratio and impurity content $([\mathrm{H}]$ and $[\mathrm{C}]$ at. \%). The crystalline properties of the $\mathrm{TiO}_{x}$ films are depicted in Figure 4, which shows grazing incidence XRD patterns for films deposited at $300{ }^{\circ} \mathrm{C}$ with $\left\langle V_{\text {bias }}\right\rangle$ ranging from $0 \mathrm{~V}$ to $-254 \mathrm{~V}$. Figure $4 \mathrm{a}$ denotes patterns for $\left\langle V_{\text {bias }}\right\rangle$ applied for the entire $10 \mathrm{~s} \mathrm{O}_{2}$ plasma exposure step while Figure $4 \mathrm{~b}$ shows results for $\left\langle V_{\text {bias }}\right\rangle$ applied during the last half (5 $\mathrm{s})$ of the $10 \mathrm{~s}$ plasma exposure step. The microstructure of the $\mathrm{TiO}_{x}$ films can be visualized in Figure 5 which shows plan-view HAADF STEM images for films deposited on planar TEM windows at $300{ }^{\circ} \mathrm{C}$ with and without substrate biasing.

No Substrate Bias. In the absence of substrate biasing during plasma exposure, (i.e., grounded substrate or $\left\langle V_{\text {bias }}\right\rangle=0 \mathrm{~V}$, bias duty cycle $=0 \%$, Figure 1a) the film had a GPC of $0.48 \pm 0.02 \AA$ (Figure 3a) which is similar to the growth rate reported by Wei et al. ${ }^{31}$ for $\mathrm{TiO}_{x}$ deposited at the same temperature using TDMAT and $\mathrm{O}_{2}$ plasma. The values obtained for the refractive index and mass density were $2.47 \pm 0.03$ and $3.7 \pm 0.2 \mathrm{~g} / \mathrm{cm}^{3}$ (Figure $3 \mathrm{~b}$ and c), respectively, which is comparable to the values reported in the literature for the anatase phase of $\mathrm{TiO}_{x}{ }^{32}$ This film was found to have a tensile residual stress (Figure $3 \mathrm{~d}$ ) which was also reported for $\mathrm{TiO}_{x}$ deposited at $300{ }^{\circ} \mathrm{C}$ in previous work. ${ }^{33} \mathrm{An} \mathrm{O} /$ Ti ratio of $2.0 \pm 0.1$ (Table 2) was observed for this film indicating the formation of stoichiometric $\mathrm{TiO}_{2}$ for deposition without any $\left\langle V_{\text {bias }}\right\rangle$. Low impurity contents in terms of $[\mathrm{H}]$ and [C] ( $3 \pm 7$ at. $\%$ and $<8$ at. $\%$, respectively) were obtained in all films (Table 2). The XRD pattern for the film deposited without biasing (Figure 4a) shows diffraction peaks that correspond to the anatase phase of $\mathrm{TiO}_{2}$. The intense and narrow (101) peak indicates the presence of a highly crystalline $\mathrm{TiO}_{2}$ film with large anatase crystal grains. This is confirmed by the complementary information from the TEM image for the film deposited without biasing (Figure 5a), which shows a compact or void-free microstructure with lateral grain sizes on the order of $\sim 150 \mathrm{~nm}$.

Effect of Bias Magnitude. For the $10 \mathrm{~s}$ bias duration condition (bias duty cycle $=100 \%$, Figure $1 b$ ), the GPC showed a monotonic increase with increasing $\left\langle V_{\text {bias }}\right\rangle$ and reached a value of $0.80 \pm 0.02 \AA$ at $-254 \mathrm{~V}$ (Figure $3 \mathrm{a}$ ). This is also reflected in the

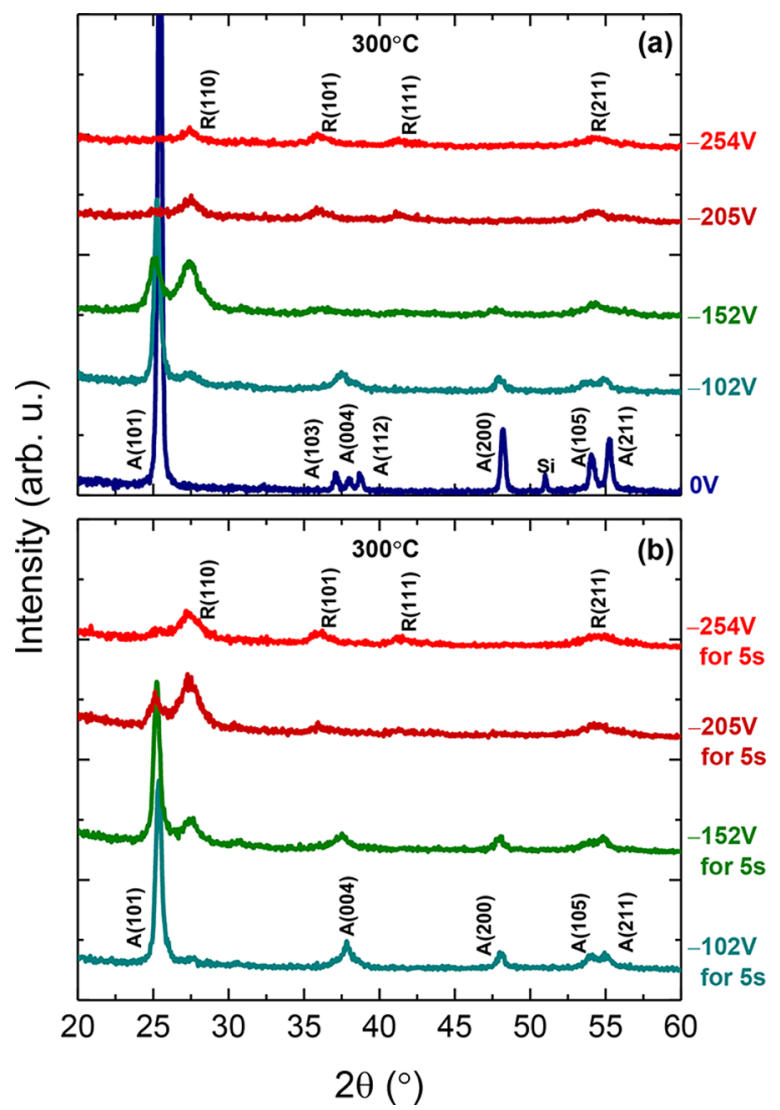

Figure 4. Grazing incidence $\mathrm{X}$-ray diffractograms for titanium oxide films deposited at $300{ }^{\circ} \mathrm{C}$ with average bias voltages, $\left\langle V_{\text {bias }}\right\rangle$, ranging from 0 to $-254 \mathrm{~V}$ applied for the (a) entire duration and (b) last half (5 s) of the $10 \mathrm{~s} \mathrm{O}_{2}$ plasma exposure step. Peaks corresponding to the anatase and rutile phase are denoted with "A" and "R", respectively.

GPC [Ti $]$ and GPC $[\mathrm{O}]$ values which increased to $1.71 \pm 0.03 \mathrm{Ti}$ and $3.85 \pm 0.05 \mathrm{O}$ at. $/ \mathrm{nm}^{2}$, respectively, at $-205 \mathrm{~V}$ applied for all $10 \mathrm{~s}$ of plasma exposure (Table 2). The trends for refractive index, mass density and residual stress can be categorized into two stages composed of an initial buildup to a maximum followed by a gradual decrease with increasing $\left\langle V_{\text {bias }}\right\rangle$. In the first stage, the refractive index and mass density reached peak values of $2.51 \pm$ 0.03 and $4.1 \pm 0.2 \mathrm{~g} / \mathrm{cm}^{3}$, respectively, as $\left\langle V_{\text {bias }}\right\rangle$ was increased to $-152 \mathrm{~V}$ (Figure $3 \mathrm{~b}$ and $\mathrm{c}$ ). The corresponding behavior of the residual stress for $\mathrm{TiO}_{x}$ in the first stage consisted of a change from tensile to compressive on applying a bias to the substrate, denoted by negative values on the vertical axis of Figure $3 \mathrm{~d}$. This stress evolution from tensile to compressive is similar to that frequently reported in the literature for thin-film deposition 


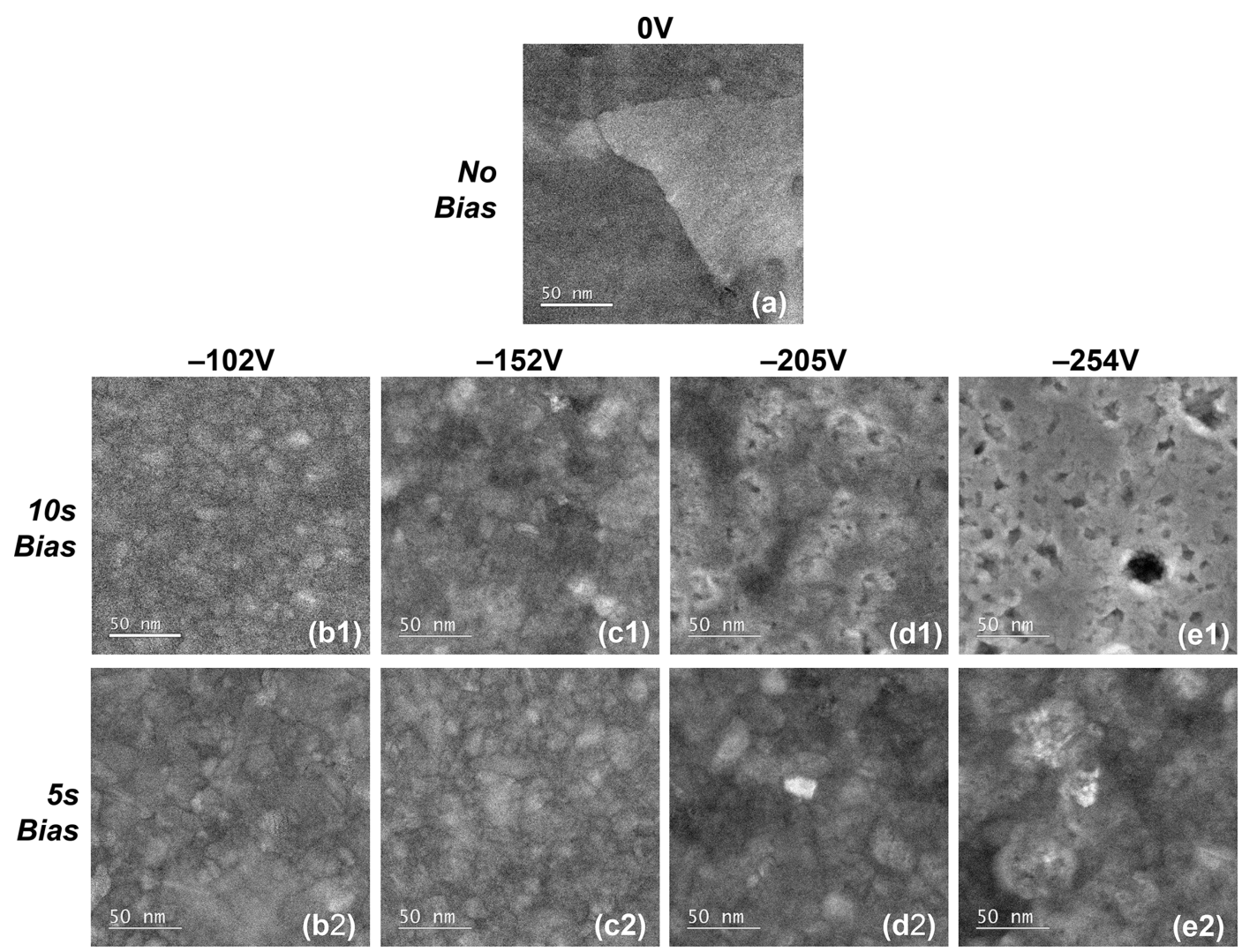

Figure 5. Plan-view high angle annular dark-field (HAADF) STEM images for titanium oxide films deposited at $300{ }^{\circ} \mathrm{C}$ with (a) $0 \mathrm{~V}$, (b1 and b2) - 102 $\mathrm{V},(\mathrm{c} 1$ and $\mathrm{c} 2)-152 \mathrm{~V},(\mathrm{~d} 1$ and $\mathrm{d} 2)-205 \mathrm{~V}$ and $(\mathrm{e} 1$ and $\mathrm{e} 2)-254 \mathrm{~V}$ average bias voltages, $\left\langle V_{\text {bias }}\right\rangle$. Images (b1), (c1), (d1), and (e1) denote $\left\langle V_{\text {bias }}\right\rangle$ applied for the entire duration of the $10 \mathrm{~s}_{2}$ plasma exposure step while images (b2), (c2), (d2), and (e2) represent $\left\langle V_{\text {bias }}\right\rangle$ applied for the last half $(5 \mathrm{~s})$ of the $10 \mathrm{~s}$ plasma exposure step.

using energetic particle bombardment. ${ }^{19,34-37}$ The compressive stress reached a maximum as $\left\langle V_{\text {bias }}\right\rangle$ was increased to $-152 \mathrm{~V}$, similar to the peaking of refractive index and mass density with biasing at the same voltage. The maximization of compressive stress for deposition using energetic particle bombardment has been reported in the literature to be related to the formation of bombardment induced point defects, such as interstitials in the film bulk. ${ }^{34-37}$ Under conditions of intense ion bombardment during film growth, the implantation of the energetic ions or the formation of subsurface interstitial atoms resulting from ionsurface interactions that push deposited atoms into the film bulk (i.e., recoil implantation or forward sputtering of knock-on atoms generated by ion-surface collisions) can increase atomic packing of the growing film. ${ }^{34-37}$ This raises compressive stress as well as the mass density which scale with the concentration of those point defects. ${ }^{34-37}$ The $\mathrm{O} / \mathrm{Ti}$ ratio for the film deposited using $-152 \mathrm{~V}$ applied for $10 \mathrm{~s}$ of plasma exposure was observed to increase to $2.2 \pm 0.1$ (Table 2) indicating the formation of an oxygen rich film during energetic oxygen ion bombardment. The excess oxygen can be speculated to be present as interstitial species which could stimulate an increase in compressive stress while also contributing toward elevating mass density and refractive index observed when increasing $\left\langle V_{\text {bias }}\right\rangle$ up to $-152 \mathrm{~V}$. Applying and steadily increasing $\left\langle V_{\text {bias }}\right\rangle$ to $-152 \mathrm{~V}$ cause the anatase diffraction peaks in the XRD patterns (Figure $4 a$ ) to gradually decrease in magnitude while new peaks corresponding to the rutile phase of $\mathrm{TiO}_{2}$ appeared. This is similar to the results obtained in previous work conducted in our group where the crystalline phase of $\mathrm{TiO}_{x}$ films, grown using different precursors $^{19,20}$ in a home-built plasma ALD tool equipped with substrate biasing, could be transformed by varying $\left\langle V_{\text {bias }}\right\rangle$ during the $\mathrm{O}_{2}$ plasma step. $\mathrm{TiO}_{x}$ is known to have a higher refractive index and mass density in the rutile compared to the anatase phase. $^{32}$ Therefore, besides the effect of a higher interstitial content on material properties, the observed increase in GPC, refractive index, material density and compressive stress could also be caused by phase transformation, or more specifically, the formation of denser rutile crystallites in the mixed phase (anatase + rutile) $\mathrm{TiO}_{x}$ films obtained using $\left\langle V_{\text {bias }}\right\rangle$ up to $-152 \mathrm{~V}$ (Figure $4 a)$. The deposited films were observed to retain a compact and void-free microstructure for $\left\langle V_{\text {bias }}\right\rangle$ up to $-152 \mathrm{~V}$ (Figure $5 \mathrm{~b} 1$ and $\mathrm{cl}$ ). However, based on estimates of lattice fringe areas in magnified TEM images (see Figure S4b1 and S4c1), lateral grain sizes of $\sim 20 \mathrm{~nm}$ were observed in the bias deposited films which were nearly an order of magnitude smaller than the grains formed without biasing.

For $\left\langle V_{\text {bias }}\right\rangle$ beyond $-152 \mathrm{~V}$ applied for all $10 \mathrm{~s}$ of plasma exposure, the GPC (Figure 3a), GPC [Ti], GPC [O], and O/Ti ratio (Table 2 ) continued to increase but the refractive index and mass density entered their second stage where they rapidly decreased, reaching values of $2.27 \pm 0.03$ and $3.7 \pm 0.2 \mathrm{~g} / \mathrm{cm}^{3}$, respectively, at $-254 \mathrm{~V}$ (Figure $3 \mathrm{~b}$ and c). Furthermore, increase in $\left\langle V_{\text {bias }}\right\rangle$ beyond $-152 \mathrm{~V}$ also initiated the second stage in residual stress behavior. The compressive stress began to decrease, similar to the trends in refractive index and mass density as $\left\langle V_{\text {bias }}\right\rangle$ was increased to $-254 \mathrm{~V}$ (Figure $3 \mathrm{~d}$ ). The anatase diffraction peaks in the XRD patterns completely disappeared and only rutile diffraction peaks remained (Figure 4a). The intensities and widths of these peaks became lower and broader, respectively, on increasing $\left\langle V_{\text {bias }}\right\rangle$ beyond $-152 \mathrm{~V}$ 
indicating an increase in the degree of disorder or amorphization of the film microstructure. This onset of amorphization induced by highly energetic ion bombardment has also been reported in the literature ${ }^{14,37,38}$ and it could play a role in lowering the refractive index and mass density of the films. Furthermore, the relaxation of compressive stress on increasing $\left\langle V_{\text {bias }}\right\rangle$ beyond $-152 \mathrm{~V}$ suggests that the yield strength of the material could have been exceeded under such intense ion bombardment, which could then lead to plastic deformation. ${ }^{14,36,39,40}$ These aforementioned trends in material properties were in line with the appearance of voids in the film microstructure for $\mathrm{TiO}_{x}$ deposited with $\left\langle V_{\text {bias }}\right\rangle$ greater than $-152 \mathrm{~V}$ (Figure $5 \mathrm{~d} 1$ and e 1 ). The void fraction increased with increasing $\left\langle V_{\text {bias }}\right\rangle$, which could also play a role in compressive stress relaxation together with decreasing refractive index and mass density. The surface of $\mathrm{TiO}_{x}$ films initially became smoother with biasing as the RMS roughness decreased at $-102 \mathrm{~V}$ (Figure $3 \mathrm{e}$ ). This could be due to a combined effect of phase transformation, material densification and/or coalescence at grain boundaries due to enhanced mobility of surface species induced by energetic ions ${ }^{37}$ during film growth. The roughness increased with further increase in $\left\langle V_{\text {bias }}\right\rangle$ to $-254 \mathrm{~V}$, which could be attributed to the onset of void incorporation or ion bombardment induced surface damage. ${ }^{37}$ The trends in RMS surface roughness obtained from XRR were corroborated with additional measurements performed using atomic force microscopy (see Figure S5 and S6). Altogether, the results above demonstrate how the growth and material properties of $\mathrm{TiO}_{x}$ films deposited using TDMAT and $\mathrm{O}_{2}$ plasma can be tuned by altering the magnitude of $\left\langle V_{\text {bias }}\right\rangle$ applied with a $100 \%$ duty cycle during the plasma exposure step of PEALD.

Effect of Bias Duration/Duty Cycle. When $\left\langle V_{\text {bias }}\right\rangle$ having the same magnitude but different duty cycle was applied during the $\mathrm{O}_{2}$ plasma exposure step (i.e., the last $5 \mathrm{~s}$ of the $10 \mathrm{~s}$ plasma exposure, bias duty cycle $=50 \%$, Figure 1c), differences were observed in the variation of $\mathrm{TiO}_{x}$ film properties. The GPC again showed a trend of increasing with $\left\langle V_{\text {bias }}\right\rangle$, but at a slower rate than the $10 \mathrm{~s}$ bias condition reaching a comparatively lower value at $-254 \mathrm{~V}$ (Figure 3a). This was also the case for GPC [Ti] and GPC [O] values (Table 2), which increased to comparatively lower values at $-205 \mathrm{~V}$ applied for the shorter $5 \mathrm{~s}$ of plasma exposure. The refractive index and mass density of the films also increased with biasing for the shorter $5 \mathrm{~s}$ condition, but were consistently higher than the corresponding values for films deposited using the same $\left\langle V_{\text {bias }}\right\rangle$ applied for a longer duration of $10 \mathrm{~s}$ (Figure $3 \mathrm{~b}$ and $\mathrm{c}$ ). The refractive index and mass density for the $5 \mathrm{~s}$ bias condition reached higher maximum values at a higher $\left\langle V_{\text {bias }}\right\rangle$ of $-205 \mathrm{~V}$ compared to the corresponding peaks at -152 $\mathrm{V}$ obtained using the $10 \mathrm{~s}$ bias condition (Figure $3 \mathrm{~b}$ and $\mathrm{c}$ ). The residual stress of the $\mathrm{TiO}_{x}$ films again changed from tensile to compressive for the $5 \mathrm{~s}$ bias condition and also reached a higher maximum at a higher $\left\langle V_{\text {bias }}\right\rangle$ of $-205 \mathrm{~V}$ compared to the maximum obtained at $-152 \mathrm{~V}$ using the $10 \mathrm{~s}$ bias condition (Figure 3d). The $\mathrm{O} / \mathrm{Ti}$ ratio for the film deposited using $-205 \mathrm{~V}$ applied for the shorter duration of $5 \mathrm{~s}$ was $2.3 \pm 0.1$ (Table 2) which again indicates the formation of an oxygen rich film during energetic oxygen ion bombardment. Since compressive stress tends to scale with the concentration of point defects such as interstitials, ${ }^{34-37}$ the higher fraction of excess oxygen in the film grown with $-205 \mathrm{~V}$ applied for the shorter duration of $5 \mathrm{~s}$ could explain why it had a higher compressive stress, mass density and refractive index compared to the film grown with $-152 \mathrm{~V}$ applied for $10 \mathrm{~s}$. It is worth noting that the use of $-102 \mathrm{~V}$ for the shorter duration of $5 \mathrm{~s}$ yielded $\mathrm{TiO}_{x}$ that was approximately stress-free in nature as evidenced by the insignificant value of $-25 \pm 50 \mathrm{MPa}$ measured for that film. Furthermore, $\mathrm{TiO}_{x}$ films deposited using the $5 \mathrm{~s}$ bias condition retained a compact and void-free microstructure up to a higher $\left\langle V_{\text {bias }}\right\rangle$ of $-205 \mathrm{~V}$ (Figure 5b2, $\mathrm{c} 2$, and $\mathrm{d} 2$ ) compared to the $-152 \mathrm{~V}$ ceiling for obtaining similar void-free films using the $10 \mathrm{~s}$ bias condition (Figure $5 \mathrm{~b} 1$ and $\mathrm{cl}$ ). Increasing $\left\langle V_{\text {bias }}\right\rangle$ beyond $-205 \mathrm{~V}$ using the $5 \mathrm{~s}$ bias condition led to a decrease in both refractive index and mass density together with compressive stress relaxation (Figure $3 b, c$ and d), similar to the trends observed for the $10 \mathrm{~s}$ bias condition beyond $-152 \mathrm{~V}$. This can again be attributed to the incorporation of voids in the film microstructure (Figure 5e2) and/or the onset of plastic deformation ${ }^{14,36,39,40}$ for $\mathrm{TiO}_{x}$ deposited at $-254 \mathrm{~V}$ using the $5 \mathrm{~s}$ bias condition. The $\mathrm{TiO}_{x}$ film surface initially became smoother with biasing using the $5 \mathrm{~s}$ condition, similar to the $10 \mathrm{~s}$ condition. However, the lowest RMS roughness was now at $-152 \mathrm{~V}$ applied for the last $5 \mathrm{~s}$ (Figure 3e) compared to $-102 \mathrm{~V}$ applied for all 10 $\mathrm{s}$ of plasma exposure. Further increase in $\left\langle V_{\text {bias }}\right\rangle$ beyond $-152 \mathrm{~V}$ using the $5 \mathrm{~s}$ bias condition increased surface roughness. Similar to the delayed changes observed in the aforementioned properties, the anatase to rutile phase transformation using the $5 \mathrm{~s}$ bias condition also occurred at a slower rate compared to the $10 \mathrm{~s}$ bias condition (Figure $4 \mathrm{~b}$ ). It is worth noting that for the $10 \mathrm{~s}$ bias condition, using $-152 \mathrm{~V}$ leads to a combined anatase and rutile mixed phase with the most intense $\mathrm{R}(110)$ peak (Figure $4 \mathrm{a})$ whereas for the $5 \mathrm{~s}$ condition, a similar mixed phase with the most intense $\mathrm{R}(110)$ peak is observed at $-205 \mathrm{~V}$ (Figure $4 \mathrm{~b}$ ). It seems that for PEALD of $\mathrm{TiO}_{x}$ with substrate biasing, optimum material quality in terms of a high refractive index, high density and compact microstructure is obtained for films with a mixed phase content having the highest $\mathrm{R}(110)$ peak intensity and no voids. Varying the duration of the applied bias translates to changing the dose or fluence (i.e., particle flux integrated over time) of energetic ions impinging on the substrate. The dose or fluence of energetic ions has also been reported in the literature as a parameter that can have significant effects on material properties. ${ }^{13,14,21}$ Altogether, these results effectively demonstrate how the growth and material properties of $\mathrm{TiO}_{x}$ films deposited using TDMAT and $\mathrm{O}_{2}$ plasma can be tuned, not only by varying the magnitude of $\left\langle V_{\text {bias }}\right\rangle$, but also by changing the duration or duty cycle of $\left\langle V_{\text {bias }}\right\rangle$ applied during the plasma exposure step.

Effect of Substrate Bias at Lower Deposition Temperature. Figure 6 shows selected area electron diffraction patterns and plan-view HAADF STEM images for $\mathrm{TiO}_{x}$ films deposited at a lower temperature of $150{ }^{\circ} \mathrm{C}$ with and without substrate biasing applied during $10 \mathrm{~s}$ of $\mathrm{O}_{2}$ plasma exposure. For the film deposited without any $\left\langle V_{\text {bias }}\right\rangle$, the diffuse rings in the electron diffraction pattern (Figure 6a1) and the absence of crystal lattice fringes in the plan-view HAADF STEM image (Figure 6a2) clearly indicate the amorphous nature of the film. However, the appearance of sharp rings (Figure 6b1) and crystal lattice fringes (Figure 6b2) indicate the presence of polycrystalline material in the film deposited with $\left\langle V_{\text {bias }}\right\rangle$ of $-205 \mathrm{~V}$. This is confirmed by the appearance of diffraction peaks corresponding to the rutile phase of $\mathrm{TiO}_{x}$ in the grazing incidence XRD pattern for the film deposited with $-205 \mathrm{~V}$ at $150{ }^{\circ} \mathrm{C}$ (see Figure S7). Profijt et al. ${ }^{20}$ reported a similar result for $\mathrm{TiO}_{x}$ deposited at $200{ }^{\circ} \mathrm{C}$ using $\mathrm{Ti}\left(\mathrm{Cp}^{\mathrm{Me}}\right)\left(\mathrm{NMe}_{2}\right)_{3}$ as the precursor. Their film deposited without biasing was amorphous, while applying $-100 \mathrm{~V}$ bias during the whole duration of the $\mathrm{O}_{2}$ plasma exposure yielded crystallinity, evidenced by the $\mathrm{R}(110)$ diffraction peak in the 


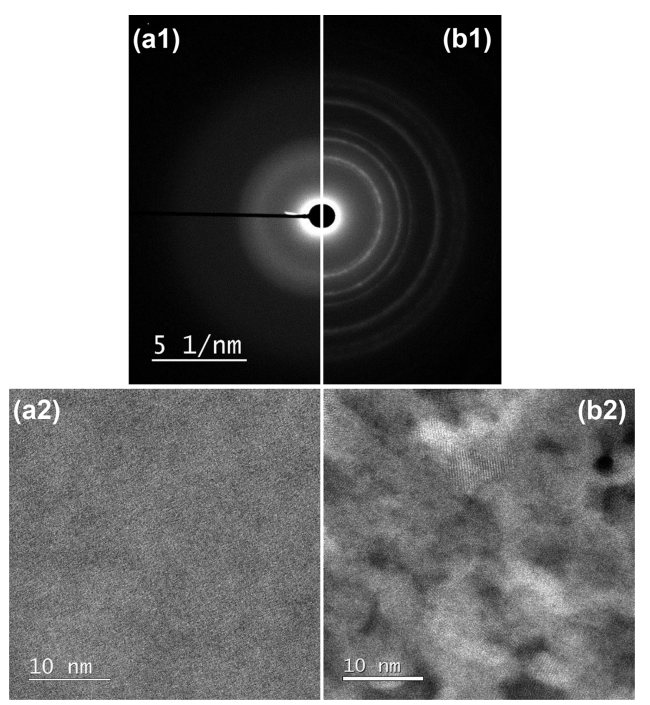

Figure 6. (a1, b1) Selected area electron diffraction patterns and (a2, b2) plan-view high angle annular dark-field (HAADF) STEM images for titanium oxide films deposited at $150{ }^{\circ} \mathrm{C}$. Panels (a1) and (a2) are for the film deposited without substrate biasing $\left(\left\langle V_{\text {bias }}\right\rangle=0 \mathrm{~V}\right)$ while panels (b1) and (b2) are for the film deposited with substrate biasing $\left(\left\langle V_{\text {bias }}\right\rangle=\right.$ $-205 \mathrm{~V})$ applied during $10 \mathrm{~s}$ of the $\mathrm{O}_{2}$ plasma exposure step.

XRD pattern. The results obtained in this work using a different precursor (TDMAT) effectively reproduce the phenomenon of inducing crystalline material formation with substrate biasing at a comparatively lower temperature that would typically yield amorphous films.

Hafnium Oxide $\left(\mathrm{HfO}_{x}\right)$. The growth and material properties of $\mathrm{HfO}_{x}$ films deposited on planar substrates at $150{ }^{\circ} \mathrm{C}$ were investigated for $\left\langle V_{\text {bias }}\right\rangle$ between 0 and $-280 \mathrm{~V}$ applied during the $\mathrm{O}_{2}$ plasma exposure step. Figure 7 shows these properties in terms of the GPC, refractive index, mass density, residual stress and surface roughness expressed as a function of $\left\langle V_{\text {bias }}\right\rangle$ applied during plasma exposure. The crystalline properties of the $\mathrm{HfO}_{x}$ films can be analyzed in Figure 8 which shows grazing incidence $\mathrm{XRD}$ patterns for films deposited with $\left\langle V_{\text {bias }}\right\rangle$ ranging from 0 to $-280 \mathrm{~V}$. Additional information regarding the crystallinity and film microstructure can be obtained in Figure 9 which shows selected area electron diffraction patterns and plan-view HAADF STEM images for $\mathrm{HfO}_{x}$ deposited on planar TEM windows with and without substrate biasing.

For deposition without any bias voltage, the film had a GPC of $1.03 \pm 0.02 \AA$ and a refractive index of $2.04 \pm 0.03$ (Figure 7a and b) which are comparable to the values reported by Sharma et al. ${ }^{25}$ for $\mathrm{HfO}_{x}$ deposited using TDMACpH and $\mathrm{O}_{2}$ plasma at the same temperature. The film was observed to have a mass density of 9.0 $\pm 0.2 \mathrm{~g} / \mathrm{cm}^{3}$ (Figure $7 \mathrm{c}$ ). The lack of diffraction peaks in the XRD pattern (Figure 8) indicate the formation of amorphous $\mathrm{HfO}_{x}$ deposited without biasing. This is confirmed by diffuse rings in the electron diffraction pattern (Figure 9a1) and absence of lattice fringes in the HAADF STEM image (Figure 9a2). A void rich amorphous matrix is also revealed in the HAADF STEM image which could explain the low mass density and refractive index of this film when compared to bulk $\mathrm{HfO}_{x}{ }^{41,42}$ The film had a tensile residual stress of $770 \pm 50 \mathrm{MPa}$ (Figure $7 \mathrm{~d}$ ) which is comparable to that reported for $\mathrm{HfO}_{x}$ in previous work. ${ }^{30}$

When substrate biasing was implemented during plasma exposure, the GPC showed a slow increase with $\left\langle V_{\text {bias }}\right\rangle$ up to $-204 \mathrm{~V}$ (Figure $7 \mathrm{a}$ ). Further increase in $\left\langle V_{\text {bias }}\right\rangle$ to $-280 \mathrm{~V}$ led to a

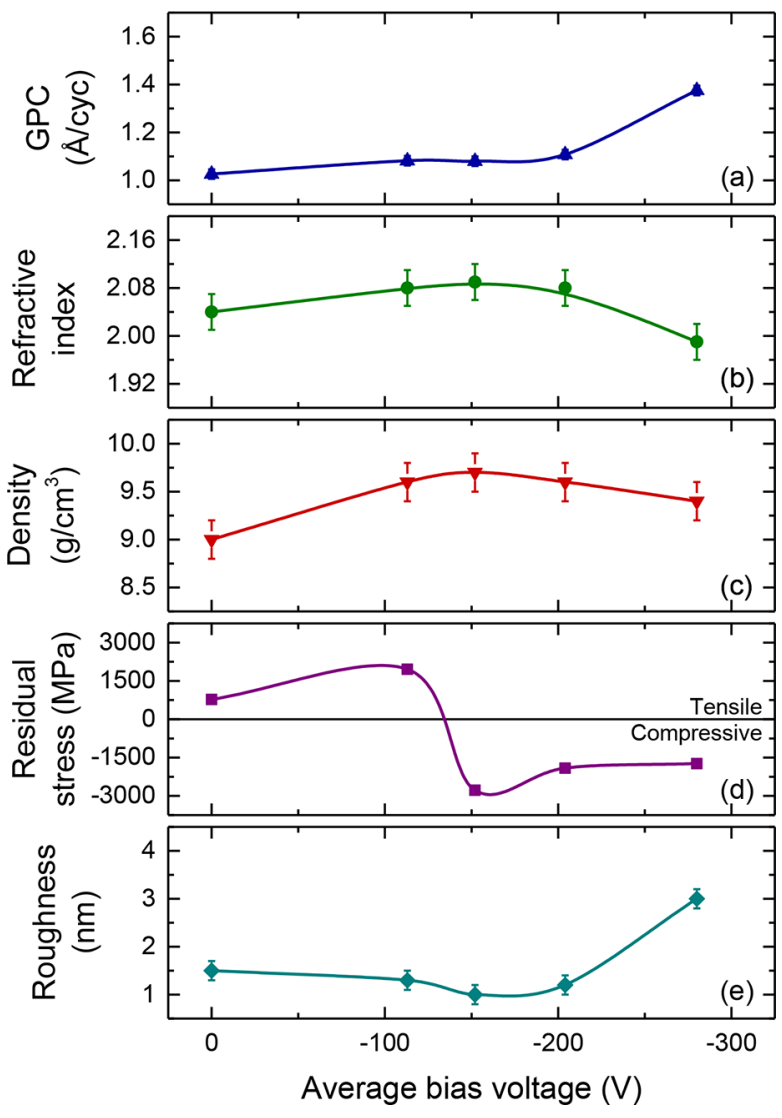

Figure 7. (a) Growth per cycle (GPC), (b) refractive index, (c) mass density, (d) residual stress, and (e) RMS surface roughness of hafnium oxide films deposited at $150{ }^{\circ} \mathrm{C}$ expressed as a function of the average bias voltage, $\left\langle V_{\text {bias }}\right\rangle$, applied during the $\mathrm{O}_{2}$ plasma exposure step.

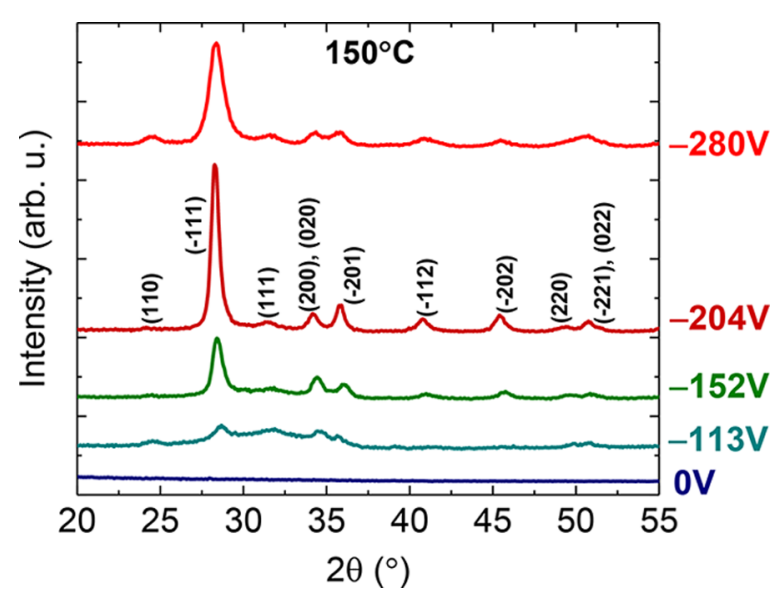

Figure 8. Grazing incidence X-ray diffractograms for hafnium oxide films deposited at $150{ }^{\circ} \mathrm{C}$ with average bias voltages, $\left\langle V_{\text {bias }}\right\rangle$, ranging from 0 to $-280 \mathrm{~V}$ applied during the $\mathrm{O}_{2}$ plasma exposure step. Peaks corresponding to lattice planes in monoclinic hafnium oxide are indicated.

rapid increase in GPC. The refractive index and mass density showed a two stage behavior where they initially increased with $\left\langle V_{\text {bias }}\right\rangle$ reaching a maximum of $2.09 \pm 0.03$ and $9.7 \pm 0.2 \mathrm{~g} / \mathrm{cm}^{3}$, respectively, at $-152 \mathrm{~V}$ (Figure $7 \mathrm{~b}$ and $\mathrm{c}$ ) which are closer to the values for bulk $\mathrm{HfO}_{x}{ }^{41,42}$ Applying and steadily increasing $\left\langle V_{\text {bias }}\right\rangle$ led to the appearance of diffraction peaks in the XRD patterns (Figure 8) corresponding to lattice planes of monoclinic $\mathrm{HfO}_{x}$. 


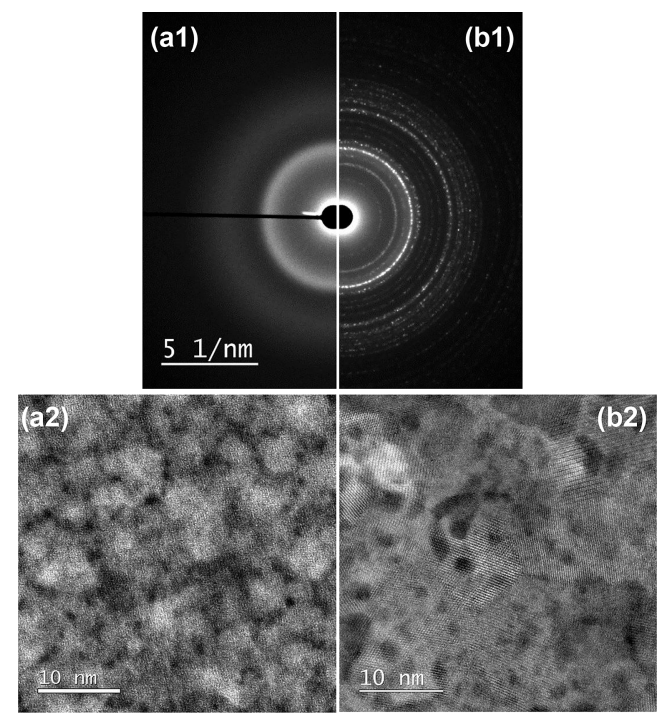

Figure 9. (a1, b1) Selected area electron diffraction patterns and (a2, b2) plan-view high angle annular dark-field (HAADF) STEM images for hafnium oxide films deposited at $150{ }^{\circ} \mathrm{C}$. Panels a1 and a2 are for the film deposited without substrate biasing $\left(\left\langle V_{\text {bias }}\right\rangle=0 \mathrm{~V}\right)$ while panels b1 and $\mathrm{b} 2$ are for the film deposited with substrate biasing $\left(\left\langle V_{\text {bias }}\right\rangle=-204\right.$ $\mathrm{V})$ applied during the $\mathrm{O}_{2}$ plasma exposure step.

The phenomenon of crystalline material formation with substrate biasing at low temperature discussed previously for $\mathrm{TiO}_{x}$ was also effectively demonstrated in case of $\mathrm{HfO}_{x}$. Increasing $\left\langle V_{\text {bias }}\right\rangle$ to $-152 \mathrm{~V}$ led to higher diffraction peak intensities and narrower peak widths indicating the presence of a higher crystalline fraction and formation of larger crystal grains. ${ }^{43}$ Therefore, the observed increase in GPC, refractive index and mass density with $\left\langle V_{\text {bias }}\right\rangle$ can be initially attributed to the formation of crystalline material at $-113 \mathrm{~V}$, followed by an increase in crystalline content and/or grain size at $-152 \mathrm{~V}$. The increase in refractive index and mass density with biasing could in principle, also be due to a reduction in void content observed for the film grown without biasing. A similar increase in film crystallinity, refractive index and mass density of $\mathrm{HfO}_{x}$ films was reported by Sharma et al. $^{25}$ due to an increase in substrate temperature. Therefore, the results obtained in this work demonstrate that enhancing the ion energy during PEALD of $\mathrm{HfO}_{x}$ provides an alternate route for tuning such properties. Unlike the previous case of $\mathrm{TiO}_{x}$ or any other material investigated in this work, the residual stress of $\mathrm{HfO}_{x}$ showed a three stage behavior. In the first stage, the tensile residual stress of the $\mathrm{HfO}_{x}$ films increased with $\left\langle V_{\text {bias }}\right\rangle$ to $1960 \pm 50 \mathrm{MPa}$ at -113 $\mathrm{V}$ (Figure $7 \mathrm{~d}$ ). This is in contrast to the trend exhibited by $\mathrm{TiO}_{x}$, which showed a change in stress from tensile to compressive when applying a similar $\left\langle V_{\text {bias }}\right\rangle$. The difference in stress behavior could be due to the difference in initial microstructure of the two films grown without biasing. $\mathrm{TiO}_{x}$ deposited at a higher temperature $\left(300{ }^{\circ} \mathrm{C}\right)$ yielded a highly crystalline and void-free film, whereas $\mathrm{HfO}_{x}$ deposited at a lower temperature $\left(150{ }^{\circ} \mathrm{C}\right)$ consisted of a void rich amorphous matrix. Therefore, when applying a similar $\left\langle V_{\text {bias }}\right\rangle$ around $-100 \mathrm{~V}, \mathrm{TiO}_{x}$ changed from one void-free crystalline state to another, whereas $\mathrm{HfO}_{x}$ transitioned from a disordered and porous amorphous matrix to a more ordered crystalline structure, with perhaps a lower void content. Further increase in $\left\langle V_{\text {bias }}\right\rangle$ led to the second stage in stress behavior where $\mathrm{HfO}_{x}$ went from a tensile maximum at $-113 \mathrm{~V}$ to a compressive maximum at $-152 \mathrm{~V}$ (Figure $7 \mathrm{~d}$ ). This may again be related to another change in film microstructure. In this case, $\mathrm{HfO}_{x}$ transitioned from a less crystalline film with small grains at $-113 \mathrm{~V}$ to a comparatively more crystalline film with larger grains and possibly, an even lower void content at $-152 \mathrm{~V}$. The surface roughness of the films also showed a two stage behavior with substrate biasing. The films initially became smoother on increasing $\left\langle V_{\text {bias }}\right\rangle$ as the RMS roughness decreased to a minimum at $-152 \mathrm{~V}$ (Figure $7 \mathrm{e})$. This could again stem from coalescence at the grain boundaries ${ }^{25,37}$ due to enhanced mobility of surface species induced by energetic ions during film growth, similar to the case of $\mathrm{TiO}_{x}$.

For $\left\langle V_{\text {bias }}\right\rangle$ beyond $-152 \mathrm{~V}$, the refractive index and mass density entered their second stage where they now decreased with substrate biasing (Figure $7 \mathrm{~b}$ and $\mathrm{c}$ ). On the contrary, increasing $\left\langle V_{\text {bias }}\right\rangle$ to $-204 \mathrm{~V}$ led to a more intense and narrower $(-111)$ diffraction peak in the XRD pattern (Figure 8). This, combined with the decrease in refractive index and mass density of $\mathrm{HfO}_{x}$ at $-204 \mathrm{~V}$ suggests the formation of a more crystalline film with larger grains and a porous microstructure. This is confirmed by the electron diffraction pattern and HAADF STEM image in Figure 9. Sharp rings corresponding to monoclinic $\mathrm{HfO}_{x}$ (Figure 9b1) and crystal lattice fringes (Figure 9b2) reaffirm polycrystalline material formation using $\left\langle V_{\text {bias }}\right\rangle$ of -204 $\mathrm{V}$, while the dark regions (Figure $9 \mathrm{~b} 2$ ) provide evidence of a void rich microstructure. Application of $\left\langle V_{\text {bias }}\right\rangle$ above $-204 \mathrm{~V}$ led to a gradual decrease in peak intensities and broadening of peak widths in the XRD patterns (Figure 8). This indicates a decrease in crystallinity or material amorphization ${ }^{14,37,38}$ under intense ion bombardment. The trend in residual stress entered its third stage for $\left\langle V_{\text {bias }}\right\rangle$ exceeding $-152 \mathrm{~V}$ due to the onset of compressive stress relaxation (Figure $7 \mathrm{~d}$ ). A rise in RMS roughness was observed on increasing $\left\langle V_{\text {bias }}\right\rangle$ to $-280 \mathrm{~V}$ (Figure $7 \mathrm{e})$ implying that the trend for surface roughness had transitioned to its second stage. These trends for $\mathrm{HfO}_{x}$ deposited using $\left\langle V_{\text {bias }}\right\rangle$ beyond $-152 \mathrm{~V}$ are similar to those observed earlier for $\mathrm{TiO}_{x}$ films grown using high $\left\langle V_{\text {bias }}\right\rangle$. As a result, the degradation of $\mathrm{TiO}_{x}$ properties due to increase in film void content, plastic deformation ${ }^{14,36,39,40}$ and ion bombardment induced surface damage ${ }^{37}$ at high $\left\langle V_{\text {bias }}\right\rangle$ could also hold true for $\mathrm{HfO}_{x}$ deposited using similar conditions. Further analysis regarding the effects of biasing on $\mathrm{HfO}_{x}$ microstructure, composition and deposition at a higher temperature will be reported in a subsequent publication.

Silicon Oxide $\left(\mathrm{SiO}_{x}\right)$. Figure 10 shows the GPC, refractive index, mass density, residual stress and surface roughness of $\mathrm{SiO}_{x}$ films deposited at $200{ }^{\circ} \mathrm{C}$ as a function of $\left\langle V_{\text {bias }}\right\rangle$ applied during the $\mathrm{O}_{2}$ plasma exposure step. For the deposition performed without biasing during plasma exposure the film had a GPC of $1.02 \pm 0.02 \AA$, refractive index of $1.45 \pm 0.03$, mass density of 2.3 $\pm 0.2 \mathrm{~g} / \mathrm{cm}^{3}$ and RMS surface roughness of $1.0 \pm 0.2 \mathrm{~nm}$, similar to those reported in previous work by Dingemans et al. ${ }^{27}$ In contrast with the tensile residual stress observed for $\mathrm{TiO}_{x}$ and $\mathrm{HfO}_{x}$ deposited without biasing, a compressive residual stress of $-96 \pm 50 \mathrm{MPa}$ was observed for $\mathrm{SiO}_{x}$ deposited without biasing, similar to that reported previously for $\mathrm{SiO}_{x}$ deposited at the same temperature. ${ }^{30}$

When implementing substrate biasing during the $\mathrm{O}_{2}$ plasma exposure step, the GPC showed a monotonic decrease with increasing $\left\langle V_{\text {bias }}\right\rangle$ and reached a value of $0.62 \pm 0.02 \AA$ at $-295 \mathrm{~V}$ (Figure 10a). This is in contrast to the trends in GPC observed earlier for $\mathrm{TiO}_{x}$ and $\mathrm{HfO}_{x}$ but similar to the monotonic decrease in GPC observed for cobalt oxide reported by Profijt et al. ${ }^{19}$ It serves to demonstrate how the trends in growth properties as a 


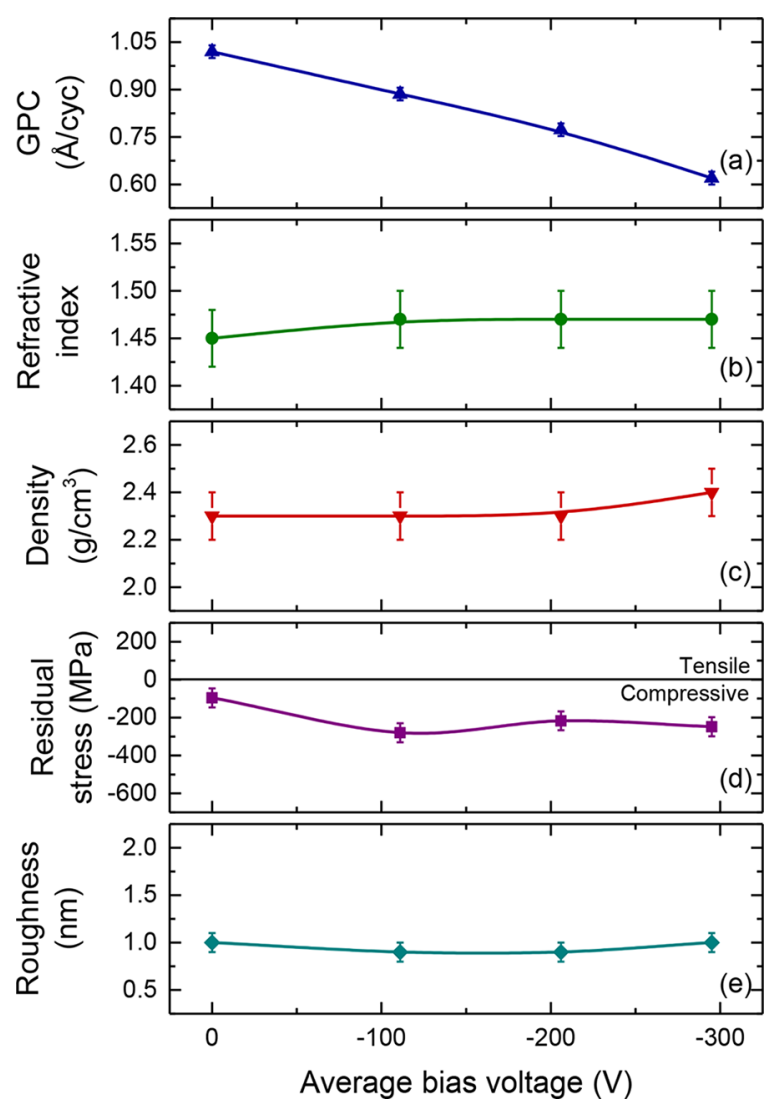

Figure 10. (a) Growth per cycle (GPC), (b) refractive index, (c) mass density, (d) residual stress, and (e) RMS surface roughness of silicon oxide films deposited at $200{ }^{\circ} \mathrm{C}$ expressed as a function of the average bias voltage, $\left\langle V_{\text {bias }}\right\rangle$, applied during the $\mathrm{O}_{2}$ plasma exposure step.

function of $\left\langle V_{\text {bias }}\right\rangle$ can be material specific. The refractive index of $\mathrm{SiO}_{x}$ was observed to increase slightly to $1.47 \pm 0.03$ by applying $\left\langle V_{\text {bias }}\right\rangle$ of $-111 \mathrm{~V}$, but did not increase beyond this value with further increase in biasing. The mass density was observed to remain fairly unchanged with biasing with a slight increase to 2.4 $\pm 0.2 \mathrm{~g} / \mathrm{cm}^{3}$ using $\left\langle V_{\text {bias }}\right\rangle$ of $-295 \mathrm{~V}$. The residual stress of the $\mathrm{SiO}_{x}$ films remained compressive when deposited with substrate biasing and reached a maximum value of $-280 \pm 50 \mathrm{MPa}$ at $-111 \mathrm{~V}$. Further increase in $\left\langle V_{\text {bias }}\right\rangle$ did not lead to any significant change in the compressive stress. The RMS surface roughness also remained fairly constant when using $\left\langle V_{\text {bias }}\right\rangle$ to deposit $\mathrm{SiO}_{x}$ films. Unlike the significant variations in growth and material properties observed for $\mathrm{TiO}_{x}$ and $\mathrm{HfO}_{x}$ previously, the results for $\mathrm{SiO}_{x}$ showed a significant variation in the growth rate but a very small change in material properties as a function of $\left\langle V_{\text {bias }}\right\rangle$ during plasma exposure. Further analysis of film $\mathrm{OH}$ content, optical transmission losses, wet-etch resistance, etc., will be reported in a subsequent publication that will provide more insight on the effects of substrate biasing during PEALD of $\mathrm{SiO}_{x}$.

PEALD of Nitrides on Planar Substrates. Titanium Nitride $\left(\operatorname{TiN}_{x}\right)$. The growth and material properties of $\operatorname{TiN}_{x}$ films deposited on planar substrates at $200{ }^{\circ} \mathrm{C}$ was investigated for $\left\langle V_{\text {bias }}\right\rangle$ between $0 \mathrm{~V}$ and $-255 \mathrm{~V}$ applied during the $\mathrm{Ar}+\mathrm{H}_{2}$ plasma exposure step. Figure 11 shows these properties in terms of the GPC, resistivity, mass density, residual stress, and surface roughness expressed as a function of $\left\langle V_{\text {bias }}\right\rangle$ applied during plasma exposure. Table 3 outlines additional growth and material properties from RBS analysis for the films deposited with and without substrate biasing. The growth properties are outlined in

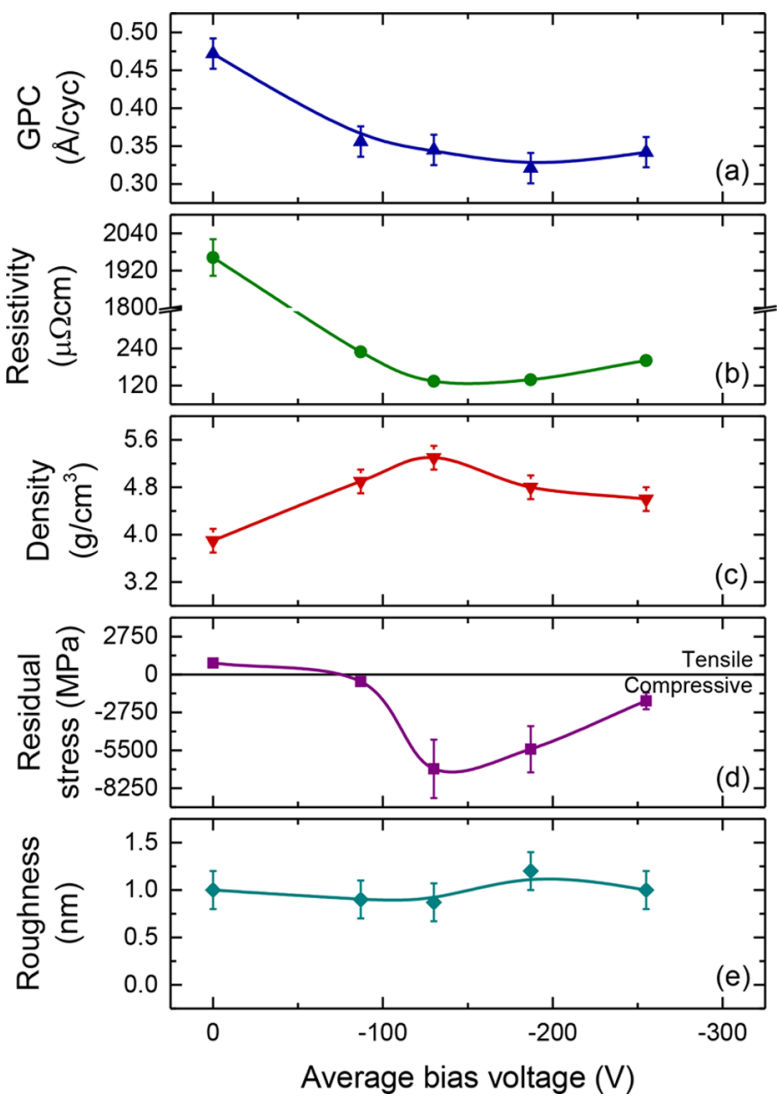

Figure 11. (a) Growth per cycle (GPC), (b) resistivity, (c) mass density, (d) residual stress, and (e) RMS surface roughness of titanium nitride films deposited at $200{ }^{\circ} \mathrm{C}$ expressed as a function of the average bias voltage, $\left\langle V_{\text {bias }}\right\rangle$, applied during the $\mathrm{Ar}+\mathrm{H}_{2}$ plasma exposure step.

terms of the number of titanium, nitrogen and oxygen atoms deposited per $\mathrm{nm}^{2}$ per cycle (GPC [Ti], GPC $[\mathrm{N}]$, and GPC $[\mathrm{O}]$, respectively) while the material properties are outlined in terms of the N/Ti ratio and impurity content $([\mathrm{C}],[\mathrm{Ar}]$, and $[\mathrm{H}])$. Note that both $\mathrm{Ti}$ and $\mathrm{N}$ species in the deposited $\mathrm{TiN}_{x}$ films originated from the precursor itself while the reductive $\mathrm{Ar}+$ $\mathrm{H}_{2}$ plasma resets the surface by the formation of amino ligands to enable precursor adsorption in the subsequent cycle. ${ }^{23}$ The crystalline properties of the $\mathrm{TiN}_{x}$ films are depicted in Figure 12 which shows grazing incidence XRD patterns for films deposited with $\left\langle V_{\text {bias }}\right\rangle$ ranging from $0 \mathrm{~V}$ to $-255 \mathrm{~V}$. The microstructure of the $\operatorname{TiN}_{x}$ films can be observed in Figure 13 which shows planview HAADF STEM images for films deposited on planar TEM windows with and without substrate biasing.

For film deposition without any biasing, a GPC of $0.47 \pm 0.02$ $\AA$ was obtained (Figure 11a) which is comparable to that reported for $\mathrm{TiN}_{x}$ deposited using TDMAT and $\mathrm{Ar}+\mathrm{H}_{2}$ plasma at this temperature. ${ }^{24}$ The film had a resistivity of $1960 \pm 60$ $\mu \Omega \mathrm{cm}$ and a mass density of $3.9 \pm 0.2 \mathrm{~g} / \mathrm{cm}^{3}$ (Figure $11 \mathrm{~b}$ and $\mathrm{c}$, respectively). Compared to the resistivity and density of bulk $\mathrm{TiN}_{x}$, the higher resistivity and lower density of the $\mathrm{TiN}_{x}$ film grown without biasing hint toward the presence of impurities ${ }^{23,24}$ and/or void incorporation at grain boundaries. ${ }^{44,45}$ This is partly confirmed by the high [O] and [H] impurity contents of $28 \pm 5$ at. $\%$ and $10 \pm 7$ at. \%, respectively, for this film leading to a nonstoichiometric $\mathrm{N} / \mathrm{Ti}$ ratio of $0.63 \pm 0.06$ and a GPC [O] value of $0.92 \pm 0.05 \mathrm{O}$ at. $/ \mathrm{nm}^{2}$ (Table 3). The GPC [O] is significant when compared to the GPC $[\mathrm{Ti}]$ and GPC $[\mathrm{N}]$ values (Table 3). No inert argon gas or detectable carbon impurities 
Table 3. GPC (Film Thickness per Cycle and Number of Atoms Deposited per $\mathbf{n m}^{2}$ per Cycle) and Elemental Composition of Titanium Nitride Films Deposited at $200{ }^{\circ} \mathrm{C}$ with and without Average Bias Voltages, $\left\langle V_{\text {bias }}\right\rangle$, Applied during the Ar $+\mathrm{H}_{2} \mathrm{Plasma}$ Exposure Step ${ }^{a}$

\begin{tabular}{|c|c|c|c|c|c|c|c|c|c|}
\hline \multirow{3}{*}{$\begin{array}{c}\left\langle V_{\text {bias }}\right\rangle \\
(\mathrm{V})\end{array}$} & \multirow{3}{*}{$\begin{array}{c}\text { GPC } \\
(\AA / \text { cycle })\end{array}$} & \multicolumn{7}{|c|}{ RBS } & \multirow{3}{*}{$\begin{array}{c}\text { ERD } \\
{[\mathrm{H}]} \\
\text { at. \% }\end{array}$} \\
\hline & & GPC [Ti] (\# Ti at. per & GPC $[\mathrm{N}]$ (\# N at. per & GPC [O] (\# O at. per & & {$[\mathrm{O}]$} & {$[\mathrm{C}]$} & {$[\mathrm{Ar}]$} & \\
\hline & & $\mathrm{nm}^{2}$ per cycle) & $\mathrm{nm}^{2}$ per cycle) & $\mathrm{nm}^{2}$ per cycle) & $\mathrm{N} / \mathrm{Ti}$ & at. $\%$ & at. $\%$ & at. $\%$ & \\
\hline 0 & $0.47 \pm 0.02$ & $1.22 \pm 0.03$ & $0.76 \pm 0.10$ & $0.92 \pm 0.05$ & $0.63 \pm 0.06$ & $28 \pm 5$ & $<$ d...$^{b}$ & $0 \pm 0.06$ & $10 \pm 7$ \\
\hline-130 & 0.35 & $1.46 \pm 0.01$ & $1.18 \pm 0.04$ & $0.10 \pm 0.02$ & $0.80 \pm 0.02$ & $3 \pm 2$ & $<$ d.l. & $0.20 \pm 0.05$ & $3 \pm 3$ \\
\hline-255 & 0.34 & 1.18 & 1.17 & 0.06 & 1.0 & 2 & $12 \pm 3$ & 0.77 & 2 \\
\hline
\end{tabular}

${ }^{a}$ Typical uncertainties are given in the first and second rows unless otherwise stated. ${ }^{b}$ Values below detection limit (d.1.) of 8 at. \% for [C].

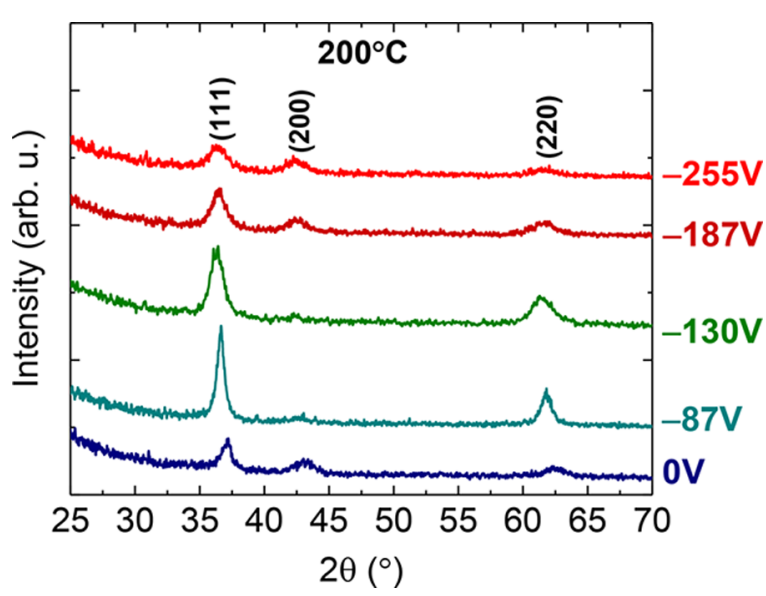

Figure 12. Grazing incidence $X$-ray diffractograms for titanium nitride films deposited at $200{ }^{\circ} \mathrm{C}$ with average bias voltages, $\left\langle V_{\text {bias }}\right\rangle$, ranging from 0 to $-255 \mathrm{~V}$ applied during the $\mathrm{Ar}+\mathrm{H}_{2}$ plasma exposure step. Peaks corresponding to lattice planes in cubic titanium nitride are indicated.

were incorporated in this film (Table 3). For deposition involving highly reactive materials such as $\mathrm{Ti}, \mathrm{Hf}, \mathrm{Nb}$, etc., the partial pressure of the vacuum species (e.g., background water, oxygen) can influence the amount of impurity incorporation (e.g., up to tens of an atomic percent of oxygen) in the deposited film. ${ }^{26,36,46,47}$ Assuming a partial pressure of $\sim 10^{-8}$ Torr for background impurities (for the base pressure of $\sim 10^{-6}$ Torr in the FlexAL system) corresponds to an impingement rate of about $\sim 0.5$ impurity atoms per $\mathrm{nm}^{2} / \mathrm{s}$ on the growing film surface. ${ }^{36,48}$ A plasma exposure time of $10 \mathrm{~s}$ can therefore, lead to the incorporation of $\sim 0.5$ impurity at. $/ \mathrm{nm}^{2}$ in the film (assuming a sticking coefficient of 1) which is of the same order as the GPC [O] value obtained for the $\mathrm{TiN}_{x}$ film grown without biasing. Another reason for the significant [O] content could be due to oxidation of the film upon exposure to the environment. The film was observed to have a tensile residual stress (Figure 11a) similar to that reported for $\mathrm{TiN}_{x}$ in previous work. ${ }^{49}$ The XRD pattern for this film (Figure 12) shows diffraction peaks that correspond to cubic $\mathrm{TiN}_{x}$. The fairly small peak intensities and broad peak widths indicate the presence of small crystal grains. This was confirmed by complementary information in the magnified planview HAADF STEM image of the film (see Figure S8a). It showed small lateral grain sizes of the order of $\sim 5 \mathrm{~nm}$ based on estimates of lattice fringe areas. A loosely packed microstructure consisting of crystalline grains with porous regions in between was also revealed. The small grain size together with intergranular voids observed in the TEM image could also contribute toward the high resistivity and low density of the $\mathrm{TiN}_{x}$ film deposited without biasing.

When substrate biasing was applied during the last half $(5 \mathrm{~s})$ of the $10 \mathrm{~s} \mathrm{Ar}+\mathrm{H}_{2}$ plasma exposure step, the trends in GPC, resistivity, mass density, and residual stress again consisted of two stages as observed earlier for the transition metal oxides. In the

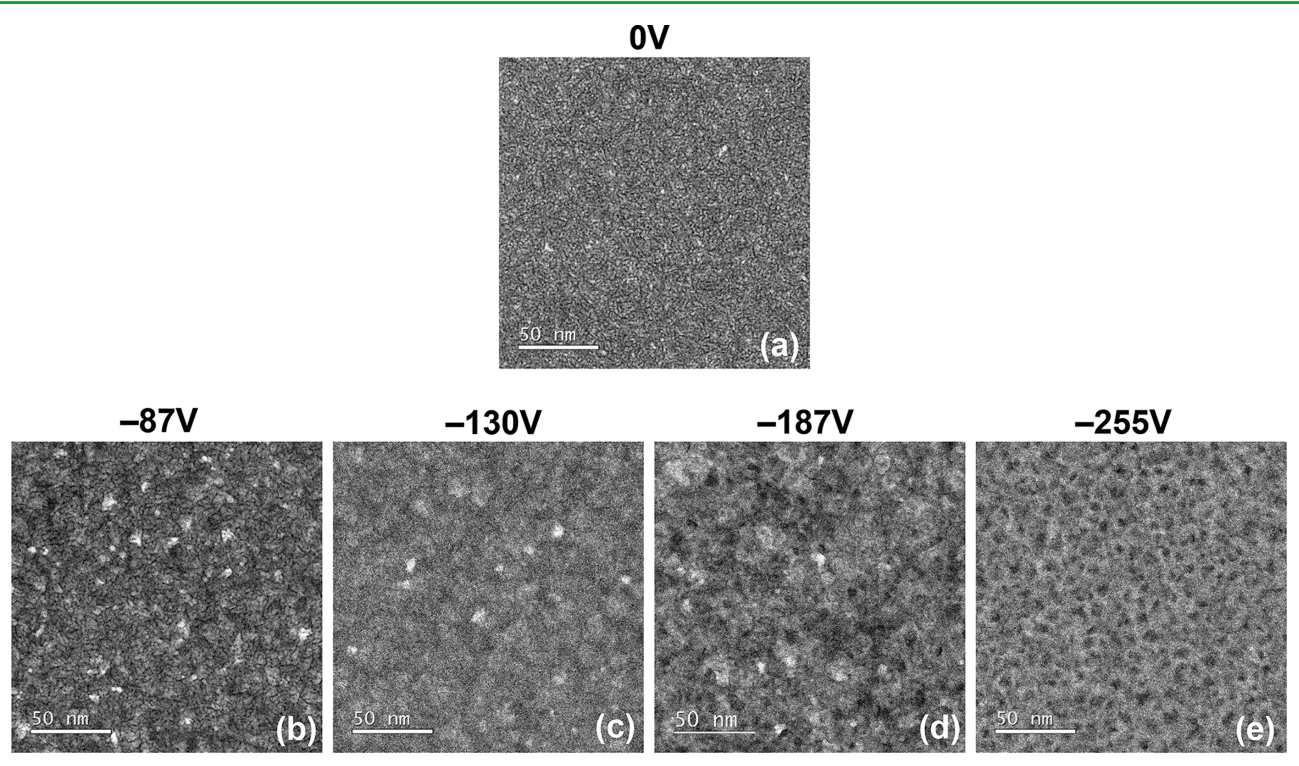

Figure 13. Plan-view high-angle annular dark-field (HAADF) STEM images for titanium nitride films deposited at $200{ }^{\circ} \mathrm{C}$ with (a) $0 \mathrm{~V}$, (b) -87 V, (c) $-130 \mathrm{~V},(\mathrm{~d})-187 \mathrm{~V}$, and $(\mathrm{e})-255 \mathrm{~V}$ average bias voltages, $\left\langle V_{\text {bias }}\right\rangle$, applied during the $\mathrm{Ar}+\mathrm{H}_{2}$ plasma exposure step. 
first stage, the GPC decreased with substrate biasing and reached a minimum value of $0.32 \pm 0.02 \AA$ at $\left\langle V_{\text {bias }}\right\rangle$ of $-187 \mathrm{~V}$ (Figure 11a). This decrease in GPC for $\mathrm{TiN}_{x}$ is unlike the trends in GPC observed for the transition metal oxide films discussed previously, but similar to that observed for $\mathrm{SiO}_{x}$. This again illustrates how the trends in growth properties as a function of $\left\langle V_{\text {bias }}\right\rangle$ can be material specific. The reduction in film GPC coincided with a 9-fold decrease in GPC [O] with biasing at $-130 \mathrm{~V}$ (Table 3). The large decrease in GPC [O] outweighed the comparatively smaller increase in GPC $[\mathrm{Ti}]$ and GPC $[\mathrm{N}]$ at $-130 \mathrm{~V}$ (Table 3). As a result, a large reduction in the film [O] content to $3 \pm 2$ at. \% and a simultaneous increase of the N/Ti ratio to $0.8 \pm 0.03$ (Table 3) was observed when $\left\langle V_{\text {bias }}\right\rangle$ was increased to $-130 \mathrm{~V}$. The $[\mathrm{H}]$ content also decreased significantly to $3 \pm 3$ at. \% while any carbon impurities that may have been incorporated using $-130 \mathrm{~V}$ still remained below the detection limit (Table 3 ). The significant decrease in [O] and $[\mathrm{H}]$ impurity contents and improvement in $\mathrm{TiN}_{x}$ stoichiometry was reflected in an order of magnitude lower resistivity and a higher mass density of $134 \pm 5 \mu \Omega \mathrm{cm}$ and $5.3 \pm 0.2 \mathrm{~g} / \mathrm{cm}^{3}$ (Figure $11 \mathrm{~b}$ and $\mathrm{c}$ ), respectively, at $-130 \mathrm{~V}$. Energetic ion bombardment during deposition of $\mathrm{TiN}_{x}^{50}$ and other nitrides ${ }^{11,51}$ has been reported to improve material purity by removing adsorbed oxygen/OH species from the growing film surface originating from background impurities in the vacuum environment. Therefore, the large reduction in $[\mathrm{O}]$ and $[\mathrm{H}]$ impurity content by energetic ion bombardment during $\mathrm{Ar}+\mathrm{H}_{2}$ plasma exposure with biasing can contribute toward lowering GPC, while improving film density and electronic conductivity. The residual stress behavior of the $\mathrm{TiN}_{x}$ films in the first stage changed from tensile to compressive on applying $\left\langle V_{\text {bias }}\right\rangle$ to the substrate (Figure 11d). The compressive stress reached a maximum as $\left\langle V_{\text {bias }}\right\rangle$ was increased to $-130 \mathrm{~V}$, analogous to the minimum in resistivity and maximum in mass density obtained at the same $\left\langle V_{\text {bias }}\right\rangle$. The stress evolution from tensile to compressive for deposition of $\mathrm{TiN}_{x}$ using energetic particle bombardment could be due to the interplay of several factors discussed in the literature. ${ }^{44,45,52}$ A part of the reason could be due to the change in film composition when increasing $\left\langle V_{\text {bias }}\right\rangle$ up to $-130 \mathrm{~V}$ leading to the formation of cleaner $\mathrm{TiN}_{x}$ films that have a higher bulk density compared to pure $\mathrm{TiO}_{2}$ or contaminated $\mathrm{TiN}_{x} \mathrm{O}_{y} \mathrm{H}_{z}$. Another factor that could play a role is inert argon gas incorporation, even below 1 at. \%, at interstitial positions which has been reported in the literature to induce significant compressive stress. ${ }^{44,52}$ This is in agreement with the small but measurable quantity of $0.20 \pm 0.05$ at. $\%$ for $[\mathrm{Ar}]$ in the highly compressive $\mathrm{TiN}_{x}$ film deposited using $-130 \mathrm{~V}$ (Table 3). Analysis of film crystalline properties revealed that applying $\left\langle V_{\text {bias }}\right\rangle$ initially led to more intense and narrower (111) and (220) peaks while suppressing the (200) peak, as observed in the XRD pattern for $-87 \mathrm{~V}$ (Figure 12). This suggests the presence of a more crystalline material with larger grains which was corroborated by the magnified HAADF STEM image of the film deposited using $-87 \mathrm{~V}$ (see Figure $\mathrm{S} 8 \mathrm{~b}$ ). It showed increased lateral grain dimensions of the order of $\sim 10 \mathrm{~nm}$ and a more closely packed film microstructure with a reduced void fraction. However, further increase in $\left\langle V_{\text {bias }}\right\rangle$ to $-130 \mathrm{~V}$ led to a gradual decrease in intensity and broadening of the (111) and (220) peaks in the XRD pattern while the (200) peak slowly reappeared (Figure 12). Although this seems to suggest a decrease in the crystalline order or grain size, the TEM image of the film deposited at $-130 \mathrm{~V}$ (Figure 13c) revealed a very compact $\mathrm{TiN}_{x}$ film with a void-free microstructure that retained grain dimensions of $\sim 10 \mathrm{~nm}$ (see also Figure S8c). The presence of a void-free microstructure with large crystal grains for $\mathrm{TiN}_{x}$ deposited using $-130 \mathrm{~V}$ could also be another factor behind the high electronic conductivity, mass density and compressive stress discussed earlier for this film. The discrepancy between XRD and the rest of the results could be due to the highly compressive stress measured in this film which can also play a role in diffraction peak broadening ${ }^{43-45}$ of XRD patterns besides a decrease in crystal grain size and/or volume fraction.

For $\left\langle V_{\text {bias }}\right\rangle$ greater than $-130 \mathrm{~V}$, the GPC continued to decrease until a voltage of $-187 \mathrm{~V}$ beyond which it entered its second stage and started to rise (Figure 11a). The GPCs for films deposited using $\left\langle V_{\text {bias }}\right\rangle$ of $-130 \mathrm{~V}$ and $-255 \mathrm{~V}$ were comparable to each other (Table 3). The values for GPC [Ti], GPC [N], and GPC [O] decreased when $\left\langle V_{\text {bias }}\right\rangle$ was increased from -130 to $-255 \mathrm{~V}$ (Table 3). Although the N/Ti ratio became unity when $\left\langle V_{\text {bias }}\right\rangle$ was increased to $-255 \mathrm{~V}$, which seemingly suggested growth of stoichiometric $\mathrm{TiN}_{x}$, the [C] and [Ar] contents became significantly large reaching values of $12 \pm 3$ at. \% and 0.77 \pm 0.05 at. $\%$, respectively, at that voltage (Table 3 ). The elevated $[\mathrm{C}]$ and $[\mathrm{Ar}]$ impurities could partly explain the rise in film GPC when $\left\langle V_{\text {bias }}\right\rangle$ was increased from $-187 \mathrm{~V}$ to $-255 \mathrm{~V}$. The $[\mathrm{H}]$ content did not change significantly when $\left\langle V_{\text {bias }}\right\rangle$ was increased beyond $-130 \mathrm{~V}$ (Table 3 ). The trends in resistivity and mass density also entered their second stage when using $\left\langle V_{\text {bias }}\right\rangle$ larger than $-130 \mathrm{~V}$ with the resistivity becoming larger and the mass density decreasing. Furthermore, increase in $\left\langle V_{\text {bias }}\right\rangle$ beyond $-130 \mathrm{~V}$ also initiated the next stage in residual stress behavior with a relaxation of the compressive stress (Figure 11d), similar to the trends in resistivity and mass density. For the (111) and (220) diffraction peaks in the XRD pattern, the intensities and widths became significantly smaller and wider, respectively, while the (200) peak became more prominent on increasing $\left\langle V_{\text {bias }}\right\rangle$ beyond $-130 \mathrm{~V}$ (Figure 12). These observations were in line with the onset of amorphization induced by highly energetic ion bombardment, ${ }^{14,37,38}$ similar to the cases of $\mathrm{TiO}_{x}$ and $\mathrm{HfO}_{x}$ discussed earlier, and could contribute in lowering the electronic conductivity and mass density of the $\mathrm{TiN}_{x}$ films. Furthermore, the relaxation of compressive stress on increasing $\left\langle V_{\text {bias }}\right\rangle$ beyond $-130 \mathrm{~V}$ also indicates that the yield strength of the material could have been exceeded under intense ion bombardment leading to plastic deformation. ${ }^{14,36,39,40}$ These aforementioned trends in material properties were concomitant with the reappearance of voids in the film microstructure for $\operatorname{TiN}_{x}$ deposited with $\left\langle V_{\text {bias }}\right\rangle$ greater than $-130 \mathrm{~V}$ (Figure $13 \mathrm{~d}$ and e). The void fraction increased with increasing $\left\langle V_{\text {bias }}\right\rangle$ which could also play a role in compressive stress relaxation together with decreasing conductivity and mass density. Other factors that could contribute toward relieving compressive stress include bubble formation from excess argon incorporation ${ }^{44,53}$ and change in composition to $\mathrm{TiN}_{x} \mathrm{C}_{y}$ owing to the significant carbon impurity content seen for the film deposited using $-255 \mathrm{~V}$. The RMS roughness of the $\mathrm{TiN}_{x}$ film surface seemed to remain fairly constant (around $\sim 1$ $\mathrm{nm})$ when using $\left\langle V_{\text {bias }}\right\rangle$ during the plasma exposure step.

Hafnium Nitride $\left(H f N_{x}\right)$. Figure 14 shows the GPC, resistivity, mass density, residual stress and surface roughness of $\mathrm{HfN}_{x}$ films deposited at $450^{\circ} \mathrm{C}$ as a function of $\left\langle V_{\text {bias }}\right\rangle$ applied during the $\mathrm{H}_{2}$ plasma exposure step. All films were deposited with $\left\langle V_{\text {bias }}\right\rangle$ applied for the entire duration of the $10 \mathrm{~s}$ plasma exposure step (solid symbols) apart for a film deposited at $\left\langle V_{\text {bias }}\right\rangle$ of $-210 \mathrm{~V}$ applied during the last half $(5 \mathrm{~s})$ of the $10 \mathrm{~s}$ plasma exposure step (hollow symbols). For the deposition without substrate biasing during plasma exposure, the film had a GPC of $0.35 \pm 0.03 \AA$ and 


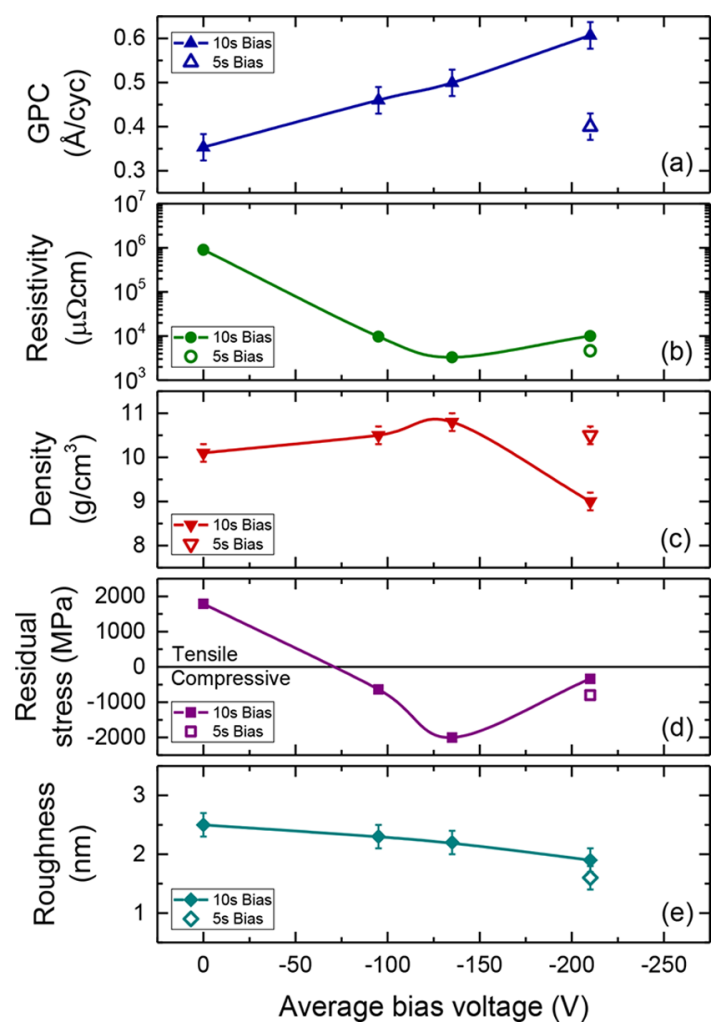

Figure 14. (a) Growth per cycle (GPC), (b) resistivity, (c) mass density, (d) residual stress, and (e) RMS surface roughness of hafnium nitride films deposited at $450{ }^{\circ} \mathrm{C}$ expressed as a function of the average bias voltage, $\left\langle V_{\text {bias }}\right\rangle$, applied for the entire duration and last half $(5 \mathrm{~s}$, only for $\left.\left\langle V_{\text {bias }}\right\rangle=-210 \mathrm{~V}\right)$ of the $10 \mathrm{~s} \mathrm{H}_{2}$ plasma exposure step.

a resistivity of $(90 \pm 7) \times 10^{4} \mu \Omega \mathrm{cm}$ (Figure $14 \mathrm{a}$ and $\mathrm{b}$ ) which are comparable to the values reported by Karwal et al. ${ }^{26}$ for $\mathrm{HfN}_{x}$ deposited using TDMACpH and $\mathrm{H}_{2}$ plasma at the same temperature. The low film conductivity was attributed to a high oxygen impurity content of 15 at. \% that got incorporated in the film mainly during deposition due to background water present in the $\sim 10^{-6}$ Torr vacuum environment of the ALD system, ${ }^{26}$ similar to what was speculated previously for $\mathrm{TiN}_{x}$. The $\mathrm{HfN}_{x}$ film deposited without biasing was also observed to have a mass density of $10.1 \pm 0.2 \mathrm{~g} / \mathrm{cm}^{3}$, tensile residual stress of $1786 \pm$ $50 \mathrm{MPa}$ and an RMS surface roughness of $2.5 \pm 0.2 \mathrm{~nm}$ (Figure $14 c$, d and e).

For the $10 \mathrm{~s}$ bias duration condition (bias duty cycle $=100 \%$, Figure $1 b)$, the GPC showed a monotonic increase with increasing $\left\langle V_{\text {bias }}\right\rangle$ (Figure 14a). This is in contrast to the initial dip followed by a gradual rise in GPC as a function of $\left\langle V_{\text {bias }}\right\rangle$ observed earlier for $\mathrm{TiN}_{x}$, but similar to the corresponding trends for $\mathrm{TiO}_{x}$ and $\mathrm{HfO}_{x}$. However, the film resistivity, mass density and residual stress showed a two stage behavior with increasing $\left\langle V_{\text {bias }}\right\rangle$, similar to the trends seen before for $\mathrm{TiN}_{x}$. The use of substrate biasing during the plasma exposure step was observed to trigger a drastic improvement in the electronic properties of $\mathrm{HfN}_{x}$ through a reduction in film resistivity by 2 orders of magnitude (Figure 14b). For the $10 \mathrm{~s}$ bias duration condition, increasing $\left\langle V_{\text {bias }}\right\rangle$ led to an initial decrease in film resistivity that reached a minimum value of $(33 \pm 7) \times 10^{2} \mu \Omega \mathrm{cm}$ at $-130 \mathrm{~V}$. The mass density initially increased slightly with biasing and reached a peak at the same voltage (Figure 14b). In the initial stage, the residual stress changed from tensile to compressive on applying $\left\langle V_{\text {bias }}\right\rangle$ during plasma exposure. The compressive stress reached a maximum of $-2004 \pm 50 \mathrm{MPa}$ on increasing $\left\langle V_{\text {bias }}\right\rangle$ to $-130 \mathrm{~V}$, similar to the minimization of resistivity and peaking of mass density at the same voltage. The RMS surface roughness of the films was observed to decrease slightly with biasing (Figure $14 \mathrm{e})$. For $\left\langle V_{\text {bias }}\right\rangle$ beyond $-130 \mathrm{~V}$ applied for $10 \mathrm{~s}$ of plasma exposure, an increase in film resistivity, reduction in mass density and relaxation of the compressive stress (Figure 14b-d) signaled a transition to the second stage of $\mathrm{HfN}_{x}$ property variation with substrate biasing. Given the similar trends in material properties for PEALD of TiN $x$ and $\mathrm{HfN}_{x}$ with substrate biasing, factors that could contribute toward the initial rise in film conductivity, mass density and compressive stress include a reduced oxygen content, improved stoichiometry (i.e., N/Hf ratio closer to 1), enhanced grain size or crystalline content, reduced void content and grain boundary density, all induced by energetic ion bombardment. Similarly, for $\left\langle V_{\text {bias }}\right\rangle$ beyond $-130 \mathrm{~V}$, the onset of ion bombardment induced amorphization, ${ }^{14,37,38}$ plastic deformation, ${ }^{14,36,39,40}$ void creation or carbon impurity incorporation could play roles in lowering film conductivity, mass density, and compressive stress.

Using $\left\langle V_{\text {bias }}\right\rangle$ of the same magnitude but different duration/ duty cycle during plasma exposure (bias duty cycle $=50 \%$, Figure 1c) created a difference in the way that the growth and material properties of $\mathrm{HfN}_{x}$ were altered, similar to the case observed earlier for $\mathrm{TiO}_{x}$. The growth rate of the $\mathrm{HfN}_{x}$ film deposited using $-210 \mathrm{~V}$ applied during the last half $(5 \mathrm{~s})$ of the $10 \mathrm{~s} \mathrm{H}_{2}$ plasma exposure step was significantly lower than the corresponding value obtained using the longer bias duration of $10 \mathrm{~s}$ (Figure 14a). A lower resistivity and higher mass density were obtained for the film deposited with the shorter $5 \mathrm{~s}$ bias duration compared to the corresponding values of the film grown with the longer $10 \mathrm{~s}$ bias duration for the same $\left\langle V_{\text {bias }}\right\rangle$ magnitude of $-210 \mathrm{~V}$ (Figure 14c). Similarly, the compressive stress at -210 $\mathrm{V}$ was higher when implementing the shorter bias duration of $5 \mathrm{~s}$ during $\mathrm{H}_{2}$ plasma exposure (Figure $14 \mathrm{~d}$ ). The surface was also smoother in case of the film grown using $5 \mathrm{~s}$ of bias (Figure 14e). These results again demonstrate how altering the bias duration/ duty cycle leads to a varying dose or fluence (i.e., particle flux integrated over time) of energetic ions impinging on the substrate, which can provide an alternative route for tuning material properties ${ }^{13,14,21}$ during PEALD. Further analysis on the effects of ion energy control with substrate biasing during PEALD of $\mathrm{HfN}_{x}$ will be reported in a subsequent publication.

Silicon Nitride $\left(\operatorname{SiN}_{x}\right)$. The growth and material properties of $\mathrm{SiN}_{x}$ films deposited on planar substrates at $500{ }^{\circ} \mathrm{C}$ was investigated for $\left\langle V_{\text {bias }}\right\rangle$ between 0 and $-103 \mathrm{~V}$ applied during the last half $(10 \mathrm{~s})$ of the $20 \mathrm{~s} \mathrm{~N}_{2}$ plasma exposure step. Figure 15 shows these properties in terms of the GPC, refractive index, mass density, residual stress and surface roughness expressed as a function of $\left\langle V_{\text {bias }}\right\rangle$ applied during plasma exposure. Table 4 outlines additional growth and material properties from RBS analysis for the films deposited with and without substrate biasing. The growth properties are given in terms of the number of silicon and nitrogen atoms deposited per $\mathrm{nm}^{2}$ per cycle (GPC $[\mathrm{Si}]$ and GPC $[\mathrm{N}]$, respectively) while the material properties are outlined in terms of the $\mathrm{N} / \mathrm{Si}$ ratio and impurity content $([\mathrm{O}]$, $[\mathrm{C}]$, and $[\mathrm{H}]$ at. \%).

In the absence of substrate biasing during plasma exposure, the film had a GPC, refractive index, and mass density of $0.14 \pm 0.02$ $\AA$, $1.96 \pm 0.03$, and $2.9 \pm 0.2 \mathrm{~g} / \mathrm{cm}^{3}$ (Figure $15 \mathrm{a}-\mathrm{c}$ ), respectively. These values are comparable to the results reported in our previous work ${ }^{28}$ for $\mathrm{SiN}_{x}$ deposited using DSBAS and $\mathrm{N}_{2}$ plasma at the same temperature. The residual stress of this film was 


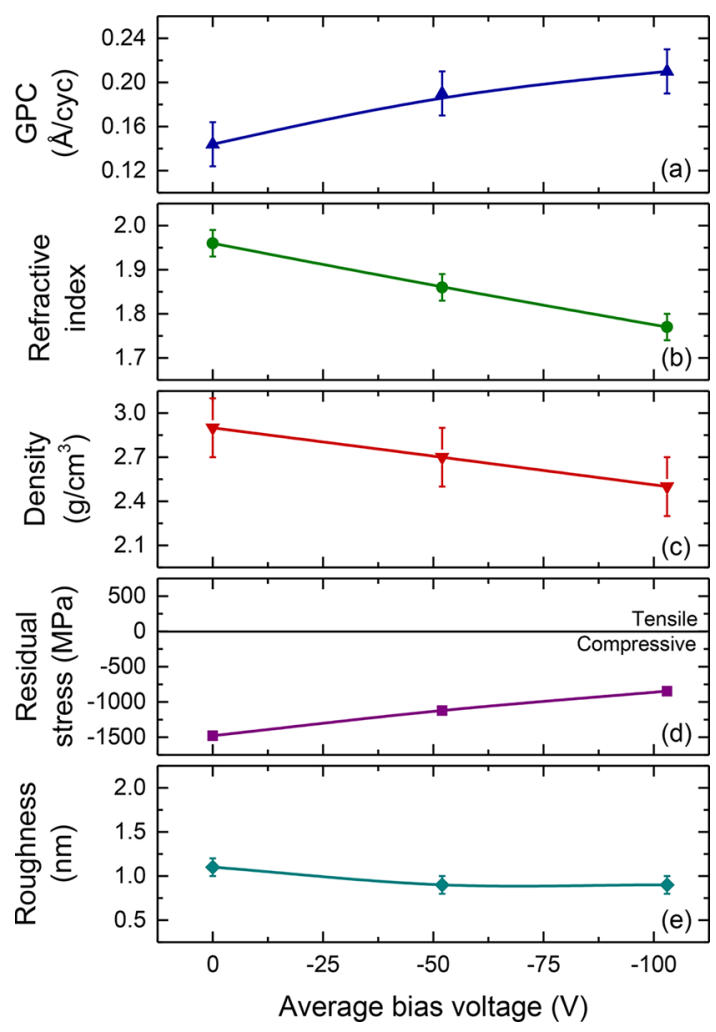

Figure 15. (a) Growth per cycle (GPC), (b) refractive index, (c) mass density, (d) residual stress, and (e) RMS roughness of silicon nitride films deposited at $500{ }^{\circ} \mathrm{C}$ expressed as a function of the average bias voltage, $\left\langle V_{\text {bias }}\right\rangle$, applied during the $\mathrm{N}_{2}$ plasma exposure step.

found to be compressive in nature (Figure 15d) similar to that reported previously for $\mathrm{SiN}_{x}$ deposited at a comparable temperature. ${ }^{54}$ The nature of the stress for $\mathrm{SiN}_{x}$ is unlike the tensile stresses observed earlier for the transition metal compounds deposited without biasing but similar to the compressive stress obtained for $\mathrm{SiO}_{x}$. An N/Si ratio of $1.4 \pm$ 0.1 was observed for this film (Table 4) indicating the formation of nearly stoichiometric $\mathrm{Si}_{3} \mathrm{~N}_{4}$ (N/Si ratio of 1.33) for deposition without any biasing. Low impurity contents in terms of [O], [C], and $[\mathrm{H}](2 \pm 2$ at. $\%,<8$ at. $\%$ and $4 \pm 3$ at. $\%$, respectively $)$ were measured for this film (Table 4) indicating the formation of high quality $\mathrm{SiN}_{x}$.

For deposition with substrate biasing, the GPC showed a monotonic increase with $\left\langle V_{\text {bias }}\right\rangle$ (Figure 15a). Although GPC [Si] remained fairly unchanged, the increase in GPC could be partly explained by an increase in GPC $[\mathrm{N}]$ that reached a value of $0.91 \pm 0.04 \mathrm{~N}$ at. $/ \mathrm{nm}^{2}$ at $-103 \mathrm{~V}$ (Table 4). This indicated the formation of a nitrogen rich film with increase in $\left\langle V_{\text {bias }}\right\rangle$, which was corroborated by a higher $\mathrm{N} / \mathrm{Si}$ ratio of 1.7 obtained for deposition using $-103 \mathrm{~V}$ (Table 4). The refractive index and mass density showed a monotonic decrease with $\left\langle V_{\text {bias }}\right\rangle$ (Figure $15 \mathrm{~b}$ and $\mathrm{c}$ ). The trends in refractive index and mass density were accompanied by a relaxation of the compressive stress as a function of $\left\langle V_{\text {bias }}\right\rangle$ (Figure 15d). The film surface became slightly smoother as the RMS roughness decreased with increasing $\left\langle V_{\text {bias }}\right\rangle$ (Figure 15e). The impurity contents increased with $\left\langle V_{\text {bias }}\right\rangle$ as observed by the elevated $[\mathrm{O}],[\mathrm{C}]$, and $[\mathrm{H}]$ values at $-103 \mathrm{~V}$ (Table 4). The simultaneous decrease in refractive index, mass density, and compressive stress together with an increase in the impurity content indicate that energetic ion bombardment through substrate biasing during PEALD of $\mathrm{SiN}_{x}$ degrades its material properties on planar substrates. These monotonic trends in refractive index, mass density and residual stress of $\mathrm{SiN}_{x}$ deposited using relatively small $\left\langle V_{\text {bias }}\right\rangle(\leq-100 \mathrm{~V})$ are unlike any of the trends observed previously for other materials investigated in this work. It suggests that even the slightest increase in ion energies during $\mathrm{N}_{2}$ plasma exposure could induce plastic deformation, ${ }^{14,36,39,40}$ excess nitrogen content, $\mathrm{N}_{2}$ gas bubble formation, ${ }^{14,55}$ and void incorporation, which could then be factors responsible for film quality degradation. This sort of material degradation was also observed in the other materials (except $\mathrm{SiO}_{x}$ ) but only when using comparatively higher $\left\langle V_{\text {bias }}\right\rangle$ $(\geq-130 \mathrm{~V})$, indicating the presence of higher ion energy thresholds for degradation in those materials.

Thickness Uniformity on $200 \mathrm{~mm}$ Substrates. The thickness uniformity of films on large-area planar substrates (200 $\mathrm{mm} \mathrm{c-Si} \mathrm{wafers)} \mathrm{was} \mathrm{investigated} \mathrm{for} \mathrm{all} \mathrm{six} \mathrm{oxides} \mathrm{and} \mathrm{nitrides}$ deposited with and without substrate biasing. Note that the results obtained were not from optimized precursor dose and plasma exposure times intended for attaining the best uniformities but serve to demonstrate the role of substrate biasing on thickness uniformity during PEALD on large-area substrates. The thickness nonuniformity was defined as the ratio of the standard deviation in thicknesses measured at several points across the wafer to the average thickness of all data points measured. The values obtained are expressed as percentages in Table 5. The results show that for most cases the thickness uniformity of films on $200 \mathrm{~mm}$ substrates improved when using substrate biasing during PEALD, except for $\mathrm{HfO}_{x}$ and $\mathrm{SiN}_{x}$, where the uniformity remained fairly unchanged. For $\mathrm{TiO}_{x}$ deposited with biasing, the change in thickness nonuniformity was also observed to depend on the duration or duty cycle of the bias applied during $\mathrm{O}_{2}$ plasma exposure. The use of a longer bias duration $(10 \mathrm{~s})$ increased nonuniformity to $2.8 \%$, whereas the same $\left\langle V_{\text {bias }}\right\rangle$ applied for a shorter bias duration $(5 \mathrm{~s})$ decreased nonuniformity to $2.0 \%$ relative to the nonuniformity of the film grown without biasing $(2.3 \%)$. The two transition metal nitride films deposited without biasing had the highest thickness nonuniformities on $200 \mathrm{~mm}$ planar substrates $\left(7.5 \%\right.$ for $\mathrm{TiN}_{x}$, 9.4\% for $\mathrm{HfN}_{x}$ ). The use of substrate biasing during PEALD of

Table 4. GPC (Film Thickness Per Cycle and Number of Atoms Deposited per $\mathbf{n m}^{2}$ per Cycle) and Elemental Composition of Silicon Nitride Films Deposited at $500{ }^{\circ} \mathrm{C}$ with and without Average Bias Voltages, $\left\langle V_{\text {bias }}\right\rangle$, Applied during the $\mathrm{N}_{2}$ Plasma Exposure Step $^{a}$

\begin{tabular}{|c|c|c|c|c|c|c|c|}
\hline \multirow{3}{*}{$\begin{array}{c}\left\langle V_{\text {bias }}\right\rangle \\
(\mathrm{V})\end{array}$} & \multirow{3}{*}{$\begin{array}{c}\text { GPC } \\
(\AA / \text { cycle })\end{array}$} & \multicolumn{5}{|c|}{ RBS } & \multirow{2}{*}{$\frac{\text { ERD }}{[\mathrm{H}]}$} \\
\hline & & $\mathrm{GPC}[\mathrm{Si}]$ & $\mathrm{GPC}[\mathrm{N}]$ & & {$[\mathrm{O}]$} & {$[\mathrm{C}]$} & \\
\hline & & (\# Si at. per $\mathrm{nm}^{2}$ per cycle) & (\# $\mathrm{N}$ at. per $\mathrm{nm}^{2}$ per cycle) & $\mathrm{N} / \mathrm{Si}$ & at. $\%$ & at. $\%$ & at. $\%$ \\
\hline 0 & $0.14 \pm 0.02$ & $0.55 \pm 0.02$ & $0.79 \pm 0.04$ & $1.4 \pm 0.1$ & $2 \pm 2$ & $<$ d..$^{b}{ }^{b}$ & $4 \pm 3$ \\
\hline-103 & 0.21 & 0.53 & 0.91 & 1.7 & 10 & $8 \pm 3$ & 6 \\
\hline
\end{tabular}

${ }^{a_{T}}$ Typical uncertainties are given in the first row unless otherwise stated. ${ }^{b}$ Values below detection limit (d.l.) of 8 at. $\%$ for [C]. 
Table 5. Thickness Uniformity of Films Deposited on $200 \mathrm{~mm}$ Planar c-Si Wafers without and with Average Bias Voltages, $\left\langle V_{\text {bias }}\right\rangle$, Applied during Plasma Exposure Steps

\begin{tabular}{lccc} 
& $\begin{array}{c}\text { No substrate bias } \\
(\%)\end{array}$ & $\begin{array}{c}\text { With substrate bias } \\
(\%)\end{array}$ & $\begin{array}{c}\left\langle V_{\text {bias }}\right\rangle \\
(\mathrm{V})\end{array}$ \\
\hline titanium oxide & 2.3 & $2.8^{a}, 2.0^{b}$ & -205 \\
hafnium oxide & 4.6 & 4.6 & -152 \\
silicon oxide & 1.1 & 0.7 & -200 \\
titanium nitride & 7.5 & 6.6 & -187 \\
hafnium nitride & 9.4 & $7.7^{a}, 6.7^{b}$ & -210 \\
silicon nitride & 3.5 & 3.6 & -103
\end{tabular}

${ }^{a}$ Substrate biasing applied for the entire duration of the plasma exposure step. ${ }^{b}$ Substrate biasing applied for the last half of the plasma exposure step.

these two nitrides led to the most significant improvements in thickness uniformity among all the materials. For $\mathrm{TiN}_{x}$ deposited using $-187 \mathrm{~V}$, the thickness nonuniformity decreased to $6.6 \%$, while for $\mathrm{HfN}_{x}$ deposited using $-210 \mathrm{~V}$ (applied for the entire duration of the $10 \mathrm{~s} \mathrm{H}_{2}$ plasma exposure step), the thickness nonuniformity decreased to $7.7 \%$. Interestingly, when $\mathrm{HfN}_{x}$ was deposited using the same $\left\langle V_{\text {bias }}\right\rangle$ but a lower bias duration of $5 \mathrm{~s}$, the thickness nonuniformity decreased to an even lower value of $6.7 \%$. These results demonstrate that both the ion energy and the dose of higher energy ions can play roles in altering film uniformity.

PEALD on 3D Substrates. Titanium Oxide $\left(T i O_{x}\right)$. The cross-sectional TEM image of a $\mathrm{TiO}_{x}$ layer on $3 \mathrm{D}$ trench nanostructures is shown in Figure 16. The film was deposited at

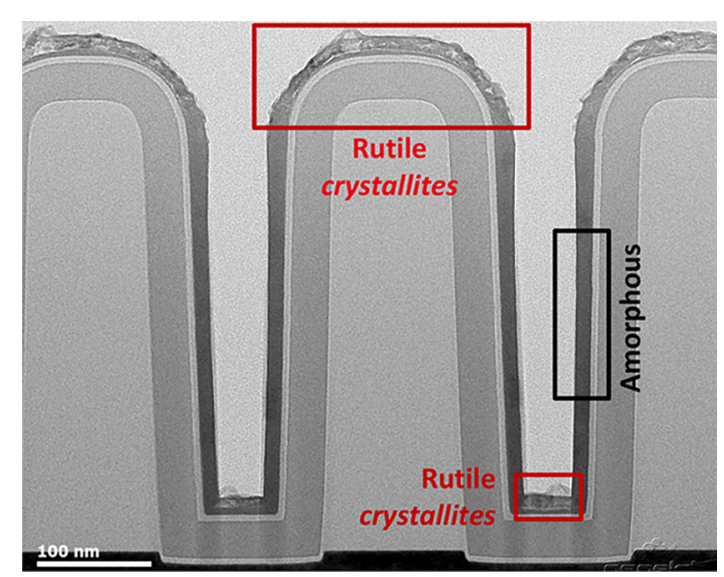

Figure 16. Cross-sectional TEM image of titanium oxide film on $3 \mathrm{D}$ trench nanostructures $(\mathrm{AR}=4.5: 1)$ deposited at $150^{\circ} \mathrm{C}$ with an average bias voltage $\left(\left\langle V_{\text {bias }}\right\rangle=-205 \mathrm{~V}\right)$ applied during the entire duration of the $10 \mathrm{~s} \mathrm{O}_{2}$ plasma exposure step. The presence of crystalline material (rutile) on planar surfaces and amorphous material on vertical sidewall surfaces are indicated.

$150{ }^{\circ} \mathrm{C}$ using $-205 \mathrm{~V}$ applied during the entire duration of the 10 $\mathrm{s} \mathrm{O}_{2}$ plasma exposure step. Film conformalities of $84 \%$ and $100 \%$ were measured at the bottom-side and bottom regions of the trench, respectively (see Figure S9). As discussed before, an increase in film GPC was observed during PEALD of $\mathrm{TiO}_{x}$ with substrate biasing on planar substrates. This can cause film GPCs at the planar top and bottom surfaces of the $3 \mathrm{D}$ trench nanostructure to exceed the GPC at the vertical bottom-side region and thereby yield a lower conformality at that region of the 3D substrate. Furthermore, the effect of enhanced ion energies is also visible in Figure 16 in terms of the different morphologies of the $\mathrm{TiO}_{x}$ film at planar and vertical surfaces of the 3D trench nanostructures. Previously, it was shown that for PEALD of $\mathrm{TiO}_{x}$ on a planar substrate at $150{ }^{\circ} \mathrm{C}$, an amorphous film was obtained when the deposition was performed without substrate biasing (Figure 6a1 and a2). However, using $-205 \mathrm{~V}$ during the $10 \mathrm{~s} \mathrm{O}_{2}$ plasma exposure step resulted in the formation of polycrystalline $\mathrm{TiO}_{x}$ (Figure $6 \mathrm{~b} 1$ and $\mathrm{b} 2$ ) in the rutile phase (see Figure S7) on a planar substrate. As a result, the $\mathrm{TiO}_{x}$ film regions formed at planar top and bottom surfaces of the $3 \mathrm{D}$ trench nanostructures in Figure 16 can be assumed to consist of polycrystalline grains formed in the rutile phase, while the $\mathrm{TiO}_{x}$ film deposited at the vertical sidewall surface regions can be considered to be amorphous. This can be explained by the directional or anisotropic nature of ions when they travel through a nearly collisionless plasma sheath ${ }^{56}$ before impinging on a substrate. Using substrate biasing makes the directional ions impinge on the planar surface regions of the 3D trench nanostructures with much more energy than on its vertical sidewalls, thereby inducing differing film properties at different regions of the $3 \mathrm{D}$ substrate.

Hafnium Oxide $\left(\mathrm{HfO}_{x}\right)$. The cross-sectional TEM image of a $\mathrm{HfO}_{x}$ layer on $3 \mathrm{D}$ trench nanostructures is shown in Figure 17. The film was deposited at $150{ }^{\circ} \mathrm{C}$ using $-204 \mathrm{~V}$ applied during the $\mathrm{O}_{2}$ plasma exposure step. Film conformality of $71 \%$ and $80 \%$ was measured at the bottom-side and bottom regions of the trench, respectively, (see Figure S10) which is comparable with the results reported by Sharma et al. ${ }^{25}$ for $\mathrm{HfO}_{x}$ deposited on such $3 \mathrm{D}$ trench nanostructures. Similar to the result for $\mathrm{TiO}_{x}$ discussed in the previous section, the role of energetic ion bombardment with substrate biasing during deposition is again observed in Figure 17 where the deposited $\mathrm{HfO}_{x}$ film has

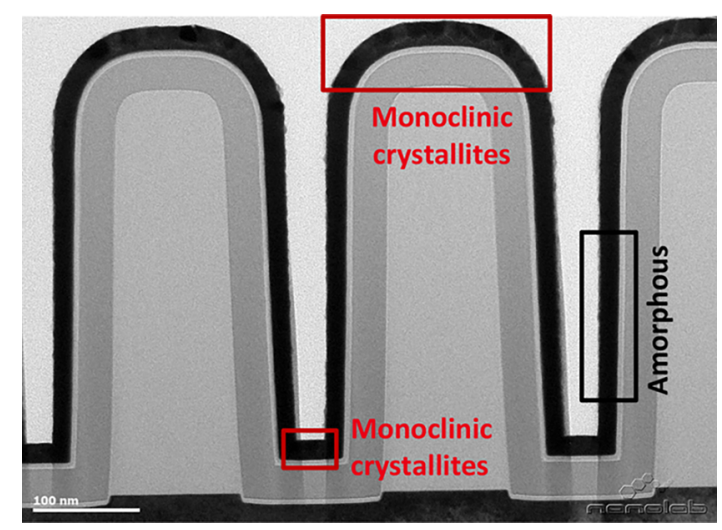

Figure 17. Cross-sectional TEM image of hafnium oxide film on 3D trench nanostructures $(\mathrm{AR}=4.5: 1)$ deposited at $150{ }^{\circ} \mathrm{C}$ with an average bias voltage $\left(\left\langle V_{\text {bias }}\right\rangle=-204 \mathrm{~V}\right)$ applied during the $\mathrm{O}_{2}$ plasma exposure step. The presence of crystalline material (monoclinic) on planar surfaces and amorphous material on vertical sidewall surfaces are indicated.

different morphologies on the planar and vertical surfaces of the $3 \mathrm{D}$ trench nanostructures. Earlier on, it was shown that PEALD of $\mathrm{HfO}_{x}$ on a planar substrate at $150{ }^{\circ} \mathrm{C}$ yielded an amorphous film when no $\left\langle V_{\text {bias }}\right\rangle$ was applied during plasma exposure (Figure $9 \mathrm{a} 1$ and $\mathrm{a} 2$ ). The use of $-205 \mathrm{~V}$ during the $\mathrm{O}_{2}$ plasma exposure step led to the growth of polycrystalline $\mathrm{HfO}_{x}$ (Figure $9 \mathrm{~b} 1$ and b2) with a monoclinic crystal lattice structure (Figure 8). Consequently, the $\mathrm{HfO}_{x}$ film region at the planar top and bottom surfaces of the 3D trench nanostructures in Figure 17 can be expected to consist of polycrystalline monoclinic grains while the 
$\mathrm{HfO}_{x}$ film grown at the vertical sidewall surface regions can be assumed to be amorphous. This can again be attributed to the role of directional ions traveling through a nearly collisionless plasma sheath that bombard planar surface regions of the $3 \mathrm{D}$ trench nanostructures with more energy than the vertical sidewalls when implementing substrate biasing. The results obtained for $\mathrm{HfO}_{x}$ effectively reproduce the phenomenon seen earlier for $\mathrm{TiO}_{x}$, where enhancing the energy of directional oxygen ions during film deposition induced simultaneous growth of different phases (crystalline and amorphous) of the same material at different surfaces (planar and vertical) of a $3 \mathrm{D}$ substrate.

Silicon Nitride $\left(\operatorname{SiN}_{x}\right)$. Cross-sectional TEM images of $\operatorname{SiN}_{x}$ layers on $3 \mathrm{D}$ trench nanostructures are shown in Figure 18. The images for as-deposited films grown at $500{ }^{\circ} \mathrm{C}$ without any substrate biasing and with $-103 \mathrm{~V}$ during $\mathrm{N}_{2}$ plasma exposure are shown in Figure 18A and B, respectively. Conformalities of 37\% and $56 \%$ were obtained at the bottom-side and bottom of the trench structures, respectively, for the film deposited without any $\left\langle V_{\text {bias }}\right\rangle$ (Figure 18A), similar to the values reported by in our previous work ${ }^{28}$ for $\mathrm{SiN}_{x}$ deposited on such $3 \mathrm{D}$ substrates. The bottom-side film conformality improved slightly to $39 \%$ while that at the bottom improved significantly to $78 \%$ for the film deposited using $-103 \mathrm{~V}$ during $\mathrm{N}_{2}$ plasma exposure (Figure $18 \mathrm{~B})$. Note that some significant corner tapering was observed for the $\mathrm{SiN}_{x}$ film deposited with $-103 \mathrm{~V}$. The quality of these $\mathrm{SiN}_{x}$ films was analyzed by measuring their etch resistance in dilute hydrofluoric acid solution ( $\left.\mathrm{HF}: \mathrm{H}_{2} \mathrm{O}=1: 100\right)$. The asdeposited films underwent a $30 \mathrm{~s}$ wet-etch treatment in dilute $\mathrm{HF}$ and cross-sectional TEM images of the films were measured after the etch treatment. Figure $18 \mathrm{~A}^{\prime}$ and $\mathrm{B}^{\prime}$ show the post wet-etch TEM images of the films deposited without any substrate biasing and with $-103 \mathrm{~V}$ applied during $\mathrm{N}_{2}$ plasma exposure, respectively. The wet-etch rate (WER) values were determined by comparing the as-deposited and post wet-etch film thicknesses at three different regions (top, bottom-side, bottom) of the 3D trench nanostructures which are outlined in Table 6. The $\mathrm{SiN}_{x}$ film deposited without biasing seemed to be highly etch resistant at the planar top and bottom regions of the trench as indicated by the small or insignificant WER values $(\leq 1 \pm 1 \mathrm{~nm}$ / min, Table 6) at those regions. These low WERs indicate the formation of high quality $\mathrm{SiN}_{x}$ films on planar top and bottom surfaces of the 3D trench nanostructures for deposition without any substrate biasing. This is also in agreement with the high mass density, refractive index (Figure 15b,c) and low impurity content (Table 4) of $\mathrm{SiN}_{x}$ deposited without biasing on a planar c-Si substrate, as discussed earlier. The WER observed at the bottom-side region of the trench $(3 \pm 1 \mathrm{~nm} / \mathrm{min}$, Table 6$)$ is relatively higher than those at the two planar trench regions, indicating a reduced HF-etch resistance of $\mathrm{SiN}_{x}$ at the vertical trench sidewalls. However, the value is small in absolute magnitude indicating an overall high HF-etch resistance at both planar and vertical trench surfaces for the film deposited without substrate biasing. For the $\mathrm{SiN}_{x}$ film deposited with -103 $\mathrm{V}$ during $\mathrm{N}_{2}$ plasma exposure, the film regions located at the planar top and bottom surfaces of the trench exhibited very high WERs and were completely removed after the etch treatment (Figure 18B'). These high WERs indicate the degradation of $\mathrm{SiN}_{x}$ films on planar top and bottom surfaces of the $3 \mathrm{D}$ trench nanostructures for deposition with substrate biasing. This is corroborated by the lower refractive index, mass density (Figure $15 \mathrm{~b}, \mathrm{c}$ ) and higher impurity content (Table 4) observed earlier for $\mathrm{SiN}_{x}$ deposited on planar substrates using $-103 \mathrm{~V}$ during $\mathrm{N}_{2}$

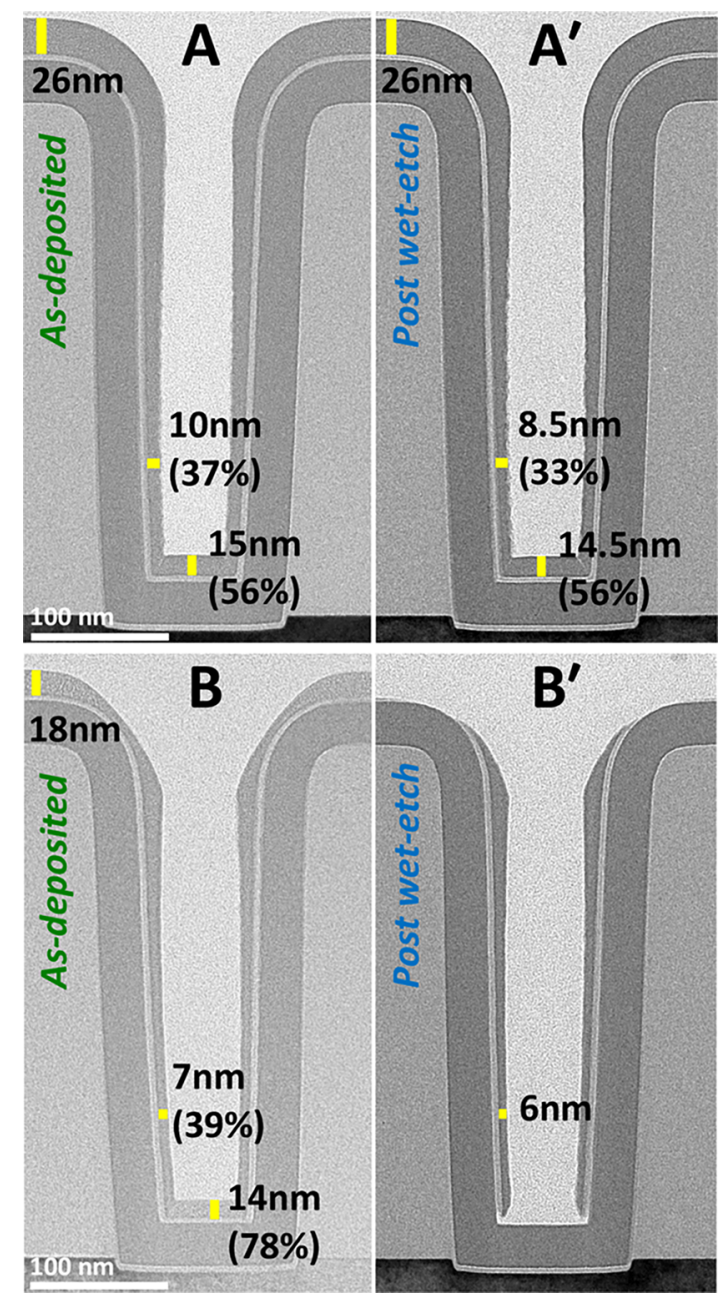

Figure 18. Cross-sectional TEM images of $(\mathrm{A}, \mathrm{B})$ as-deposited and $\left(\mathrm{A}^{\prime}\right.$, $B^{\prime}$ ) post wet-etch (in $30 \mathrm{~s}$ dilute $\mathrm{HF}$ ) silicon nitride films grown on $3 \mathrm{D}$ trench nanostructures $(\mathrm{AR}=4.5: 1)$ at $500{ }^{\circ} \mathrm{C}$. Images $(\mathrm{A})$ and $\left(\mathrm{A}^{\prime}\right)$ are for films deposited without substrate biasing $\left(\left\langle V_{\text {bias }}\right\rangle=0 \mathrm{~V}\right)$, while images (B) and $\left(\mathrm{B}^{\prime}\right)$ are for films deposited with substrate biasing $\left(\left\langle V_{\text {bias }}\right\rangle=-103 \mathrm{~V}\right)$. Film conformality at the bottom-side and bottom regions of the trench are indicated as a percentage of film thickness at the top of the trench.

Table 6. Wet-Etch Rates of Silicon Nitride on 3D Trench Nanostructures $(\mathrm{AR}=4.5: 1)$ for Films Deposited at $500{ }^{\circ} \mathrm{C}$ without $\left(\left\langle V_{\text {bias }}\right\rangle=0 \mathrm{~V}\right)$ and with Substrate Biasing $\left(\left\langle V_{\text {bias }}\right\rangle=\right.$ -103 V) Applied during $\mathrm{N}_{2}$ Plasma Exposure ${ }^{a}$

\begin{tabular}{cccc} 
& \multicolumn{3}{c}{ wet-etch rate $(\mathrm{nm} / \mathrm{min})$} \\
\cline { 2 - 4 }$\left\langle V_{\text {bias }}\right\rangle(\mathrm{V})$ & top & bottom-side & bottom \\
0 & $0 \pm 1$ & $3 \pm 1$ & $1 \pm 1$ \\
-103 & completely etched & $2 \pm 1$ & completely etched
\end{tabular}

${ }^{a_{T}}$ The wet-etch rates are reported for silicon nitride films located at planar (top, bottom) and vertical (bottom-side) regions of the 3D substrate topographies after $30 \mathrm{~s}$ dip in an etchant solution of dilute hydrofluoric acid ( $\left.\mathrm{HF}: \mathrm{H}_{2} \mathrm{O}=1: 100\right)$. Typical uncertainties are given in the first row.

plasma exposure. However, $\mathrm{SiN}_{x}$ film regions located at the vertical sidewalls of the trench nanostructures exhibited low WERs $(\sim 2 \pm 1 \mathrm{~nm} / \mathrm{min}$, Table 6$)$, similar to that for the film deposited without biasing, and remained selectively at the trench sidewalls after the wet-etch treatment (Figure 18B'). This can 
again be explained by the combined factors of high energy and directionality of ions traveling through a nearly collisionless plasma sheath when $\left\langle V_{\text {bias }}\right\rangle$ is applied to the substrate. These energetic ions collide with much more energy on the horizontal top and bottom surfaces of the 3D trenches than the vertical sidewalls. Consequently, the $\mathrm{SiN}_{x}$ films growing at the top and bottom trench regions are selectively degraded in comparison to those growing at the sidewalls. As a result, the film regions obtained at those sidewalls for deposition with substrate biasing retain the high quality and HF-etch resistance inherent for films formed at the same vertical surfaces for deposition without any $\left\langle V_{\text {bias }}\right\rangle$.

\section{DISCUSSION}

$\left\langle V_{\text {bias }}\right\rangle$ Regimes during PEALD for Tuning Properties. The results obtained in this work demonstrate how substrate biasing during PEALD can have prominent effects on the growth or material properties of oxide and nitride thin-films. In the case of the four transition metal compounds, the trends in material properties as a function of $\left\langle V_{\text {bias }}\right\rangle$ mostly showed a two stage behavior composed of an initial buildup (or decrease) followed by a gradual fall (or increase) with increasing $\left\langle V_{\text {bias }}\right\rangle$. These trends observed for the large range of $\left\langle V_{\text {bias }}\right\rangle$ investigated in this work enabled identification of regimes for material property improvement (i.e., higher refractive index, conductivity, and mass density) and degradation in PEALD processes. $\left\langle V_{\text {bias }}\right\rangle$ up to approximately $-150 \mathrm{~V}$ during $\mathrm{O}_{2}$ plasma exposure and $-130 \mathrm{~V}$ during $\mathrm{H}_{2}$ or $\mathrm{Ar}+\mathrm{H}_{2}$ plasma exposure improved material properties of the transition metal oxide and nitride films, respectively. Applying $\left\langle V_{\text {bias }}\right\rangle$ beyond these values showed material property degradation. For silicon oxide and silicon nitride, a one stage behavior was observed where material properties improved slightly for the former and instantly degraded for the latter as a function of substrate biasing. Besides varying $\left\langle V_{\text {bias }}\right\rangle$ magnitude, reducing the duration of substrate biasing during plasma exposure extended the $\left\langle V_{\text {bias }}\right\rangle$ regime for improving $\mathrm{TiO}_{x}$ material properties to about $-200 \mathrm{~V}$. These results indicate that regimes exist not only for the ion energy but also for the dose of higher energy ions. Consequently, both the magnitude of $\left\langle V_{\text {bias }}\right\rangle$ and the duration/duty cycle of the applied bias can be used as tunable parameters for influencing ion-surface interactions by modifying the ion energy and dose/fluence of higher energy ions, respectively. It is interesting to note that even though an $\mathrm{H}_{2}$ plasma generates lighter ions (e.g., $\mathrm{H}^{3+}, \mathrm{H}^{2+}$ ) than an $\mathrm{Ar}+\mathrm{H}_{2}$ plasma (e.g., $\mathrm{ArH}^{+}, \mathrm{Ar}^{+}$), similar trends in material properties were observed for the two transition metal nitrides when grown using these two plasmas with substrate biasing. This will be investigated in future work on the basis of growing a transition metal nitride using these plasmas with substrate biasing and measuring the corresponding ion characteristics (e.g., energy, flux, etc.) and material properties. Furthermore, the trends in material property variation reported for substrate biasing during conventional flux-controlled deposition processes (PECVD or PVD) are similar to those observed in the surfacecontrolled PEALD processes of this work for all films ${ }^{44,57-60}$ except $\mathrm{SiN}_{x}$. Enhancing ion energies during PEALD of $\mathrm{SiN}_{x}$ with relatively small $\left\langle V_{\text {bias }}\right\rangle(<-100 \mathrm{~V})$ lowered mass density, refractive index, and compressive stress while simultaneously increasing WER which are opposite to the trends reported for $\mathrm{SiN}_{x}$ PECVD or PVD processes with substrate biasing. ${ }^{61,62}$ Even for substrate biasing during PEALD, the mass density of $\mathrm{TiO}_{x}$ as a function of $\left\langle V_{\text {bias }}\right\rangle$ increased for films in this work but decreased for films deposited in previous work reported by Profijt et al., who used different Ti precursors. ${ }^{19,20}$ The unique trends in property variation with substrate biasing signify how the effects of controlling ion-surface interactions can be highly material and/or process specific. It therefore, necessitates further empirical investigation of other materials and process conditions for PEALD with substrate biasing.

As mentioned in the Introduction, several inherent characteristics of the material deposited using varying ion energies or doses of higher energy ions can also influence the final film properties. It is beyond the scope of this work to provide a detailed account correlating all the characteristics with the observed results, so a brief discussion is made based on two factors. For instance, the bond energies are higher for oxides relative to nitrides for the six materials investigated in this work (see Table S1). This could play a role in the transition metal oxides showing a higher $\left\langle V_{\text {bias }}\right\rangle$ threshold than the corresponding nitrides before the onset of material degradation (i.e., reduction of mass density, increase in film void content and amorphization). Indeed, $\mathrm{Si}-\mathrm{O}$ has the highest and $\mathrm{Si}-\mathrm{N}$ the lowest bond energy among the six materials which could also be a factor behind $\mathrm{SiO}_{x}$ material properties remaining fairly unchanged even at large $\left\langle V_{\text {bias }}\right\rangle(>-200 \mathrm{~V})$, while $\mathrm{SiN}_{x}$ films degraded at low $\left\langle V_{\text {bias }}\right\rangle$. Furthermore, the four transition metal compounds investigated in this work have been reported to form in a crystalline phase for PEALD processes between 100 and $250{ }^{\circ} \mathrm{C}$ (see Table S2). PEALD processes for $\mathrm{SiO}_{x}$ and $\mathrm{SiN}_{x}$ reported in the literature so far have yielded only amorphous films since these materials require much higher temperatures for crystallization ( $>900{ }^{\circ} \mathrm{C}$, see Table S2) either during deposition or postdeposition annealing treatment. The high crystallization temperature could be a reason why the silicon compounds showed a one stage behavior compared to the two stage behavior of the transition metal compounds whose crystalline properties (phase, volume fraction) varied with enhanced ion energies.

Prospects for Substrate Biasing during PEALD. On the basis of the results obtained in this work, the implementation of substrate biasing during PEALD can provide several opportunities for enhancing the capabilities of atomic scale processing. Controlling the energy and/or dose of ions during the plasma exposure step can enable the tuning of a wide range of material properties for the same precursor/plasma reactants and deposition temperature. Furthermore, the crystalline phase of certain materials such as the transition metal compounds can be obtained using low temperatures at which PEALD without substrate biasing typically yields amorphous films. This also eliminates the requirement of specific substrate surfaces to deposit a high temperature crystalline phase material at a low temperature, for example, the need for $\mathrm{RuO}_{2}$ surface to deposit rutile phase $\mathrm{TiO}_{2}$ at $250{ }^{\circ} \mathrm{C} .{ }^{63}$ This phase is known to have a high dielectric constant which is a desired property for semiconductor device applications. ${ }^{63}$ Furthermore, mixed phase anatase + rutile $\mathrm{TiO}_{2}$ is reported to have a higher photocatalytic activity ${ }^{64}$ than the individual phases while films with small grains and/or a porous microstructure (i.e., high surface to volume ratio) have a higher sensitivity for gas sensing. ${ }^{65}$ During PEALD of $\mathrm{TiN}_{x}$ in this work, the Ti-N bonds in the deposited film originated from $\mathrm{Ti}-\mathrm{N}$ bonds present in the TDMAT precursor. Substrate biasing during the subsequent reducing $\mathrm{Ar}+\mathrm{H}_{2}$ plasma step altered material composition by lowering [O] content that could have originated from background impurities in the vacuum environment. The chemical composition could also be modified at high $\left\langle V_{\text {bias }}\right\rangle$ by an increase in [C] content. While a low [O] and [C] content yielded more conductive $\mathrm{TiN}_{x}$, an increase in [C] 
content could have an influence on the material work function. ${ }^{66}$ The decrease in [O] content enabled by substrate biasing during a reducing plasma could in principle, be applicable for varying the composition of metal oxide films deposited with precursors containing metal-O bonds. Recently, it was shown that substoichiometric $\mathrm{TaO}_{x}$ films could be obtained with PEALD using $\mathrm{Ta}\left(\mathrm{OC}_{2} \mathrm{H}_{5}\right)_{5}$ as the precursor (that already contained $\mathrm{Ta}-$ O bonds), followed by a reducing $\mathrm{Ar}+\mathrm{H}_{2}$ plasma. ${ }^{67}$ This process scheme led to the incorporation of oxygen vacancies in the deposited metal oxide. In this regard, it can be speculated that enhancing ion energies during the reductive plasma step could potentially confer in situ control over the amount of generated oxygen vacancies. As a result, PEALD with substrate biasing could be a method for growing substoichiometric metal oxide layers with a tunable composition, relevant for emerging applications such as resistive nonvolatile memory devices (e.g., RRAMs) ${ }^{68}$

Substrate biasing during PEALD has thus far been implemented in the second step of a two-step PEALD process, that is, during the $B$ step of an $(A B)_{n}$ process where $n$ is the number of cycles. It could also be implemented in multistep PEALD processes, such as during the third $C$ step of an $(A B C)_{n}$ cycle or an $\left[(A B)_{x} C\right]_{n}$ supercycle, where $x$ is the number of $A B$ cycles completed before the $C$ step is performed and $n$ is the number of supercycles (see Figures S1 and S2) ${ }^{18}$ Furthermore, substrate biasing during PEALD has so far been carried out using reactive plasmas where enhancing ion energies result in combined physicochemical process during film growth. Using an inert plasma (e.g., Ar) in the $C$ step of the aforementioned multistep cycles and applying a bias only at that step could in principle, lead to purely physical effects during energetic ion bombardment. Such purely physical processes could induce differences in the trends of material property variation as a function of substrate biasing. Other variants of multistep PEALD supercycles are used to deposit layered film stacks (or nanolaminates ${ }^{69}$ ) that rely on the differences in properties of the individual layers. These differences are generally procured by growing at least two different materials alternately for the stacked layers. Since enhanced ion energies during PEALD can tailor the properties of a given material, stacked layers with different properties using the same material could in principle, be created by growing one layer without (Figure 1a) and the next layer with substrate biasing (Figure $1 \mathrm{~b}$ or $\mathrm{c}$ ). This technique could also be employed for growing films on sensitive substrates that cannot withstand the effects of enhanced ion energies. Deposition with biasing can be carried out only after initially performing some PEALD (or even thermal ALD) cycles without any biasing on such substrates. This could in principle, lead to energetic ionsurface interactions on the initial layer of the deposited film and not on the substrate (provided the initially grown layer is of a sufficient thickness). For stacked layers comprised of different materials, substrate biasing during PEALD can enable better control over the properties of those layers, for example, by reducing tensile stress of $\mathrm{HfO}_{2}$ layers in $\mathrm{HfO}_{2} / \mathrm{Al}_{2} \mathrm{O}_{3}$ bilayers to prevent delamination. ${ }^{30}$ Film growth with steadily increasing/ decreasing bias voltages with each subsequent cycle could also enable tailoring of interface properties, for example, formation of a gradually changing instead of an abrupt interface.

Furthermore, substrate biasing during plasma exposure can also be implemented as pre- or postdeposition treatment steps which, based on the reactants used and the treatment duration, can modify surface or subsurface regions (i.e., a few monolayers below the surface). This can enable in situ surface functionaliza- tion that can either promote or inhibit film growth. For the case of substrate biasing applied in an interleaved manner in the plasma step (i.e., during a part of the plasma exposure time), another aspect that could potentially influence material properties is variation of the moment at which the bias is applied. For instance, a $50 \%$ bias duty cycle can be implemented in a $10 \mathrm{~s}$ plasma step by applying it for $5 \mathrm{~s}$ during either the first, middle or last half of the plasma exposure time. Simultaneous ignition of the plasma and the bias could lead to the cracking of bulky ligand species (e.g., amino, cyclopentadienyl, isopropoxide, etc.) remaining on the surface after precursor adsorption by the impact of high energy ions. This could lead to the incorporation of decomposed ligand species in the growing film and elevate film impurity content. Therefore, a means to prevent this could be to apply the bias near the end of the plasma exposure step as used in this work which should, in principle, lead to a cleaner or more ligand-free surface before the impingement of energetic ions.

Substrate biasing during PEALD of the two transition metal oxides on 3D trench nanostructures led to the simultaneous formation of different material phases at different surface orientations during growth of the same material in the same deposition run. This indicates how controlling the energy of directional ionic species in a collisionless plasma sheath allows for selective processing during PEALD on 3D substrates. A similar effect was also observed in case of $\mathrm{SiN}_{x}$ where enhanced ion energies during film growth induced selective degradation of material properties for the same material at different surface regions of a $3 \mathrm{D}$ substrate. Different categories of selectivity during film growth have been previously defined in terms of area-, phase-, microstructure-, or chemical composition-selective deposition. ${ }^{70}$ Recently, a new approach for carrying out selective deposition on 3D substrates was reported by Kim et al. ${ }^{3}$ Selective surface treatment of planar regions in 3D trench nanostructures was performed using directional ions that enabled selective anisotropic deposition of Pt only on the vertical sidewalls of the trenches. This approach for growing films in an area-selective manner on 3D substrates having different geometries or topographical orientation was termed as topographically selective deposition. In this regard, the results obtained in this work demonstrate how ion energy control with substrate biasing during PEALD offers an alternative pathway for topographically selective deposition. Based on the aforementioned selective growth categories, substrate biasing during PEALD on 3D substrates can be considered to induce microstructure (or chemical composition) selective growth of $\mathrm{SiN}_{x}$ and phase selective growth of $\mathrm{TiO}_{x}$ and $\mathrm{HfO}_{x}$ at different surface regions of the $3 \mathrm{D}$ substrates. Implementing such variants of selective growth on 3D substrates therefore, enables different routes for conducting topographically selective deposition. The selectivity attribute imparted by the directional impingement of high energy ions could in principle, be tuned (attenuated) by controlling (lowering) the directionality and/or energy of the ions. When substrate biasing is implemented in a collisional plasma sheath that can be obtained at high pressure conditions (e.g., $>100$ mTorr), both the directionality and the energy of the ions are affected. At these conditions, the ion mean free path becomes smaller than the thickness of the plasma sheath causing the ions to experience collisions with gas-phase species while crossing the sheath. These collisions alter the vertical trajectory of the ions while transferring both charge and energy to neutral gas-phase species such as the reactive plasma radicals. As a result, the energy of ions impinging on planar substrate surfaces can become considerably lower than the voltage drop across the plasma 
sheath. The gas-phase collisions could also lead to the impingement of both ions and radicals on the vertical surfaces of a 3D structure. Depending on the pressure and magnitude of substrate bias applied during plasma exposure, the energy of the ions and radicals colliding with sidewalls could in principle, be higher than the energy of the same species interacting with the sidewalls in a nearly collisionless plasma sheath. This could have direct implications on the conformality and material properties of films deposited on 3D substrates. Therefore, substrate biasing during PEALD on 3D substrates with highly collisional plasma exposures offer new avenues for investigation.

\section{CONCLUSIONS}

The effects of modifying ion-surface interactions during PEALD on the growth and material properties of oxide $\left(\mathrm{TiO}_{x}, \mathrm{HfO}_{x}\right.$, $\mathrm{SiO}_{x}$ ) and nitride $\left(\mathrm{TiN}_{x}, \mathrm{HfN}_{x}, \mathrm{SiN}_{x}\right)$ thin-films have been investigated using a commercial $200 \mathrm{~mm}$ remote plasma ALD system equipped with RF substrate biasing. The magnitude of $\left\langle V_{\text {bias }}\right\rangle$ and the duration/duty cycle of the applied bias during plasma exposure were demonstrated as parameters for influencing ion-surface interactions by modifying the ion energy and dose/fluence of higher energy ions, respectively. Controlling these parameters had significant material and/or process specific effects that enabled tailoring of a wide range of properties during film growth. These include, but are not limited to, the mass density, optical refractive index, electrical resistivity, residual stress, crystalline properties (e.g., volume fraction, phase, grain size, etc.), void fraction, surface roughness, thickness uniformity (on large area planar substrates), and chemical composition, which are summarized in Figure 19.

As long as ion energies remained below the regimes for ioninduced degradation, enhancing ion energies by increasing $\left\langle V_{\text {bias }}\right\rangle$ led to an improvement in the mass density for all materials except $\mathrm{SiN}_{x}$, which degraded with substrate biasing. A higher mass density was generally accompanied by an increase in the optical refractive index of dielectric films. Growth of a denser material with biasing also indicated the presence of a compact film with a void-free microstructure while the growth of underdense material generally led to an increase in the film void content. Enhancing ion energies with substrate biasing significantly reduced the electrical resistivity of the two transition metal nitrides. This was also accompanied by a significant reduction of the oxygen impurity content in $\mathrm{TiN}_{x}$ while implementing a high $\left\langle V_{\text {bias }}\right\rangle$ elevated the film carbon content. These serve to demonstrate how substrate biasing can be used for tuning the chemical composition of materials. The residual stress could be tailored from tensile under no bias conditions to compressive with substrate biasing for the transition metal compounds whereas that for the silicon compounds remained compressive as a function of $\left\langle V_{\text {bias }}\right\rangle$.

Substrate biasing during PEALD on 3D trench nanostructures effectively depicted the role of directional ion bombardment by inducing distinct film properties at different surface orientations (planar and vertical) of the $3 \mathrm{D}$ substrate. For $\mathrm{TiO}_{x}$ and $\mathrm{HfO}_{x}$ at low temperature, biasing led to phase selective growth of crystalline material on planar surfaces and amorphous material on vertical sidewalls of the trenches. For $\mathrm{SiN}_{x}$, biasing led to microstructure selective degradation of film regions growing at planar surfaces of the trenches but not those growing at vertical sidewalls. These results demonstrate how substrate biasing during PEALD can enable topographically selective growth control on $3 \mathrm{D}$ substrates. The insights obtained in this work reveal numerous opportunities afforded by this technique for
Materials and process control with substrate biasing

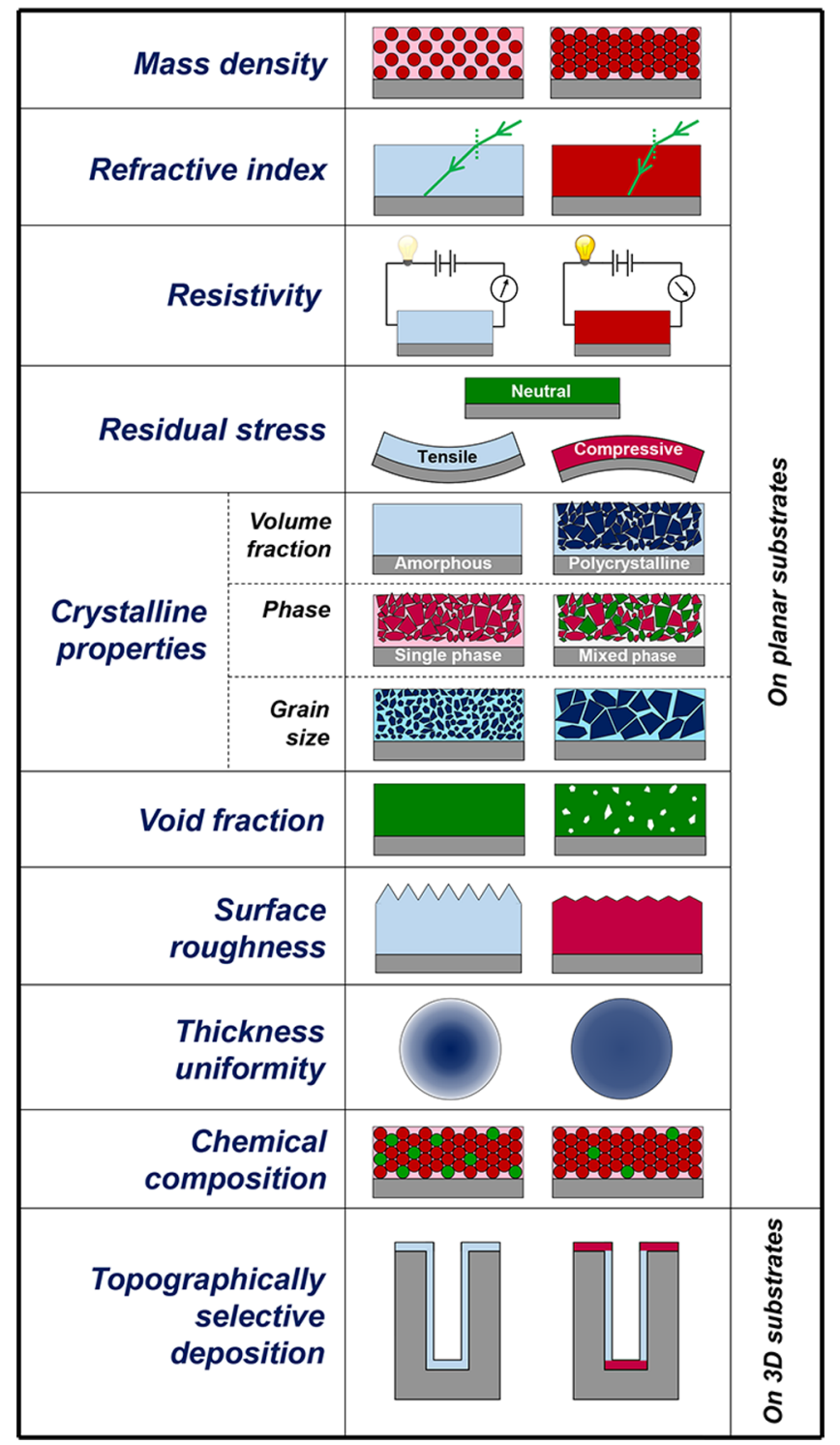

Figure 19. Schematic illustration representative of the material properties and process control enabled by substrate biasing during PEALD on planar and 3D substrate topographies.

advancing the practical applications of atomic scale processing. The effects on other material systems, material properties and processing conditions will be reported in future investigations.

\section{ASSOCIATED CONTENT}

Supporting Information

The Supporting Information is available free of charge on the ACS Publications website at DOI: 10.1021/acsami.8b00183.

Overview of applications served by the oxides and nitrides of Ti, Hf, and $\mathrm{Si}$, a detailed outline of the PEALD process conditions used for depositing materials, two figures outlining step sequences for multistep PEALD processes incorporating substrate biasing, a figure depicting thickness measurement regions in $3 \mathrm{D}$ trench nanostructures, a figure showing magnified plan-view HAADF STEM images for $\mathrm{TiO}_{x}$ films deposited on planar substrates with and without substrate biasing, a figure comparing RMS surface roughness measurements obtained using 
AFM and XRR for $\mathrm{TiO}_{x}$ films deposited with and without substrate biasing, a figure showing 2D plan-view AFM scans of $\mathrm{TiO}_{x}$ films deposited with and without substrate biasing, grazing incidence X-ray diffractograms of $\mathrm{TiO}_{x}$ films deposited at $150^{\circ} \mathrm{C}$, a figure showing magnified planview HAADF STEM images of $\mathrm{TiN}_{x}$ films deposited with and without substrate biasing, a figure showing magnified cross-sectional TEM images of $\mathrm{TiO}_{x}$ film deposited on 3D trench nanostructures with substrate biasing, a figure showing magnified cross-sectional TEM images of $\mathrm{HfO}_{x}$ film deposited on $3 \mathrm{D}$ trench nanostructures with substrate biasing, two tables outlining bond energies and crystallization temperatures of the materials investigated (PDF)

\section{AUTHOR INFORMATION}

\section{Corresponding Authors}

*E-mail: t.faraz@tue.nl.

*E-mail: w.m.m.kessels@tue.nl.

\section{ORCID}

Tahsin Faraz: 0000-0001-8497-861X

Saurabh Karwal: 0000-0001-7959-1138

Wilhelmus M. M. Kessels: 0000-0002-7630-8226

\section{Author Contributions}

The manuscript was written through contributions of all authors. All authors have given approval to the final version of the manuscript.

\section{Funding}

The research of one of the authors (W.M.M.K.) has been made possible by the Dutch Technology Foundation STW and The Netherlands Organization for scientific Research (NWO, VICI programma, 10817). Part of the work was carried out within the framework of the COST Action MP1402-Hooking together European research in Atomic Layer Deposition (HERALD). V.B. and A.Sz. acknowledge funding within the DFG SZ253/2-1 project.

\section{Notes}

The authors declare no competing financial interest.

\section{ACKNOWLEDGMENTS}

The authors would like to acknowledge Jeroen van Gerwen for his invaluable technical assistance during this work and Alfredo Mameli for fruitful discussions. Aileen O'Mahony from Oxford Instruments is acknowledged for carrying out the thickness uniformity measurements. This work was supported by Lam Research Corp. Solliance and the Dutch province of Noord Brabant are acknowledged for the Eindhoven STEM facility.

\section{REFERENCES}

(1) Nanosciences and Nanotechnology: Evolution or Revolution?; Lourtioz, J.-M., Lahmani, M., Dupas-Haeberlin, C., Hesto, P., Eds.; Springer, 2016.

(2) Ferain, I.; Colinge, C. A.; Colinge, J.-P. Multigate Transistors as the Future of Classical Metal-oxide-semiconductor Field-Effect Transistors. Nature 2011, 479 (7373), 310-316.

(3) Kim, W.-H.; Minaye Hashemi, F. S.; Mackus, A. J. M.; Singh, J.; Kim, Y.; Bobb-Semple, D.; Fan, Y.; Kaufman-Osborn, T.; Godet, L.; Bent, S. F. A Process for Topographically Selective Deposition on 3D Nanostructures by Ion Implantation. ACS Nano 2016, 10 (4), 44514458 .

(4) George, S. M. Atomic Layer Deposition: An Overview. Chem. Rev. 2010, 110, 111.
(5) Potts, S. E.; Kessels, W. M. M. Energy-Enhanced Atomic Layer Deposition for More Process and Precursor Versatility. Coord. Chem. Rev. 2013, 257 (23-24), 3254-3270.

(6) Profijt, H. B.; Potts, S. E.; van de Sanden, M. C. M.; Kessels, W. M. M. Plasma-Assisted Atomic Layer Deposition: Basics, Opportunities, and Challenges. J. Vac. Sci. Technol., A 2011, 29 (5), 050801.

(7) Manova, D.; Gerlach, J. W.; Mändl, S. Thin Film Deposition Using Energetic Ions. Materials 2010, 3 (8), 4109-4141.

(8) Takagi, T. Ion-surface Interactions during Thin Film Deposition. J. Vac. Sci. Technol., A 1984, 2 (2), 382-388.

(9) Mattox, D. M. Particle Bombardment Effects on Thin-Film Deposition: A Review. J. Vac. Sci. Technol., A 1989, 7 (3), 1105-1114.

(10) Walton, S. G.; Greene, J. E. Plasmas in Deposition Processes. In Handbook of Deposition Technologies for Films and Coatings; Martin, P. M., Ed.; Elsevier, 2010; pp 32-92.

(11) Cuomo, J. J.; Rossnagel, S. M. Property Modification and Synthesis by Low Energy Particle Bombardment Concurrent with Film Growth. Nucl. Instrum. Methods Phys. Res., Sect. B 1987, 19-20, 963974.

(12) Rossnagel, S. M.; Cuomo, J. J. Film Modification by Low Energy Ion Bombardment during Deposition. Thin Solid Films 1989, 171 (1), $143-156$

(13) Wang, S. X.; Wang, L. M.; Ewing, R. C. Irradiation-Induced Amorphization: Effects of Temperature, Ion Mass, Cascade Size, and Dose Rate. Phys. Rev. B: Condens. Matter Mater. Phys. 2000, 63 (2), 24105.

(14) Kucheyev, S. O. Ion-Beam Processing. In Materials Processing Handbook; Groza, J. R., Shackelford, J. F., Lavernia, E. J., Powers, M. T., Eds.; CRC Press, 2007; pp 3-7.

(15) Anders, A. A Structure Zone Diagram Including Plasma-Based Deposition and Ion Etching. Thin Solid Films 2010, 518 (15), 40874090.

(16) Trachenko, K.; Pruneda, J. M.; Artacho, E.; Dove, M. T. How the Nature of the Chemical Bond Governs Resistance to Amorphization by Radiation Damage. Phys. Rev. B: Condens. Matter Mater. Phys. 2005, 71 (18), 184104.

(17) Greene, J. E. Thin Film Nucleation, Growth, and Microstructural Evolution: An Atomic Scale View. In Handbook of Deposition Technologies for Films and Coatings; Martin, P. M., Ed.; Elsevier, 2010; pp 554-620.

(18) Faraz, T.; Roozeboom, F.; Knoops, H. C. M.; Kessels, W. M. M. Atomic Layer Etching: What Can We Learn from Atomic Layer Deposition? ECS J. Solid State Sci. Technol. 2015, 4 (6), N5023-N5032.

(19) Profijt, H. B.; van de Sanden, M. C. M.; Kessels, W. M. M. Substrate-Biasing during Plasma-Assisted Atomic Layer Deposition to Tailor Metal-Oxide Thin Film Growth. J. Vac. Sci. Technol., A 2013, 31 (1), $01 \mathrm{~A} 106$.

(20) Profijt, H. B.; van de Sanden, M. C. M.; Kessels, W. M. M. Substrate Biasing during Plasma-Assisted ALD for Crystalline PhaseControl of TiO2 Thin Films. Electrochem. Solid-State Lett. 2012, 15 (2), G1.

(21) Weber, W. J.; Wendler, E. Modelling Effects of Radiation Damage. In Ion Beam Modification of Solids; Wesch, W., Wendler, E., Eds.; Springer, 2016; pp 105-136.

(22) Xie, Q.; Musschoot, J.; Deduytsche, D.; Van Meirhaeghe, R. L.; Detavernier, C.; Van den Berghe, S.; Jiang, Y.-L.; Ru, G.-P.; Li, B.-Z.; Qu, X.-P. Growth Kinetics and Crystallization Behavior of $\mathrm{TiO}_{2}$ Films Prepared by Plasma Enhanced Atomic Layer Deposition. J. Electrochem. Soc. 2008, 155 (9), H688-H692.

(23) Caubet, P.; Blomberg, T.; Benaboud, R.; Wyon, C.; Blanquet, E.; Gonchond, J.-P.; Juhel, M.; Bouvet, P.; Gros-Jean, M.; Michailos, J.; Richard, C.; Iteprat, B. Low-Temperature Low-Resistivity PEALD TiN Using TDMAT under Hydrogen Reducing Ambient. J. Electrochem. Soc. 2008, 155 (8), H625.

(24) Samal, N.; Du, H.; Luberoff, R.; Chetry, K.; Bubber, R.; Hayes, A.; Devasahayam, A. Low-Temperature $\left(\leq 200{ }^{\circ} \mathrm{C}\right)$ Plasma Enhanced Atomic Layer Deposition of Dense Titanium Nitride Thin Films. J. Vac. Sci. Technol., A 2013, 31 (1), 01A137. 
(25) Sharma, A.; Longo, V.; Verheijen, M. A.; Bol, A. A.; Kessels, W. M. M. (Erwin). Atomic Layer Deposition of $\mathrm{HfO}_{2}$ Using $\mathrm{HfCp}\left(\mathrm{NMe}_{2}\right)_{3}$ and $\mathrm{O}_{2}$ Plasma. J. Vac. Sci. Technol., A 2017, 35 (1), $01 \mathrm{~B} 130$.

(26) Karwal, S.; Williams, B. L.; Niemelä, J.-P.; Verheijen, M. A.; Kessels, W. M. M.; Creatore, M. Plasma-Assisted Atomic Layer Deposition of HfNx: Tailoring the Film Properties by the Plasma Gas Composition. J. Vac. Sci. Technol., A 2017, 35 (1), $01 \mathrm{~B} 129$.

(27) Dingemans, G.; van Helvoirt, C. A. A.; Pierreux, D.; Keuning, W.; Kessels, W. M. M. Plasma-Assisted ALD for the Conformal Deposition of $\mathrm{SiO}(2)$ : Process, Material and Electronic Properties. J. Electrochem. Soc. 2012, 159 (3), H277-H285.

(28) Faraz, T.; van Drunen, M.; Knoops, H. C. M.; Mallikarjunan, A.; Buchanan, I.; Hausmann, D. M.; Henri, J.; Kessels, W. M. M. Atomic Layer Deposition of Wet-Etch Resistant Silicon Nitride Using Di(Sec -Butylamino)silane and N 2 Plasma on Planar and 3D Substrate Topographies. ACS Appl. Mater. Interfaces 2017, 9, 1858-1869.

(29) Langereis, E.; Heil, S. B. S.; Knoops, H. C. M.; Keuning, W.; van de Sanden, M. C. M.; Kessels, W. M. M. In Situ Spectroscopic Ellipsometry as a Versatile Tool for Studying Atomic Layer Deposition. J. Phys. D: Appl. Phys. 2009, 42 (7), 073001.

(30) Shestaeva, S.; Bingel, A.; Munzert, P.; Ghazaryan, L.; Patzig, C.; Tünnermann, A.; Szeghalmi, A. Mechanical, Structural, and Optical Properties of PEALD Metallic Oxides for Optical Applications. Appl. Opt. 2017, 56 (4), C47-C59.

(31) Wei, D.; Hossain, T.; Garces, N. Y.; Nepal, N.; Meyer, H. M.; Kirkham, M. J.; Eddy, C. R.; Edgar, J. H. Influence of Atomic Layer Deposition Temperatures on $\mathrm{TiO} 2 / \mathrm{n}-\mathrm{Si}$ MOS Capacitor. ECS J. Solid State Sci. Technol. 2013, 2 (5), N110-N114.

(32) Hanaor, D. A. H.; Sorrell, C. C. Review of the Anatase to Rutile Phase Transformation. J. Mater. Sci. 2011, 46 (4), 855-874.

(33) Huang, Y.; Pandraud, G.; Sarro, P. M. Characterization of Low Temperature Deposited Atomic Layer Deposition TiO2 for MEMS Applications. J. Vac. Sci. Technol., A 2013, 31 (1), 01A148.

(34) Chason, E.; Karlson, M.; Colin, J. J.; Magnfalt, D.; Sarakinos, K.; Abadias, G. A Kinetic Model for Stress Generation in Thin Films Grown from Energetic Vapor Fluxes. J. Appl. Phys. 2016, 119 (14), 145307.

(35) Chason, E.; Guduru, P. R. Tutorial: Understanding Residual Stress in Polycrystalline Thin Films through Real-Time Measurements and Physical Models. J. Appl. Phys. 2016, 119 (19), 191101.

(36) Nastasi, M.; Misra, A.; Mayer, J. W. Ion Beam Assisted Deposition. In Materials Processing Handbook; Groza, J. R., Shackelford, J. F., Lavernia, E. J., Powers, M. T., Eds.; CRC Press, 2007; pp 10-11.

(37) Gago, R.; Jimenez, I.; Albella, J. M. Thin Film Growth by IonBeam-Assisted Deposition Techniques. In Materials Surface Processing by Directed Energy Techniques; Pauleau, Y., Ed.; Elsevier, 2006; p 345.

(38) Zhang, Y.; Weber, W.J. Defect Accumulation, Amorphization and Nanostructure Modification of Ceramics. In Ion Beam Modification of Solids; Wesch, W., Wendler, E., Eds.; Springer, 2016; pp 287-318.

(39) Volkert, C. A. Stress and Plastic Flow in Silicon during Amorphization by Ion Bombardment. J. Appl. Phys. 1991, 70 (7), 3521-3527.

(40) Davis, C. A. A Simple Model for the Formation of Compressive Stress in Thin Films by Ion Bombardment. Thin Solid Films 1993, 226 (1), 30-34.

(41) Jerman, M.; Qiao, Z.; Mergel, D. Refractive Index of Thin Films of $\mathrm{SiO}_{2}, \mathrm{ZrO}_{2}$, and $\mathrm{HfO}_{2}$ as a Function of the Films' Mass Density. Appl. Opt. 2005, 44, 3006-3012.

(42) Martínez, F. L.; Toledano-Luque, M.; Gandía, J. J.; Cárabe, J.; Bohne, W.; Röhrich, J.; Strub, E.; Mártil, I. Optical Properties and Structure of HfO2 Thin Films Grown by High Pressure Reactive Sputtering. J. Phys. D: Appl. Phys. 2007, 40 (17), 5256-5265.

(43) Birkholz, M. Thin Film Analysis by X-Ray Scattering; Wiley-VCH, 2006.

(44) Petrov, I.; Hultman, L.; Sundgren, J.-E.; Greene, J. E. Polycrystalline TiN Films Deposited by Reactive Bias Magnetron Sputtering: Effects of Ion Bombardment on Resputtering Rates, Film Composition, and Microstructure. J. Vac. Sci. Technol., A 1992, 10 (2), 265-272.
(45) Patsalas, P.; Charitidis, C.; Logothetidis, S. The Effect of Substrate Temperature and Biasing on the Mechanical Properties and Structure of Sputtered Titanium Nitride Thin Films. Surf. Coat. Technol. 2000, 125 (1-3), 335-340.

(46) Nakano, T.; Hoshi, K.; Baba, S. Effect of Background Gas Environment on Oxygen Incorporation in TiN Films Deposited Using UHV Reactive Magnetron Sputtering. Vacuum 2008, 83 (3), 467-469.

(47) Cuomo, J. J.; Harper, J. M. E.; Guarnieri, C. R.; Yee, D. S.; Attanasio, L. J.; Angilello, J.; Wu, C. T.; Hammond, R. H. Modification of Niobium Film Stress by Low-energy Ion Bombardment during Deposition. J. Vac. Sci. Technol. 1982, 20 (3), 349-354.

(48) Johns, C.; Islam, M. S.; Groza, J. R. Physical and Chemical Vapor Deposition Processes. In Materials Processing Handbook; Groza, J. R., Shackelford, J. F., Lavernia, E. J., Powers, M. T., Eds.; CRC Press, 2007; pp 8-3.

(49) Nahar, M.; Rocklein, N.; Andreas, M.; Funston, G.; Goodner, D. Stress Modulation of Titanium Nitride Thin Films Deposited Using Atomic Layer Deposition. J. Vac. Sci. Technol., A 2017, 35 (1), $01 \mathrm{~B} 144$.

(50) Ensinger, W. Ion Bombardment Effects during Deposition of Nitride and Metal Films. Surf. Coat. Technol. 1998, 99 (1-2), 1-13.

(51) Rizzo, A.; Signore, M. A.; Valerini, D.; Altamura, D.; Cappello, A.; Tapfer, L. A Study of Suppression Effect of Oxygen Contamination by Bias Voltage in Reactively Sputtered ZrN Films. Surf. Coat. Technol. 2012, 206 (10), 2711-2718.

(52) Sundgren, J.-E. Structure and Properties of TiN Coatings. Thin Solid Films 1985, 128 (1), 21-44.

(53) Hultman, L.; Johansson, B. O.; Sundgren, J. E.; Markert, L. C.; Greene, J. E. Ar Incorporation in Epitaxial TiN Films Deposited by Reactive Magnetron Sputtering in Mixed Ar/N2 Discharges. Appl. Phys. Lett. 1988, 53 (13), 1175-1177.

(54) Triyoso, D. H.; Hempel, K.; Ohsiek, S.; Jaschke, V.; Shu, J.; Mutas, S.; Dittmar, K.; Schaeffer, J.; Utess, D.; Lenski, M. Evaluation of Low Temperature Silicon Nitride Spacer for High-K Metal Gate Integration. ECS J. Solid State Sci. Technol. 2013, 2 (11), N222-N227.

(55) Hultman, L.; et al. Ar and Excess N Incorporation in Epitaxial TiN Films Grown by Reactive Bias Sputtering in Mixed Ar/N2 and Pure N2 Discharges. J. Vac. Sci. Technol., A 1989, 7 (3), 1187.

(56) Kawamura, E.; Vahedi, V.; Lieberman, M. a; Birdsall, C. K. Ion Energy Distributions in Rf Sheaths; Review, Analysis and Simulation. Plasma Sources Sci. Technol. 1999, 8 (3), R45-R64.

(57) Li, D.; Carette, M.; Granier, A.; Landesman, J. P.; Goullet, A. Effect of Ion Bombardment on the Structural and Optical Properties of TiO2 Thin Films Deposited from Oxygen/titanium Tetraisopropoxide Inductively Coupled Plasma. Thin Solid Films 2015, 589, 783-791.

(58) Maidul Haque, S.; Sagdeo, P. R.; Balaji, S.; Sridhar, K.; Kumar, S.; Bhattacharyya, D.; Bhattacharyya, D.; Sahoo, N. K. Effect of Substrate Bias and Oxygen Partial Pressure on Properties of RF Magnetron Sputtered HfO2 Thin Films. J. Vac. Sci. Technol., B: Nanotechnol. Microelectron.: Mater., Process., Meas., Phenom. 2014, 32 (3), $03 \mathrm{D} 104$.

(59) Bang, S. B.; Chung, T. H.; Kim, Y.; Kang, M. S.; Kim, J. K. Effects of the Oxygen Fraction and Substrate Bias Power on the Electrical and Optical Properties of Silicon Oxide Films by Plasma Enhanced Chemical Vapour Deposition Using TMOS/O 2 Gas. J. Phys. D: Appl. Phys. 2004, 37 (12), 1679-1684.

(60) Gu, Z.; Wang, J.; Hu, C.; Zhang, X.; Dang, J.; Zhang, S.; Gao, J.; Wang, X.; Chen, H.; Zheng, W. Ion-Bombardment-Induced Reduction in Vacancies and Its Enhanced Effect on Conductivity and Reflectivity in Hafnium Nitride Films. Appl. Phys. A: Mater. Sci. Process. 2016, 122 (8), 776.

(61) Kim, J. H.; Chung, K. W. Microstructure and Properties of Silicon Nitride Thin Films Deposited by Reactive Bias Magnetron Sputtering. J. Appl. Phys. 1998, 83 (11), 5831-5839.

(62) Van Assche, F. J. H.; Kessels, W. M. M.; Vangheluwe, R.; Mischke, W. S.; Evers, M.; Van De Sanden, M. C. M. High Rate $(\sim 3 \mathrm{Nm} / \mathrm{s})$ Deposition of Dense Silicon Nitride Films at Low Substrate Temperatures $\left(<150^{\circ} \mathrm{c}\right)$ Using the Expanding Thermal Plasma and Substrate Biasing. Thin Solid Films 2005, 484 (1-2), 46-53.

(63) Pointet, J.; Gonon, P.; Latu-Romain, L.; Bsiesy, A.; Vallée, C. Rutile-Structured TiO2 Deposited by Plasma Enhanced Atomic Layer 
Deposition Using Tetrakis(dimethylamino)titanium Precursor on inSitu Oxidized Ru Electrode. J. Vac. Sci. Technol., A 2014, 32, 01A120.

(64) Luo, Z.; Poyraz, A. S.; Kuo, C. H.; Miao, R.; Meng, Y.; Chen, S. Y.; Jiang, T.; Wenos, C.; Suib, S. L. Crystalline Mixed Phase (Anatase/ rutile) Mesoporous Titanium Dioxides for Visible Light Photocatalytic Activity. Chem. Mater. 2015, 27 (1), 6-17.

(65) Wang, C.; Yin, L.; Zhang, L.; Xiang, D.; Gao, R. Metal Oxide Gas Sensors: Sensitivity and Influencing Factors. Sensors 2010, 10 (3), $2088-2106$

(66) Jeon, S.; Park, S. Tunable Work-Function Engineering of TiCTiN Compound by Atomic Layer Deposition for Metal Gate Applications. J. Electrochem. Soc. 2010, 157 (10), H930.

(67) Egorov, K. V.; Kuzmichev, D. S.; Chizhov, P. S.; Lebedinskii, Y. Y.; Hwang, C. S.; Markeev, A. M. In Situ Control of Oxygen Vacancies in $\mathrm{TaOx}$ Thin Films via Plasma-Enhanced Atomic Layer Deposition for Resistive Switching Memory Applications. ACS Appl. Mater. Interfaces 2017, 9 (15), 13286-13292.

(68) Kwon, D.-H.; Kim, K. M.; Jang, J. H.; Jeon, J. M.; Lee, M. H.; Kim, G. H.; Li, X.-S.; Park, G.-S.; Lee, B.; Han, S.; Kim, M.; Hwang, C. S. Atomic Structure of Conducting Nanofilaments in $\mathrm{TiO} 2$ Resistive Switching Memory. Nat. Nanotechnol. 2010, 5 (2), 148-153.

(69) Ylivaara, O. M. E.; Kilpi, L.; Liu, X.; Sintonen, S.; Ali, S.; Laitinen, M.; Julin, J.; Haimi, E.; Sajavaara, T.; Lipsanen, H.; Hannula, S.-P.; Ronkainen, H.; Puurunen, R. L. Aluminum Oxide/titanium Dioxide Nanolaminates Grown by Atomic Layer Deposition: Growth and Mechanical Properties. J. Vac. Sci. Technol., A 2017, 35 (1), $01 B 105$.

(70) Carlsson, J. O. Selective Vapor-Phase Deposition on Patterned Substrates. Crit. Rev. Solid State Mater. Sci. 1990, 16 (3), 161-212. 